\author{
UNIVERSIDADE DE SÃO PAULO \\ ESCOLA DE ARTES, CIÊNCIAS E HUMANIDADES \\ PROGRAMA DE PÓS-GRADUAÇÀO EM SUSTENTABILIDADE
}

LUÍS GUILHERME BRUNETTO

A inovação orientada para a sustentabilidade pela ótica da teoria da estruturação: uma análise de casos

São Paulo 



\title{
A inovação orientada para a sustentabilidade pela ótica da teoria da estruturação: uma análise de casos
}

\author{
Versão Corrigida
}

Dissertação apresentada à Escola de Artes, Ciências e Humanidades da Universidade de São Paulo para obtenção do título de Mestre em Ciências pelo Programa de Pós-graduação em Sustentabilidade.

Versão corrigida contendo as alterações solicitadas pela comissão julgadora em 19 de junho de 2019. A versão original encontra-se em acervo reservado na Biblioteca da EACH/USP e na Biblioteca Digital de Teses e Dissertações da USP (BDTD), de acordo com a Resolução CoPGr 6018, de 13 de outubro de 2011.

Área de concentração: Sustentabilidade

Orientadora:

Profa. Dra. Tania Pereira Christopoulos 
Autorizo a reprodução e divulgação total ou parcial deste trabalho, por qualquer meio convencional ou eletrônico, para fins de estudo e pesquisa, desde que citada a fonte.

CATALOGAÇÃO-NA-PUBLICAÇÃO

(Universidade de São Paulo. Escola de Artes, Ciências e Humanidades. Biblioteca) CRB - 4936

Brunetto, Luís Guilherme

A inovação orientada para a sustentabilidade pela ótica da teoria da estruturação: uma análise de casos / Luís Guilherme

Brunetto ; orientadora, Tania Pereira Christopoulos. - 2019 $145 \mathrm{f}$.

Dissertação (Mestrado em Ciências) - Programa de PósGraduação em Sustentabilidade, Escola de Artes, Ciências e Humanidades, Universidade de São Paulo Versão corrigida

1. Sustentabilidade. 2. Inovação. I. Christopoulos, Tania Pereira, orient. II. Título

CDD 22.ed. -577.068 
Nome: BRUNETTO, Luís Guilherme

Título: A inovação orientada para a sustentabilidade pela ótica da teoria da estruturação: uma análise de casos

Dissertação apresentada à Escola de Artes, Ciências e Humanidades da Universidade de São Paulo para obtenção do título de Mestre em Ciências pelo Programa de Pós-graduação em Sustentabilidade.

Área de concentração: Sustentabilidade

Orientadora:

Profa. Dra. Tania Pereira Christopoulos

Aprovado em: 19 / 06 / 2019

\section{Banca Examinadora}

Profa. Dra. Sylmara L.F. Gonçalves Dias Instituição: EACH - USP

Julgamento:

Assinatura:

Prof. Dr. Mário Aquino Alves

Instituição: FGV - EAESP

Julgamento:

Assinatura:

Prof. Dr. Flávio Hourneaux

Instituição: FEA - USP

Julgamento:

Assinatura: 

Aos meus pais, Liderce e Argeu (em memória). Aos meus irmãos, Claudio e Argeu. 



\section{Agradecimentos}

É interessante refletir que, muitas vezes, é somente no final de uma jornada que paramos para observar o caminho que trilhamos. Nesta observação, é potencial o realce de nossa humanidade, da vida em sociedade, da nossa dependência do outro. Neste momento, é válido poder agradecer, ou, ao menos, explicitar o sentimento de gratidão que nos trouxe até aqui.

Consciente de que toda ação que realizo é posicionada no tempo e a vida é uma continuidade de eventos, receio poder me esquecer de alguém ou mesmo reconhecer que os encontros não são tão mais frequentes e que esta seção de agradecimentos me representa no presente.

Agradeço aos meus pais Liderce e Argeu (em memória) que me deram condições suficientes para me tornar humano (aprender a falar, a andar, a me comunicar, estudar...) me desenvolver e ser...

Agradeço aos meus irmãos Claudio e Argeu. O primeiro, um amigo próximo, "pau pra toda obra" e que me suporta nas minhas andanças. O segundo, um conselheiro com preocupação fraterna.

Agradeço à Luciana (minha cunhada) que sempre motivou-me a continuar ligado à universidade. Ao Rafa e Júlia, meus sobrinhos, que me permitiram (sem saber) ter um olhar próximo sobre o desenvolvimento humano.

Aos grandes irmãos da vida, Juliano e Fábio, cujos ouvidos me emprestaram à exaustão. De fato, este texto e estas inquietações derivaram de nossas inúmeras reflexões filosóficas.

E aos notáveis amigos presentes na minha caminhada, Tiago, João e Danilo.

Agradeço especialmente a Tânia, professora que me acolheu tão bem na EACH e topou dar ouvidos a um engenheiro metido a sociólogo (Viva a interdisciplinaridade!!!).

À professora Sylmara que me acolheu para um café na faculdade de medicina da USP e me abriu as portas da EACH.

Ao Paulo, um chefe e amigo que me ensinou muito e possibilitou o meu acesso à universidade durante o período de trabalho.

Agradeço à $\mathrm{EACH}$, pela acolhida, pelas aulas e reflexões e pelas pessoas com as quais pude interagir.

À Universidade de São Paulo. 



\section{RESUMO}

BRUNETTO, Luís Guilherme. A inovação orientada para a sustentabilidade pela ótica da teoria da estruturação: uma análise de casos. 2019. 145 p. Dissertação (Mestrado em Sustentabilidade) - Escola de Artes, Ciências e Humanidades, Universidade de São Paulo, São Paulo, 2019. Versão corrigida.

A inovação orientada para a sustentabilidade (IOS) tem sido um dos posicionamentos assumidos por diversas empresas que afirmam contribuir para o desenvolvimento sustentável. Nessa perspectiva, as empresas reconhecem a problemática da escassez de recursos e de diversos problemas socioambientais e alinham sua estratégia de inovação para novos produtos e processos que, de alguma forma, poderiam ser considerados como sustentáveis. A fim de entender esse fenômeno por meio de uma lente teórica que leve em consideração os indivíduos inseridos nas atividades de inovação, este projeto teve como objetivo geral compreender a dinâmica de estruturação das práticas sociais dos processos de IOS. Como suporte teórico, foi utilizada a teoria da estruturação de Giddens (1984) e como estratégia metodológica adotou-se o estudo de caso, realizado junto a duas unidades de negócios de uma empresa multinacional. Foi possível descrever a estruturação das práticas que ocorrem no processo de inovação. Evidenciou-se que as práticas correntes de inovação têm suas estruturas ligadas fortemente às lógicas econômica e de competitividade. Tais práticas são altamente legitimadas e são praticamente inquestionáveis. Por outro lado, há elementos estruturantes, muitos deles ligados a uma visão mais abrangente do ator social e presente em vários sistemas sociais, dos quais os atores fazem parte, e que estão permitindo o surgimento, ainda que tímido, de práticas que poderiam ser entendidas como orientadas para a sustentabilidade. A partir do estudo de caso e da articulação da teoria da estruturação, este trabalho propõe um modelo de estruturação das práticas em processos de IOS. Observa-se que as estruturas da IOS apresentam elementos de esquemas interpretativos, normas e métricas e uma visão de legitimação que depende altamente do nível de mediação. Suportando essa orientação, vislumbra-se um elemento de visão de mundo e construção de significado sobre a sustentabilidade que é emergente. A agência do ator social também é considerada no modelo e elementos como mindset, rigidez da estrutura e posição social / hierárquica conferem uma dualidade, ora potencializadora, ora inibidora na mudança e surgimento de novas práticas.

Palavras-chave: Inovação. Sustentabilidade. Teoria da estruturação. Práticas. Inovação orientada para a sustentabilidade. Inovação sustentável. 



\begin{abstract}
BRUNETTO, Luís Guilherme. Sustainability-Oriented Innovation through the lens of Structuration Theory: Case Analysis. 2019. 145 p. Dissertation (Master in Sustainability) - School of Arts, Sciences and Humanities, University of São Paulo, São Paulo, 2019. Corrected version.

The sustainability-oriented innovation (SOI) has been one of the assumed positions by several companies that affirm to contribute to sustainable development. From this perspective, these companies acknowledge the problem of resources scarcity and many others socio-environmental problems. Additionally, they align their strategy of innovation to new products and processes that, in a certain way, could be considered as sustainable. Aiming to comprehend this phenomenon through a theoretical lens that takes into account the individuals inserted into the innovation activities, this project had as main objective to comprehend the dynamic of structuration of the social practices in the processes of SOI. As a theoretical background, it was applied the structuration theory of Giddens (1984) and as a methodological strategy was adopted the case study, carried out with two business unities of a multinational company. It was possible to describe the structuration of practices that take place in the innovation process. It was evidenced that the current innovation practices have their practices strongly anchored to the economic and competitiveness logics. These practices are highly legitimized and are likely unquestionable. On the other side, there are structural elements, most of them linked to a broader view of the social actor and present in several social systems which the actors are part of it, that are enabling the emergence, even weak, of practices that could be understood as oriented to sustainability. Through the case study and the articulation of the structuration theory, this work proposes a model of the structuration of the practices in SOI. It can be observed that the structures of the SOI show elements of interpretive schemas, norms and metrics and a vision of legitimation which depends highly on the level of mediation. Supporting this orientation, it can be seen an emergent element of a broader world vision and meaning construction about sustainability. The agency of the social actor is also taken into consideration in the model and elements as mindset, structure rigidity and social position / hierarchy gives a duality (sometimes enabler, sometimes restrictive) in the change and emergence of new practices.
\end{abstract}

Keywords: Innovation. Sustainability. Structuration theory. Practices. Sustainability-oriented Innovation. Sustainable innovation. 



\section{LISTA DE FIGURAS}

Figura 1: Representação esquemática da estratégia de fundamentação teórica......26

Figura 2: O modelo da sustentabilidade forte .............................................. 28

Figura 3: Ciclos econômicos / tecnológicos .................................................. 32

Figura 4: Representações do desenvolvimento sustentável .................................38

Figura 5: Modelo de inovação avançada e de alto desempenho. ...........................39

Figura 6: As dimensões da inovação orientada para a sustentabilidade ..................40

Figura 7: Modelo de inovação orientada para a sustentabilidade .........................41

Figura 8: Processo de Inovação de produto com o ciclo de vida do produto ...........47

Figura 9: Modelo conceitual de inovação sustentável ......................................49

Figura 10: Modelo conceitual da orientação das inovações sustentáveis .................50

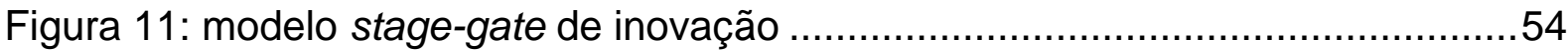

Figura 12: Representação de uma etapa stage-gate ......................................54

Figura 13: Representação das etapas salientando a retroalimentação das atividades

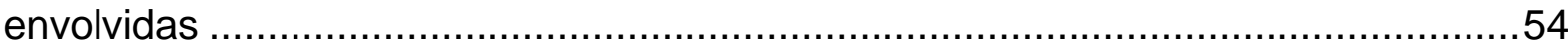

Figura 14: Representação stage-gate para diferentes complexidades de projetos...55

Figura 15: Modelo da estratificação do agente..............................................59

Figura 16: Representação da relação estrutura-prática em interação......................62

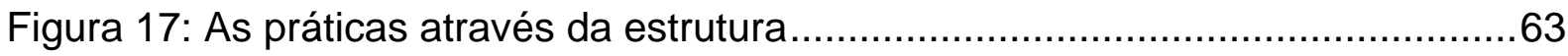

Figura 18: Relações recíprocas entre ação e estrutura (regras e recursos) no caminho tecnológico (technology path) ........................................................65

Figura 19: Práticas correntes em inovação e sua estrutura ..................................67

Figura 20: Representação das práticas em inovação orientada para a sustentabilidade 69

Figura 21: Disposição hierárquica dos entrevistados do caso 1 ............................78

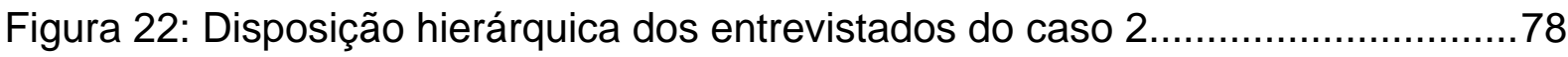

Figura 23: Resultados da avaliação temática das entrevistas ..............................84

Figura 24: Modelo de estruturação da inovação orientada para a sustentabilidade119 



\section{SUMÁRIO}

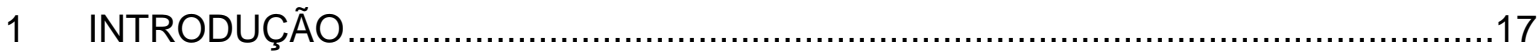

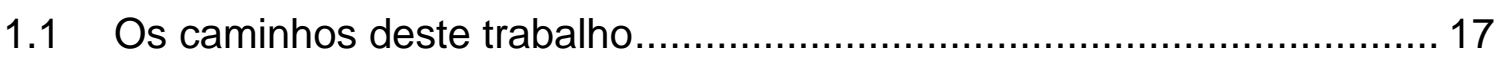

1.2 A problemática ............................................................................ 18

1.3 Justificativa e delimitação da pesquisa .......................................... 22

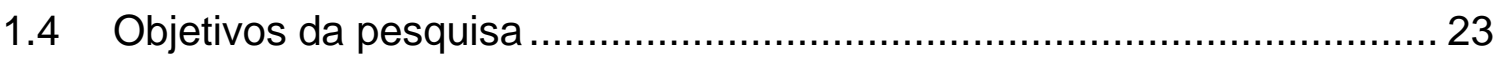

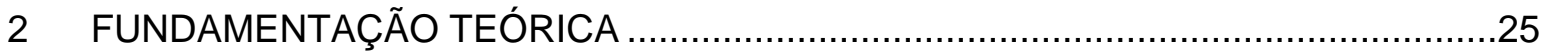

2.1 Inovação orientada para a sustentabilidade $(\mathrm{IOS})$............................. 26

2.1.1 A sustentabilidade no posicionamento das empresas ..................... 26

2.1.2 O alinhamento da inovação em busca do desenvolvimento sustentável 31

2.1.3 Os modelos de inovação orientada para a sustentabilidade ............. 37

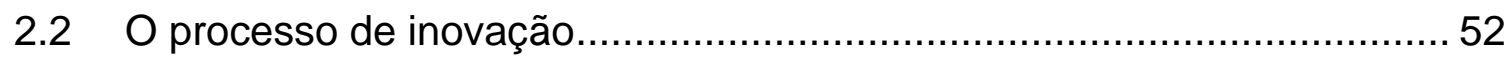

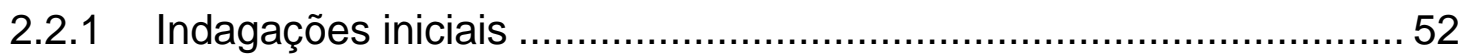

2.2.2 A complexidade do processo .............................................. 52

2.2.3 As fases iniciais do processo de inovação ................................ 56

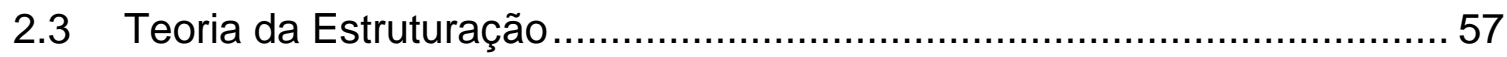

2.3.1 Conceitos e definições da teoria da estruturação ............................ 58

2.3.2 A definição do âmbito de análise .......................................... 63

2.4 Teoria da estruturação e inovação orientada para a sustentabilidade ..... 64

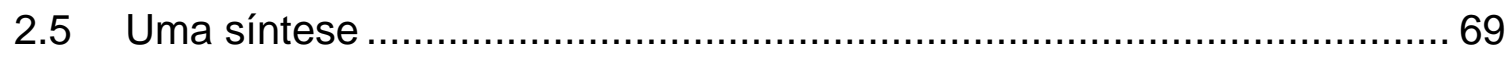

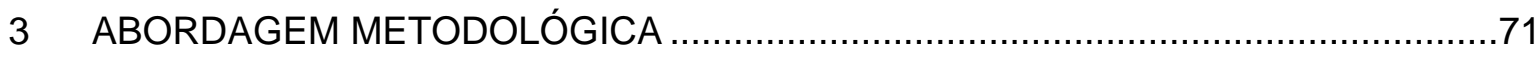

3.1 O processo de revisão da literatura.................................................. 72

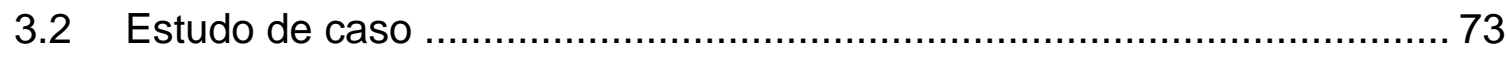


3.2.1 Descrição dos casos de inovação ................................................ 73

3.2.2 Método de coleta de dados ….................................................. 76

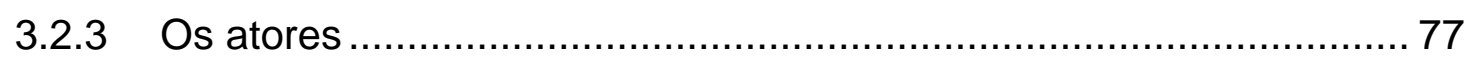

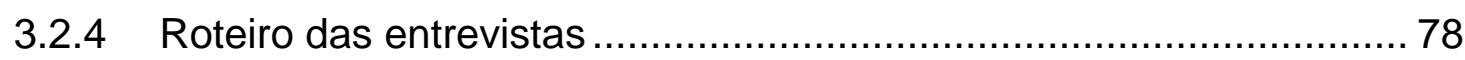

3.2.5 Método para análise das entrevistas .............................................. 80

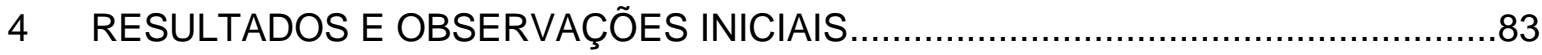

4.1 Estruturação da inovação tradicional ................................................. 84

4.2 Estruturação da inovação orientada para a sustentabilidade ................... 91

4.3 Visão de mundo e construção de significados .......................................99

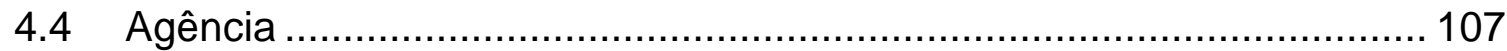

5 DISCUSSÃO

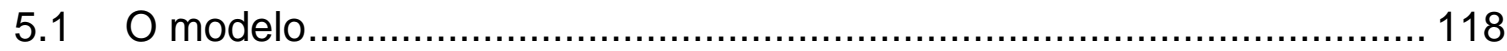

5.2 A estruturação da inovação orientada para a sustentabilidade .............. 121

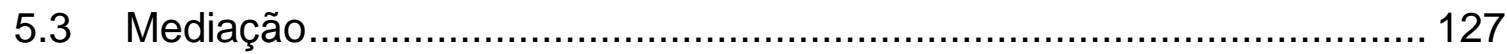

5.4 Analisando as unidades de análise ................................................ 130

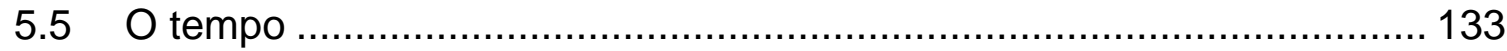

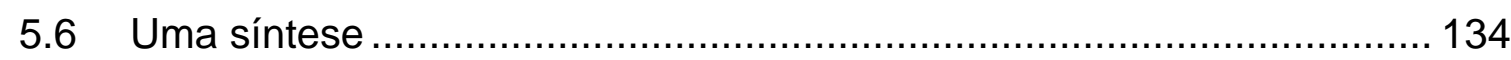

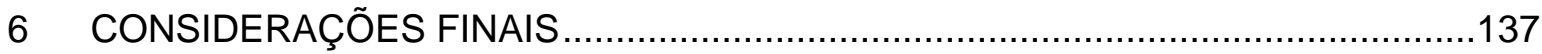

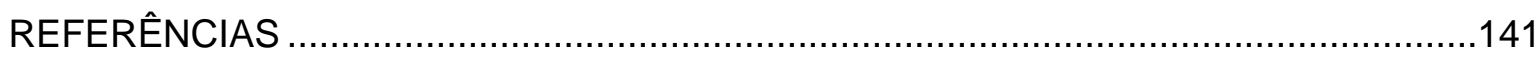

ANEXO - Roteiro das entrevistas traduzido para o inglês .............................................145 


\section{INTRODUÇÃO}

\subsection{Os caminhos deste trabalho}

Un hombre del pueblo de Neguá, en la costa de Colombia, pudo subir al alto cielo. A la vuelta contó. Dijo que había contemplado, desde allá arriba, la vida humana. Y dijo que somos un mar de fueguitos.

El mundo es eso -reveló-. Un montón de gente, un mar de fueguitos.

Cada persona brilla con luz propia entre todos los demás.

No hay dos fuegos iguales. Hay fuegos grandes y fuegos chicos y fuegos de todos colores. Hay gente de fuego sereno que ni se entera del viento, y gente de fuego loco que llena el aire de chispas. Algunos juegos, juegos bobos no alumbran ni queman; pero otros arden la vida con tantas ganas que no se puede mirarlos sin parpadear, y quien se acerca, se enciende.

(GALEANO, 2012, p.1)

Seria um exercício bastante grande tentar sintetizar o caminho que me trouxe até aqui. De fato, seria como descrever minha própria história, minhas reflexões, minhas práticas, minhas inquietações... De maneira assertiva, me apego a estas últimas, para tentar traçar um panorama diminuto do caminho trilhado.

As inquietações da vida são muitas e inconstantes. Há um quê de ardor filosófico para tentar entender o mundo a nossa volta e dar sentido para tudo que fazemos. Eu, particularmente, sempre me ative em refletir sobre a realidade dada (construída/legitimada) e como provocar mudança no meio em que vivo. Quando falo de realidade, me ocorre a experiência prática de ser brasileiro, branco, de ver uma história deturpada pelos livros de histórias, de viver numa sociedade extremamente desigual, preconceituosa, e ver uma lógica capitalista que, para mim, não faz sentido, sendo o status quo e bem disseminada.

Tenho um amigo que me emprestou sua audácia poética e me ajudou a aprender a refletir. Eduardo Galeano (em memória), embora nunca tenhamos nos encontrado, me ajudou a dar vazão aos passeios sinápticos e à reflexão sobre o mundo em que vivemos.

Nesse ambiente de reflexões, após já estar formado como engenheiro de materiais e trabalhando nessa área, busquei uma aproximação com a academia. Minha intenção? Novos ares, ou mesmo o próprio encontro com pessoas de diferentes sistemas sociais, a potencialidade de "poder beber" de outras fontes e 
uma busca por entender os caminhos da vida social, por meio de uma leitura mais humana, mais voltada para o indivíduo e suas ações. Foi assim que cheguei à Escola de Artes, Ciências e Humanidades da universidade de São Paulo e comecei a trilhar um caminho em busca de apaziguar algumas inquietações. A princípio, como ouvinte, tive acesso a um conhecimento novo sobre a temática de sustentabilidade (tema que já me atraía muito a atenção) e à leitura de autores como Amartya Sen, DiMaggio, Schumpeter, Bourdieu, Giddens e tantos outros. Após uma ótima recepção advindas das professoras Sylmara e Tânia, obtive desta última, uma parceira (orientadora) que topou me entender e suportar esse projeto de mestrado.

Para entender a ação humana, me debrucei sobre a sociologia de Anthony Giddens, principalmente. Trouxe uma inquietação latente da minha experiência prática de trabalho que diz respeito à inovação orientada para a sustentabilidade. $\mathrm{E}$ aí estavam a "faca e o queijo na mão" para tentar entender a ação humana, a criação e legitimação de práticas e a potencialidade da mudança nos sistemas sociais. De maneira sucinta e bem íntima, esse é o enredo que circunscreve esta dissertação. Boa leitura.

\subsection{A problemática}

É cada vez mais frequente a discussão sobre os limites planetários atingidos na contemporaneidade devido ao intenso uso de recursos naturais. Alguns problemas apontados são: o aquecimento global e seus possíveis impactos, a escassez de recursos naturais (sendo muitos desses recursos naturais não renováveis), a perda de biodiversidade, o desmatamento de áreas nativas, processos de desertificação, a regulação dos ciclos de nitrogênio e fósforo nos ambientes naturais (altamente impactados pelo uso de fertilizantes), a escassez de água potável, entre outros. Somam-se a esses problemas ambientais, a contínua desigualdade entre povos e nações, a má distribuição de renda e a fome (BURSZTYN; BURSZTYN, 2013). Ainda como visão futura, projeta-se um crescimento bastante exacerbado da população que acentuaria ainda mais tais problemas se mantidos os níveis de consumo na sociedade atual, principalmente dos países desenvolvidos e, ainda pior, se grandes parcelas da população que hoje se encontram em níveis de consumo baixo devido principalmente à baixa renda e 
falta de acesso, passassem a reproduzir os níveis de consumo das classes de maiores renda (JACKSON, 2013).

O conceito "desenvolvimento sustentável" emerge de um emaranhado e complexo ambiente de discussões e fóruns globais, que o sintetiza como aquele que atende "às necessidades do presente sem comprometer a capacidade das gerações futuras para atender às suas necessidades" (Brundtland Comission, 1987).

É importante salientar a complexidade que o termo traz consigo. Embora muito disseminado no meio comum, o conceito ainda está em construção e sofre inúmeros questionamentos. Inúmeras terminologias relacionadas a essa temática, comumente, aparecem em trabalhos de diversas áreas, como por exemplo, sustentabilidade fraca, sustentabilidade forte, ecologia profunda, eco-corporativismo etc. (BURSZTYN, BURSZTYN, 2013; BOFF, 2013).

A maneira de se abordar a problemática geral ou algum tema específico é diversificadaa e nota-se uma intensa produção acadêmica em muitos assuntos correlacionados. Evidencia-se a relevância dessa problemática por sua abrangência em muitos segmentos. Órgãos globais como a Organização das Nações Unidas, diferentes nações e suas unidades de organização política (estados, cidades), grupos da sociedade civil (organizações não governamentais, grupos de bairro), universidades e as empresas são alguns exemplos dos setores envolvidos.

No que tange às discussões, ações ou posicionamentos das empresas e corporações, evidencia-se que estas têm adotado um discurso de promotoras do desenvolvimento sustentável. Por serem parte integrante do sistema e, de fato, responsáveis pelo uso dos recursos naturais (no momento que manufaturam os produtos, criam e disseminam necessidades ao consumidor), as empresas posicionam-se para a discussão desse fenômeno. Um posicionamento que vem sido adotado por empresas de vários segmentos é o discurso de promoção da inovação (referente aos seus produtos e processos) orientada para a sustentabilidade. Nesse contexto, as empresas ajudariam a equilibrar os problemas e desafios globais por meio do desenvolvimento de tecnologias inovadoras que diminuiriam, significativamente, os impactos ambiental e social negativos.

Uma primeira questão que emerge da elucubração supracitada: quais as diferenças entre a proposta de inovação orientada para a sustentabilidade e a 
inovação tradicional (esta última, que sempre foi feita e, que, em última análise, foi parte integrante do movimento do uso exacerbado de recursos naturais e manutenção do nível de desigualdade)? O problema, neste nível, está em entender o que são mudanças estruturais do "fazer inovação" e o que são meramente posicionamentos simbólicos perante a sociedade e colaboradores. Ao passo que, muitos trabalhos acadêmicos e as próprias divulgações das empresas (via relatórios oficiais (GRI - Global Reporting Initiative) ou publicações diversas) apontam a inclusão de métricas ambientais e sociais e cálculos de ciclo de vida de produtos e pouco se evidencia e se discute sobre as condições estruturantes para as práticas do processo de inovação que o permitiria ser identificado como orientado para a sustentabilidade.

Para compreendermos o fenômeno, é necessário analisar como a inovação se apresenta. A inovação, seja qual linha seguir (tradicional ou orientada para a sustentabilidade) é apresentada com uma visão de processo constituída de múltiplos estágios, dos quais várias pessoas participam, interagem com eles e lhes dão dinâmica à sua evolução. Tanto na literatura, quanto na prática, valoriza-se muito esta visão sequencial, pautada por métricas que alimentam o processo e permitem a avaliação de tomada de decisões, baseadas nas vantagens que podem ser obtidas uma vez que se eliminem os riscos associados. No entanto, embora a execução das atividades vinculadas a cada etapa do processo seja obviamente praticada por indivíduos, a discussão da inovação recai, em sua maior parte, na sua estruturação cartesiana. Uma alegoria que se pode fazer é dizer que a inovação se dá por si só, desde que exista um processo estruturado.

Como aponta Granovetter (1985, p. 487, tradução nossa):

Atores não se comportam ou tomam decisões externamente ao contexto social, nem aderem cegamente a um roteiro escrito para eles através das intersecções de categorias sociais particulares que eles possam ocupar. Suas decisões em ações propositivas, ao contrário, estão imersas nas concretas e dinâmicas relações dos sistemas sociais.

Ainda mais especificamente, Coenén e López (2010, p. 1150) posicionam que "Inovações são iterativamente derivadas de redes de relações sociais, mais do que através de eventos singulares por indivíduos isolados ou organizações". 
Uma vez apresentada a orientação da inovação para a sustentabilidade e salientado que os processos estruturantes das ações de inovação são realizados por indivíduos inseridos dentro de um contexto social, aponta-se a seguinte problemática: como se evidenciar mudanças estruturais no processo de inovação que lhe permita ser entendido como, de fato, um processo de inovação orientado para a sustentabilidade? Ao se tratar de uma temática que está além das empresas e seus objetivos alcançam impacto direto em toda a sociedade, como os atores envolvidos no processo de inovação responderão a essa orientação? Para poder se aproximar dessas questões, trazemos um referencial da sociologia através de Anthony Giddens (1984) que apresenta as práticas sociais (neste caso, por exemplo, poder-se-ia pensar nas práticas sociais de inovação ao longo do processo) como construídas a partir da relação de três elementos fundamentais: estrutura, sistemas e estruturação (dualidade da estrutura). A estruturação das ações dos indivíduos traz uma dualidade entre agente/ator e estrutura, na qual cada prática é, ao mesmo tempo, facilitadora e limitadora de uma mudança da própria prática. Outro questionamento que corrobora a descrição é: existe mudança possível nas bases que estruturam as práticas de inovação que permita aos indivíduos contribuírem para o desenvolvimento de inovações mais sustentáveis? Ainda, como se dá a relação recursiva entre atores e as estruturas das atividades de inovação?

Este trabalho está assim organizado: após esta breve descrição e contextualização, são apresentadas a justificativa bem como os objetivos. Para a construção de uma argumentação articulada, na seção de fundamentação teórica, é apresentado o movimento estratégico de incorporação da temática de sustentabilidade no posicionamento das empresas, assim como o alinhamento das áreas de inovação com uma orientação para a sustentabilidade. É também apresentada uma revisão sobre os modelos de inovação sustentáveis, o referencial teórico deste trabalho (teoria da estruturação) e uma articulação do objeto de pesquisa com este mesmo referencial. Na seção 3 é apresentada a metodologia que foi realizada tanto para a revisão da fundamentação teórica como para a elaboração do estudo de caso. A seção 4 expõe os resultados do estudo e realiza uma primeira análise sobre as falas dos entrevistados, utilizando a teoria da estruturação como meio articulador. A seção 5 traz a discussão principal deste estudo, apresenta o 
modelo proposto e as principais conclusões. Por fim, apresentam-se as considerações finais na seção 6 , a lista de referências bibliográficas e os anexos.

\subsection{Justificativa e delimitação da pesquisa}

Como visto anteriormente, uma das respostas das empresas para que se posicionem como promotoras de um desenvolvimento que almeja ser reconhecido como sustentável, jaz no posicionamento de suas atividades de inovação como uma inovação orientada para a sustentabilidade.

A aproximação sobre o fenômeno "inovação orientada para a sustentabilidade" é complexa e exige uma robusta articulação sobre o que é inovação, o que é inovação orientada para a sustentabilidade, como se descreve o processo de inovação e quem são os atores envolvidos nos processos que compõem o fenômeno. Uma pergunta crucial que emerge quando se situa o constructo "inovação orientada para a sustentabilidade" é qual a diferença entre esse tipo de inovação e a inovação tradicional. Muitos estudos tentam dar conta dessa pergunta e são apresentados na fundamentação teórica. Uma constatação que também advém da fundamentação teórica é a de que ainda é precoce a avaliação sobre as práticas e os indivíduos/atores envolvidos nesse processo emergente / recursivo de inovação orientada para a sustentabilidade. Muitas são as luzes e referenciais teóricos, porém, pouca atenção se dá ao entendimento da estruturação das práticas, à formação de rotinas e à potencialidade da ação criadora na própria instanciação das práticas.

Dessa maneira, este trabalho apresenta sua relevância por trazer um referencial teórico da sociologia para se aproximar do fenômeno "inovação orientada para a sustentabilidade". O uso de tal lente permitiu a descrição da estruturação das práticas de inovação orientada para a sustentabilidade (relação entre agentes e estruturas) a fim de se compreender se há mudanças estruturais em curso (processo dinâmico) que consigam e suportem a orientação para a sustentabilidade das atividades de inovação corporativas.

\section{Delimitação da Pesquisa:}

Em termos de delimitação deste trabalho, o objeto de pesquisa foi o processo de inovação orientado para a sustentabilidade com foco em empresas. 


\subsection{Objetivos da pesquisa}

O objetivo geral deste estudo foi compreender a dinâmica de estruturação das práticas sociais dos processos de inovação orientados para a sustentabilidade. Para tanto, foram analisadas interações entre atores e estruturas sociais através de um estudo de caso. A partir da aplicação da teoria da estruturação, foi possível uma análise mais crítica do processo de inovação para visualizar suas contradições e suas potencialidades.

Este trabalho teve os seguintes objetivos específicos:

1. Descrever o processo de inovação orientada para a sustentabilidade através da teoria da estruturação;

2. Desenvolver um modelo, relacionando a teoria da estruturação com a inovação orientada para a sustentabilidade. 


\title{
2 FUNDAMENTAÇÃO TEÓRICA
}

\author{
"De teoria, na verdade, precisamos nós. De teoria que implica uma \\ inserção na realidade, num contato analítico com o existente, para \\ comprová-lo, para vivê-lo plenamente, praticamente. Neste sentido é \\ que teorizar é contemplar. Não no sentido distorcido que lhe damos, \\ de oposição à realidade." (FREIRE, 1979, p.93)
}

A fundamentação teórica apresentada articula o objetivo deste trabalho, (analisar a interação entre atores e estruturas nos processos de inovação, orientados para a sustentabilidade) demonstrando a sua contribuição ao utilizar uma lente teórica que leva em consideração os indivíduos enquanto atores efetivos das práticas (uma vez que as práticas se instanciam através dos indivíduos) associadas ao processo de inovação. Para tanto, a estruturação dessa fundamentação teórica será apresentada da seguinte forma: a seção 2.1 discute a inovação orientada para a sustentabilidade; em seguida, na seção 2.2, apresenta-se a complexidade dos processos de inovação e vislumbra-se a importância das fases iniciais para a incorporação de aspectos de sustentabilidade; a seção 2.3 traz os principais elementos do referencial teórico que será utilizado (teoria da estruturação); e, por fim, a seção 2.4 traz os elementos estruturantes deste trabalho, ao articular a teoria da estruturação com a inovação orientada para a sustentabilidade. Uma representação esquemática dessa estratégia de fundamentação teórica é apresentada na figura 1. A articulação começa abordando a sustentabilidade em seu nível macro (sociedade); segue aproximando-se do tema processo de inovação, que também revela um fenômeno macro ou intermediário; e termina por se aproximar dos indivíduos e das práticas que estes encerram, trazendo um referencial da sociologia, para analisar o fenômeno em escala micro, que são as práticas instanciadas pelos atores envolvidos nos processos de IOS. 
Figura 1: Representação esquemática da estratégia de fundamentação teórica

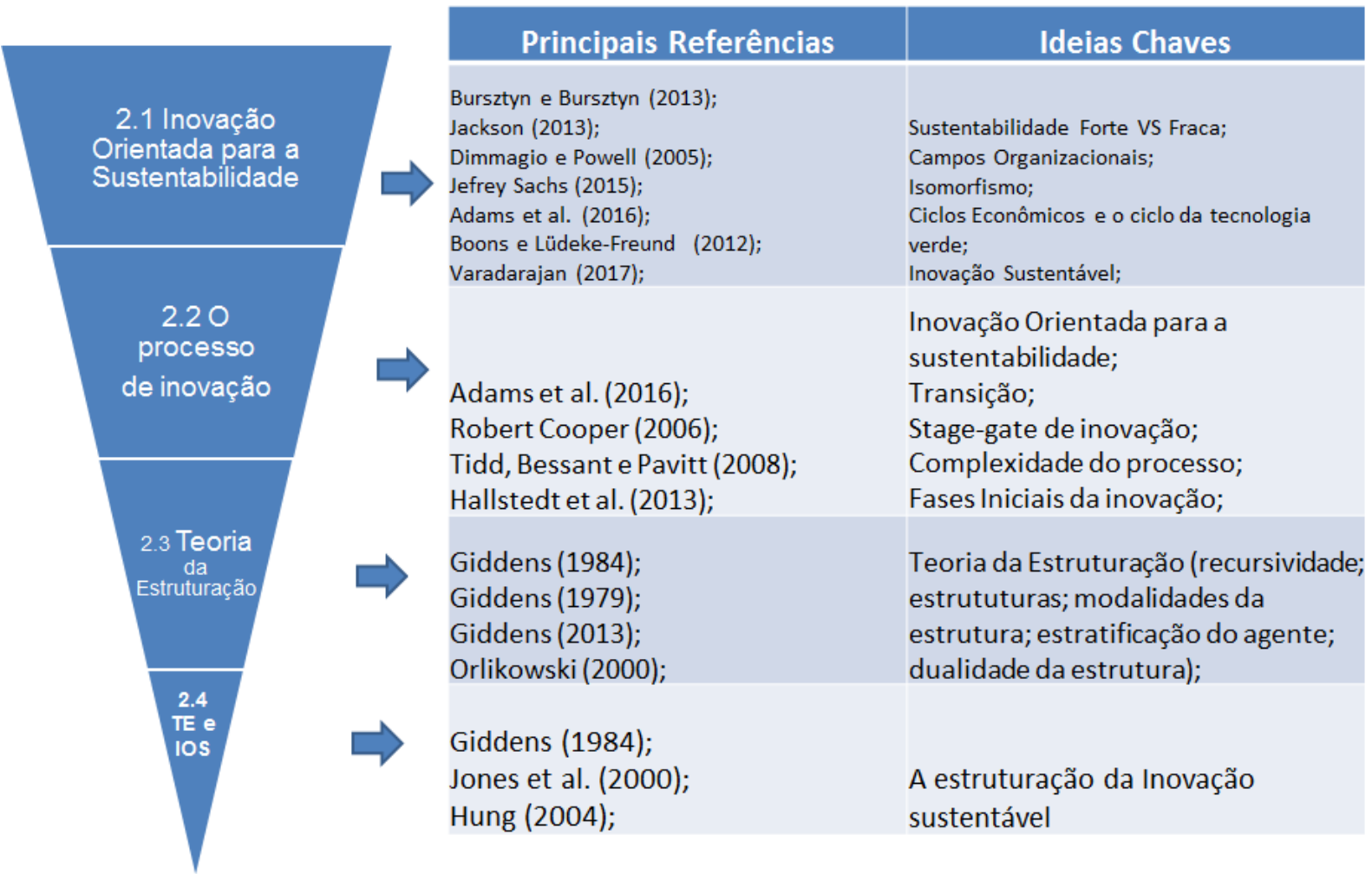

Fonte: Elaborada pelo autor

\subsection{Inovação orientada para a sustentabilidade (IOS)}

A introdução deste trabalho trouxe uma breve contextualização da problemática global, com relação aos recursos naturais e padrão de consumo alcançado pela sociedade contemporânea.

Esta seção da fundamentação teórica descreve o posicionamento das empresas com relação à sustentabilidade. Em seguida, discute-se a orientação da prática de inovação para essa visão de sustentabilidade das empresas. Por fim, são apresentados os achados sobre os modelos de inovação orientada para a sustentabilidade.

\subsubsection{A sustentabilidade no posicionamento das empresas}

Conceitos como sustentabilidade ou desenvolvimento sustentável estão em voga nos dias de hoje. Em várias atividades cotidianas, vê-se o posicionamento e a discussão de algo relacionado com esses conceitos. A compra de bens de consumo, por exemplo, traz muitas alegorias sobre questões que perpassam a discussão 
sobre o que seria sustentável. Fala-se de reciclagem de produtos, de produtos tipo "eco" etc. Fato é que não existe um conceito muito claro, não se distingue bem informação de propaganda e, ao final, as pessoas nem sempre dominam o conhecimento e informações necessários para julgarem o que estão comprando ou para se posicionarem mediante a algum tema desse amplo campo de discussão (PAGOTTO, 2013; GONÇALVES-DIAS e TEODÓSIO, 2011).

O contexto do sistema de produção capitalista, sua organização, o uso de recursos naturais renováveis ou não para a manufatura de produtos, o impacto do consumo, e o próprio modelo de consumo são fatores que integram a totalidade do fenômeno da não sustentabilidade da sociedade humana contemporânea, evidenciada por inúmeros problemas ambientais e sociais. Os atores envolvidos, tais como empresas, governos, sociedade civil, organizações não governamentais são partes integrantes desse fenômeno e, de certa forma, são ao mesmo tempo, reprodutores do status quo e potenciais agentes de mudança de toda essa problemática (JACKSON, 2013).

Como já descrito na introdução, a sintética descrição sobre o que seria desenvolvimento sustentável advém do relatório Brundtland e trata-se do desenvolvimento que atende "às necessidades do presente sem comprometer a capacidade das gerações futuras para atender às suas necessidades" (Brundtland Comission, 1987).

Embora essa definição possa parecer harmoniosa, a discussão sobre o que é sustentabilidade ou desenvolvimento sustentável transcende uma aparente harmonia desejada. Bursztyn e Bursztyn (2013) trazem a complexidade à tona ao refletirem que a incorporação do meio ambiente como elemento fundamental para a discussão da sustentabilidade pode levar a uma contradição. Toda a extração ou utilização de recursos naturais para atender ao desenvolvimento econômico da sociedade contemporânea poderia ser entendidao como uma tensão ao meio ambiente e, portanto, contrário à sustentabilidade. Bursztyn e Bursztyn (2013, p. 49) apontam:

Dependendo, portanto, do critério de avaliação, o conceito de DS pode ser considerado como uma contradição em termos, um oximoro (Mendes, 1993), já que, para ser desenvolvimento, não poderá ser sustentável. Esse tipo de visão deriva da corrente de pensamento da 
ecologia profunda e resulta no conceito de sustentabilidade forte, que por sua vez se opõe ao de sustentabilidade fraca.

Bursztyn e Bursztyn (2013, p. 51 e 52) também trazem as definições de sustentabilidade fraca e forte:

O conceito de sustentabilidade forte tem como fundamento a constatação científica de que qualquer ação humana se dá no âmbito dos limites do Planeta, ou da biosfera, onde a humanidade habita. Isso inclui a vida social em geral e as atividades econômicas em particular.

O conceito de sustentabilidade fraca refere-se ao equilíbrio entre as esferas, econômica, social e ecológica. Pressupõe a possibilidade de compatibilizar a dinâmica das atividades econômicas com a justiça social e o respeito às condições do mundo natural, de modo a que estas se mantenham no longo prazo.

A sustentabilidade forte parte do pressuposto de que a esfera da vida circunscreve a da sociedade (humana) e esta envolve a da economia (figura 2).

Figura 2: O modelo da sustentabilidade forte

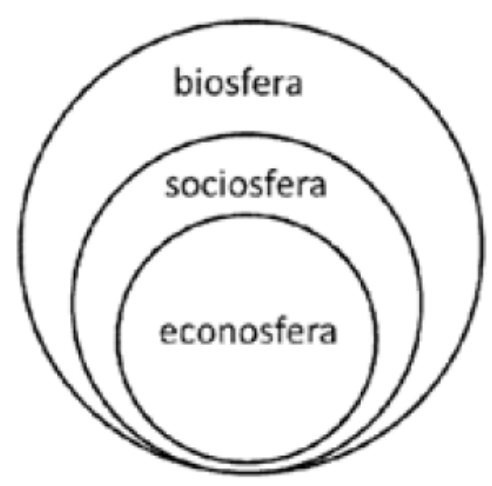

Fonte: Adams (2006)

Uma das abordagens mais conhecidas sobre desenvolvimento sustentável foi introduzida por Elkington (1997) e faz alusão ao equilíbrio de três pilares básicos, a saber, econômico, social e ambiental. A sustentabilidade, nessa perspectiva, está associada ao desenvolvimento econômico que supostamente conseguiria 
equacionar esses três pilares, respondendo às demandas da sociedade para cada um desses pilares. Claramente, essa orientação poderia ser entendida pela ótica da sustentabilidade fraca.

Muitos autores esforçam-se para demonstrar e revelar as várias dicotomias existentes num discurso de sustentabilidade fraca. A principal delas encontra nos textos de Abramovay (2012), Boff (2013) e Jackson (2013) a indagação necessária para se entender a complexidade do tema: produzir tanto, por quê? Para quem? Para quê? Esses autores trabalham com pressupostos da sustentabilidade forte e ecologia profunda.

Dentro desse contexto complexo e não harmonioso, constituindo-o e sendo constituído por ele, podemos observar o movimento histórico de adesão e aproximação por parte das empresas a uma orientação de desenvolvimento sustentável que, muitas vezes, parece questionável. Como explicita Barbieri et al. (2010), não faltam desconfianças acerca das aspirações empresariais, ainda mais porque carregam uma crença muito contestada de que crescimento econômico seria uma condição para atingir o desenvolvimento sustentável. Trata-se de um alinhamento para a sustentabilidade fraca.

Apesar de várias discussões sobre o tema, fato é que há um movimento de institucionalização em diversas esferas e campos organizacionais remetendo-se a práticas, aparentemente, mais sustentáveis. Trata-se de novos valores que estão sendo institucionalizados, como Barbieri et al. (2010, p. 149) escrevem:

As organizações buscam eficiência simbólica e eficiência técnica. A eficiência simbólica se obtém adotando-se os modelos institucionalizados no setor e na sociedade em geral e tidos como os ideais. A adoção desses modelos por parte das organizações traz legitimidade social e recursos.

A adesão ao conceito de desenvolvimento sustentável, por parte dos grupos empresariais, pode ser entendida como uma resposta organizacional a essas pressões institucionais que estão ocorrendo nas últimas décadas. 
Outra aproximação possível para esse movimento pode ser entendida como a formação de campos organizacionais que refletem o fenômeno de isomorfismo institucional. Segundo DiMaggio e Powell (2005, p. 76):

Uma vez que diferentes organizações, no mesmo ramo de negócios, estejam estruturadas em um campo concreto (seja por competição, pelo Estado e pelas categorias profissionais), forças poderosas emergem, levando-as a se tornarem mais similares umas às outras.

A teoria institucional aponta que pressões institucionais (pressões coercitivas, miméticas ou normativas) levam as empresas a adotarem estratégias, estruturas e processos similares (VARADARAJAN, 2017). Pressões institucionais se originam do ambiente das empresas e incluem pressões exercidas por regulações e políticas, colaboradores (stakeholders como investidores, clientes, provedores, empregados etc) e competidores. Pressões coercitivas são pressões sobre as empresas por meio de outras organizações sobre as quais as primeiras dependem de recursos críticos, e de instituições que defendem as expectativas culturais da sociedade para a qual elas funcionam. Pressões miméticas são aquelas experimentadas por uma organização para esta adequar-se depois que outras organizações, no mesmo campo de atuação, enfrentaram incertezas sobre objetivos, tecnologias e relações de meios e finalidades. Por fim, pressões normativas são pressões enfrentadas por uma organização para que ela se adeque a normas coletivas compartilhadas por outras organizações no seu campo, com a intenção de definir as condições e os métodos nos quais elas operam.

Especificamente para a questão da sustentabilidade, todos os tipos de pressões estão presentes e são, em última análise, suportados pelos seus principais executivos. Estes atentam para o fato de que essa orientação pode ter uma influência positiva sobre o desempenho da empresa. Além disso, investidores passaram a exigir dados mais claros sobre as práticas das empresas em relação à sustentabilidade em diversos níveis. Fala-se de sustentabilidade e responsabilidade corporativa.

Há de se salientar que a proposta de trabalhar com o isomorfismo em três dimensões, conforme descrito por DiMaggio e Powell (2005), sofre inúmeras críticas relativas à minimização do papel do agente no processo e também à simplificação 
da forma como abordam o poder. Em relação ao agente, os autores DiMaggio e Powell (2005) trabalham com base no conceito de "estruturação" (GIDDENS, 1979) para sintetizar ação e estrutura na análise sociológica, deslocando, contudo, o nível de análise para as organizações (PECI, 2006). Não há ênfase no papel do agente. Trata-se de um sujeito amorfo. Em relação a sua abordagem quanto ao poder, os autores o reconhecem poder, apenas, como uma expressão diretamente pelo controle da lei ou da opinião pública. Basicamente, os institucionalistas privilegiam a dimensão cognitiva e normativa no estudo dos processos de institucionalização, abordando o poder (quando o fazem) de uma forma simplista (PECl, 2006).

A fim de analisar o papel de um agente que se relaciona ativamente com a estrutura e que está imbricado em relações de poder na medida em que exerce e instancia práticas sociais, pretende-se neste estudo, apresentar e utilizar a teoria da estruturação, nos tópicos que seguirão a discussão sobre inovação.

\subsubsection{O alinhamento da inovação em busca do desenvolvimento sustentável}

Uma das possíveis análises sobre nossa sociedade jaz sobre o modo de produção capitalista e a organização social do trabalho. Nesse contexto, diversos autores indicam como a evolução tecnológica sempre foi um fator primordial para a sociedade capitalista. Jefrey Sachs (2015) aponta a descrição do economista Nikolai Kondratieff, autor de "The Major Economic Cycles" (1925), sobre a evolução econômica estar atrelada a grandes eras tecnológicas. Segundo ele, grandes revoluções tecnológicas levam a um ápice de desenvolvimento econômico. Em seguida, há um período de recessão econômica e incertezas, até que uma nova onda, propagada por uma nova grande revolução tecnológica ocorra. A figura 3 elucida esses grandes ciclos econômicos. Segundo Sachs (2015), estamos vivendo um momento de recessão e a nova onda tecnológica que deve surgir e dar ritmo a essa dinâmica seria aquela atrelada a tecnologias verdes e inteligentes. 
Figura 3: Ciclos econômicos / tecnológicos

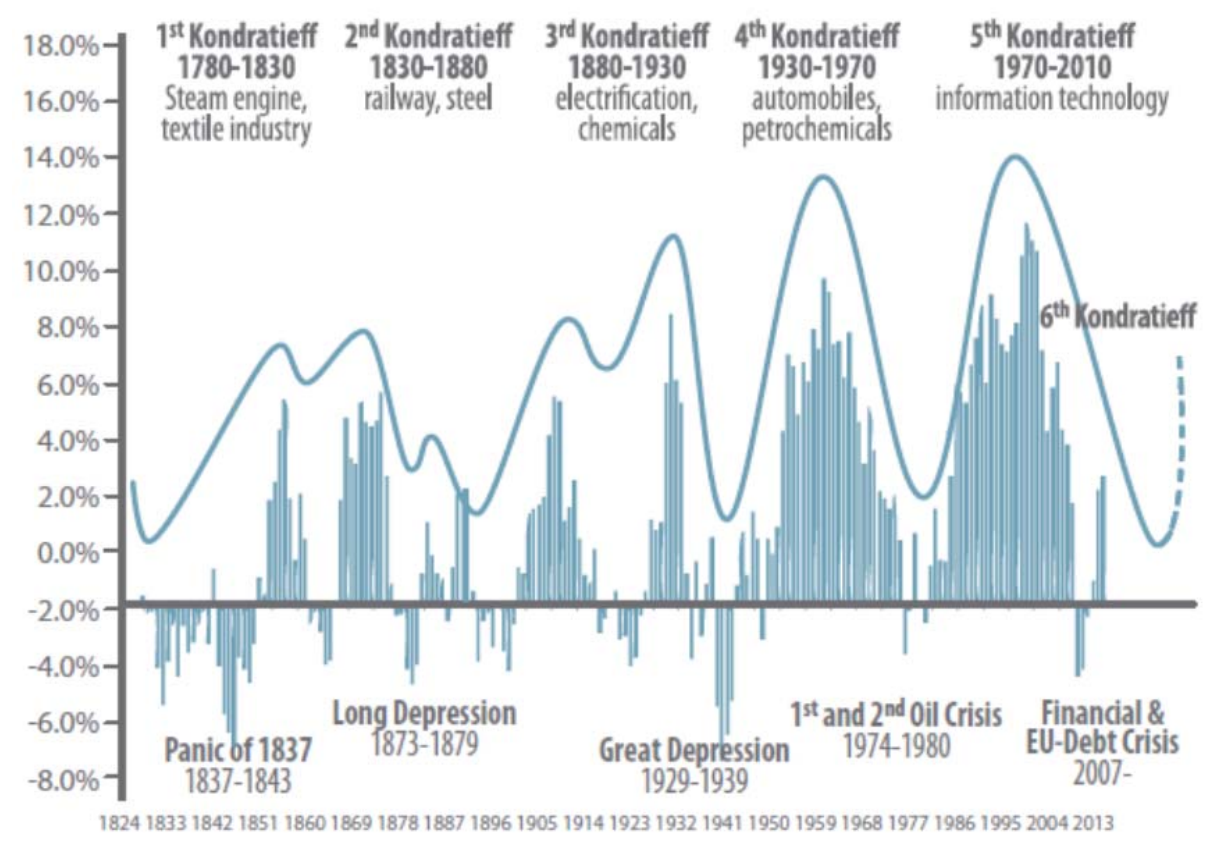

Fonte: Sachs (2015)

Uma das atividades chave das empresas é a atividade de inovação. Uma primeira análise do conceito de inovação poderia ser, meramente, descrita como o processo capaz de gerar recursos para remunerar os fatores de produção, repor os ativos usados e investir para continuar competindo (BARBIERI et al. 2010). Essa abordagem, que reproduz o que é esperado por uma organização em busca de legitimidade no seu campo organizacional, em nada difere de uma definição clássica de inovação como a fornecida por Porter (1995) e Schumpeter (1939), que a consideram como ação necessária e estratégica para a manutenção da competitividade empresarial ou de Maskell e Malmberg (1999), que apontam que em uma sociedade altamente globalizada como a atual, a competitividade deriva da habilidade das empresas em inovar.

O que parece diferir, ao longo dos últimos anos, é que a inovação ganhou roupagem adicional, por meio de um discurso que a identifica como atividade orientada para a sustentabilidade, tendo como tecido espaço-temporal aquele movimento de institucionalização de valores sustentáveis (BARBIERI et al. 2010; ADAMS, 2016; MEDEIROS et al., 2014). A sustentabilidade ganha status de um mantra (CAVALCANTI, 2012), que todos repetem, por que não querem se opor, mas 
como diria Bursztyn e Bursztyn: "se todos estão a favor, então quem está contra?" (BURSZTYN e BURSZTYN, 2013 p. 32).

$\mathrm{Na}$ academia, as produções que fazem referência à temática de sustentabilidade e suas derivações (desenvolvimento sustentável, inovação sustentável, Green innovation, Eco inovação), têm apresentado um intenso crescimento (ADAMS, 2016; BOONS et al. 2013; VARADARAJAN, 2017).

A orientação do processo de inovação para a sustentabilidade encontra diversas forças motrizes. Diferentes trabalhos dão ênfases distintas para essas motivações, mas encontram um denominador comum relacionado ao estresse do uso de recursos naturais e ao excessivo modelo de consumo da sociedade capitalista (JACKSON 2013; ROCKSTRÖN 2009; PARODI et al. 2011; ABRAMOVAY 2012).

Boons et al. (2013) apontam, primeiramente, os grandes desafios que 0 mundo está enfrentando como a mudança climática, o envelhecimento da população, a desertificação, a escassez de água e de recursos naturais. Em seguida, indicam as questões econômicas de competividade empresarial e entre nações. Um ponto importante que é salientado é a questão do posicionamento dos países em cumprirem sua função básica de garantir bem estar social e condições dignas aos indivíduos. Tal temática é o cerne na sustentabilidade social. Adams et al. (2016) resumem a orientação sustentável do processo de inovação emergindo do evidente super consumismo, da degradação ambiental, e da desigualdade social. Segundo o autor, tais constatações clamam para uma transição em direção a uma sociedade e economia mais sustentável. Hallstedt et al. (2013) e Medeiros et al. (2014) pontuam a importância da inovação orientada para a sustentabilidade como uma ação estratégica e necessária para a manutenção da competividade. Fala-se de uma sustentabilidade empresarial num discurso mais amplo sobre uma sociedade mais sustentável. Trata-se de uma abordagem dentro de uma perspectiva de modernização ecológica (BURSZTYN, BURSZTYN 2013; BOFF 2013).

Ponto comum de diversos trabalhos jaz em deixar clara a complexidade do tema e elucidar o grande número de expressões e conceitos correlatos à inovação com orientação para a sustentabilidade. Para uma breve discussão, apoiamo-nos 
no trabalho de Varadarajan 2017 (suportado pelo trabalho de Adams et al. 2012 ${ }^{1}$ ). A tabela 1 traz algumas definições dos conceitos de inovação sustentável.

Tabela 1: Síntese de várias definições do conceito de inovação sustentável encontradas na literatura

\begin{tabular}{|c|c|}
\hline \multirow{7}{*}{ Inovação Sustentável } & $\begin{array}{l}\text { Novos produtos e processos que proveem valor ao cliente e ao negócio e uma } \\
\text { significativa redução dos impactos ambientais (FUSSLER E JAMES, 1996) }\end{array}$ \\
\hline & $\begin{array}{l}\text { Novos produtos e processos que proveem valor ao cliente, por utilizar menos } \\
\text { recursos, resultando assim na redução dos impactos ambientais (JOHANSSON } \\
\text { AND MAGNUSSON 1998) }\end{array}$ \\
\hline & $\begin{array}{l}\text { Processos, técnicas, práticas, sistemas e produtos novos ou modificados que têm } \\
\text { por objetivo a prevenção ou redução do impacto ambiental (RENNINGS 2000) }\end{array}$ \\
\hline & Inovação que melhora o desempenho ambiental (ARNOLD e HOCKERTS 2011) \\
\hline & $\begin{array}{l}\text { Conceito abrangente que provê direção e visão para assimilar a ampla mudança } \\
\text { social necessária para alcançar o desenvolvimento sustentável. Inovação } \\
\text { sustentável reflete uma ênfase explícita na redução dos impactos ambientais, seja } \\
\text { como um efeito intencional ou não. ... Ela não é limitada à inovação de produtos, } \\
\text { processos, métodos de marketing e métodos organizacionais, mas também inclui } \\
\text { inovação em estruturas sociais e institucionais (MACHIBA 2010). }\end{array}$ \\
\hline & $\begin{array}{l}\text { Processos, técnicas, práticas, sistemas e produtos novos ou modificados que } \\
\text { evitem ou reduzam os impactos ambientais. Inovação sustentável pode ser } \\
\text { desenvolvida com ou sem o objetivo explícito de reduzir o impacto ambiental } \\
\text { (HALILA e RUNDQUIST 2011) }\end{array}$ \\
\hline & $\begin{array}{l}\text { Inovação sustentável é a produção, assimilação ou exploração de um produto, } \\
\text { processo produtivo, serviço ou gerenciamento ou método de negócio que é novo } \\
\text { para a organização (desenvolvido ou adotado) e que resulta, através do seu ciclo } \\
\text { de vida, na redução de riscos ambientais, poluição e outros impactos negativos de } \\
\text { uso de recursos (incluindo uso de energia) comparados a alternativas relevantes } \\
\text { (BUTOLL et al. 2012) }\end{array}$ \\
\hline \multirow[t]{2}{*}{ Inovação Ecológica } & $\begin{array}{l}\text { O desenvolvimento e implementação de novos produtos (tecnologias ambientais), } \\
\text { novos processos produtivos, novos recursos, novos mercados e novos sistemas } \\
\text { (i.e. Transporte de bens), e todos eles integrados econômica e ecologicamente, i.e., } \\
\text { introduzido os aspectos ecológicos nas estratégias econômicas (BLÄTTEL-MINK } \\
\text { 1998) }\end{array}$ \\
\hline & $\begin{array}{l}\text { Ações tomadas por indivíduos ou times que melhoram o desempenho ambiental } \\
\text { das empresas. Iniciativas de prevenção à poluição, a substituição de substâncias } \\
\text { tóxicas ou perigosas, a desmaterialização de produtos e a substituição de produtos } \\
\text { por serviços são tipos de inovações sustentáveis (RAMUS 2001) }\end{array}$ \\
\hline
\end{tabular}

\footnotetext{
${ }^{1}$ As definições da tabela 1 foram extraídas do trabalho de Adams et al. (2012, p. 87-89) por Varadarajan (2017)
} 


\begin{tabular}{|l|l|}
\hline Inovação Ambiental $^{2}$ & $\begin{array}{l}\text { Os esforços éticos e melhorias eficientes realizadas para produtos e operações } \\
\text { existentes. Sustentabilidade é definida pelas atividades corporativas inovadoras e } \\
\text { potencialmente transformadoras que geram novos produtos e processos que } \\
\text { desafiam as práticas existentes (LARSON 2000). }\end{array}$ \\
\cline { 2 - 2 } & $\begin{array}{l}\text { Qualquer tipo de inovação - técnica, econômica, legal, institucional, organizacional } \\
\text { ou comportamental - que alivie a tensão sobre os recursos ambientais sensíveis } \\
\text { (HUBER 2008) }\end{array}$
\end{tabular}

Fonte: Varadarajan (2017, p. 16), traduzida e adaptada pelo autor

Ao analisar vários trabalhos na literatura e buscar alguma linha norteadora para o seu trabalho, Varadarajan (2017, p. 17, tradução nossa) apresenta suas definições dos conceitos de inovação sustentável e inovação sustentável de produto, a saber:

Inovação sustentável é a implementação de projetos em uma firma com novos produtos, processos ou práticas, ou modificações de produtos, processos ou práticas existentes que significativamente reduzem o impacto das atividades da firma no ambiente natural.

Inovação sustentável de produto é a introdução pela firma de um novo produto ou modificação de um produto existente, cujo impacto ambiental, durante o ciclo de vida do produto, abrangendo a extração de recursos, produção, distribuição, uso, disposição pós-uso, é significativamente menor do que produtos existentes para os quais este novo produto é um substituto.

Tais definições serão úteis para a discussão deste trabalho, considerando-se a realidade dentro das empresas e serão adotadas como lentes para análise da orientação sustentável escolhida pelas empresas. Há de se salientar que, neste trabalho, optou-se por utilizar a expressão inovação orientada para a sustentabilidade (IOS) ao invés de inovação sustentável, pois esta última emprega o termo sustentável como adjetivo da inovação e isso nos levaria a uma discussão

\footnotetext{
${ }^{2}$ Sustainable innovation, ecological innovation, eco-innovation, environmental innovation, green innovation, sustainability driven innovation, sustainability enhancing innovation, and sustainability oriented innovation são alguns termos usados como intercambiáveis na literatura (Varadarajan, 2017, p. 16)
} 
sobre a hermenêutica do constructo que, embora necessária e profunda, ampliaria demais a delimitação do trabalho.

Ainda uma importante contribuição de Varadarajan (2017), vem da sua síntese para aquilo que seria a orientação da inovação para a sustentabilidade (Varadarajan, 2017, p. 25):

[...] sustainable innovations orientation is conceptualized here as broad in scope, encompassing the total enterprise and all functional areas. Siguaw, Simpson and Enz's review of extant definitions of innovation orientation shows an organization's actual behavior and/or behavioral predisposition (commitment, inclination, propensity, or tendency) to be the focus of most definitions (e.g., an organization's beliefs and understandings about innovation; an organization's beliefs and understandings underlying its actions in the realm of innovation; an organization's understandings that manifest as specific innovation enabling behaviors; an organization's common standards and beliefs about learning and knowledge that pervade and guide all functional areas toward innovation; organizational climate, organizational philosophy, organizational propensities, organizational practices, strategic direction of organization; and strategies and actions of an organization).

Por fim, o trabalho de Adams et al. (2016) traz a evolução das revisões bibliográficas sobre IOS realizadas nos últimos 20 anos, indicando as principais colaborações em termos de evolução do conceito. O estudo apresenta o movimento da literatura em direção à incorporação de novas práticas no gerenciamento da inovação orientada para a sustentabilidade. Elucida como tais práticas, no plano teórico, deixam de ser uma resposta às regulações ambientais e passam a ser incorporadas na estratégia das firmas. O conceito de eco design ganha força e uma tentativa de equilibrar os pilares econômicos, ambientais e sociais emerge. Nesta perspectiva, o foco na dimensão ecológica é superior ao direcionado à dimensão social e se reconhece a necessidade de transformação dos modelos de negócios atuais para darem conta de equilibrar as dimensões econômicas, sociais e ambientais. Deve-se salientar que essa evolução é evidenciada nos trabalhos 
acadêmicos, reportados por Adams et al. (2016), o que não garante sua aplicação à prática de grandes empresas.

\subsubsection{Os modelos de inovação orientada para a sustentabilidade}

Na seção 2.1.1 apresentamos a orientação sustentável que as empresas vêm incorporando em seus posicionamentos, perante os colaboradores (acionistas, empregados, comunidades, provedores, planeta etc). Discutiu-se o contexto em que ocorre tal orientação e a observação desse fenômeno. Em seguida, apontou-se que o alinhamento do processo de inovação para a sustentabilidade é uma das estratégias adotadas para responder a essa orientação corporativa, seja na prática (BARBIERI et al, 2010), ou no discurso (BURSZTIN E BURSZTIN, 2013, CAVALCANTI, 2012). A revisão da literatura indicou a preocupação quanto à postura das corporações, norteada para a sustentabilidade, salientando 0 desequilíbrio entre as dimensões do tripé: social, ambiental e econômico. Nesta seção, será discutido o que se pode compreender por modelo de inovação orientada para a sustentabilidade, entender quais são os detalhes, e como os indivíduos são posicionados diante desses modelos.

Para se aproximar do fenômeno "inovação orientada para a sustentabilidade", além de revisitar as definições que circundam esse campo, adotou-se a estratégia de entender como a literatura apresenta os modelos desse tipo de inovação, ou ainda, entender esse tipo de inovação. Um ponto importante que deve ser salientado jaz num detalhe contido no objetivo deste trabalho, que tenta se aproximar da relação entre agentes e estruturas nos processos de inovação orientados para a sustentabilidade. Dessa maneira, realizou-se uma ampla e extensa revisão da literatura que buscasse identificar os modelos de inovação orientada para a sustentabilidade e quais as abordagens que tais modelos trazem com relação à incorporação do agente no processo.

Uma proposição sustentada neste estudo é que os modelos não veem e nem dão ênfase aos agentes envolvidos no processo de inovação. Quando o fazem, fazem de maneira seletiva e esquecem as estruturas que possibilitam as práticas de todos os agentes envolvidos no processo global de inovação. Este trabalho não tentará provar tal proposição, mas a proposição guiará as críticas relativas aos modelos encontrados na literatura, como é apropriado no caso de pesquisas 
qualitativas, no que se refere às práticas dos agentes e sua relação com as estruturas.

A figura 4 traz algumas representações de desenvolvimento sustentável, que recorrentemente são usadas por diversas empresas, e encontram em Elkington (1997) uma sustentação básica e limitada da sustentabilidade, sendo esta constituída pelo equilíbrio dos três pilares. Na figura 4a encontra-se a representação de uma superposição das três dimensões nas quais ocorreriam as condições do desenvolvimento sustentável. As superposições dos pares econômico/social, econômico/ambiental e social/ambiental trazem respectivamente os conceitos de equidade, eco eficiência e habilidade, vistos como fundamentais para a promoção do desenvolvimento sustentável. A figura $4 \mathrm{~b}$ traz semelhante estrutura, elucidando a representação numa perspectiva da sustentabilidade empresarial. Por fim, a figura 4c elucida os três pilares (ELKINGTON, 1997) com representatividade e importância semelhantes.

As dimensões apresentadas na figura 4 levam a questionar como as organizações estão crescendo e inovando,conduzindo suas estratégias e operações. Tal representação ou sua ideia permeará a maioria dos modelos que podem se identificar com esse alinhamento de uma inovação orientada para a sustentabilidade, mas que são passíveis de questionamento, quando analisadas sob a perspectiva da sustentabilidade forte.

Figura 4: Representações do desenvolvimento sustentável

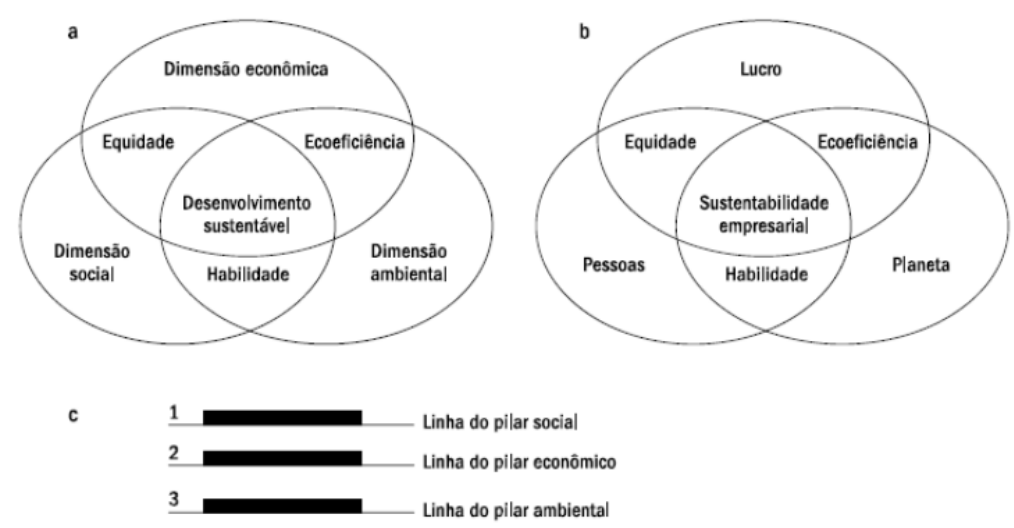

4a - Representação do Desenvolvimento Sustentável; 4b - A visão da sustentabilidade empresarial; 4c - Os pilares de Elkington;

Fonte: Barbieri (2010) 
O trabalho de Da Silva et al. (2014) discute os modelos para gestão de inovação. Embora o foco de seu trabalho seja muito mais na gestão, a autora traz, em sua revisão, a versão de Jonash e Sommerlatte (2011) para o modelo de gestão de inovação de alto desempenho representado na figura 5. Nessa visão, entende-se o processo de inovação como um contínuo de atividades e sub-processos, nos quais várias pessoas e funções da empresa estão inseridas. Nesse modelo, aparece uma sutil menção à inovação sustentável, fazendo parte do processo global.

Figura 5: Modelo de inovação avançada e de alto desempenho.

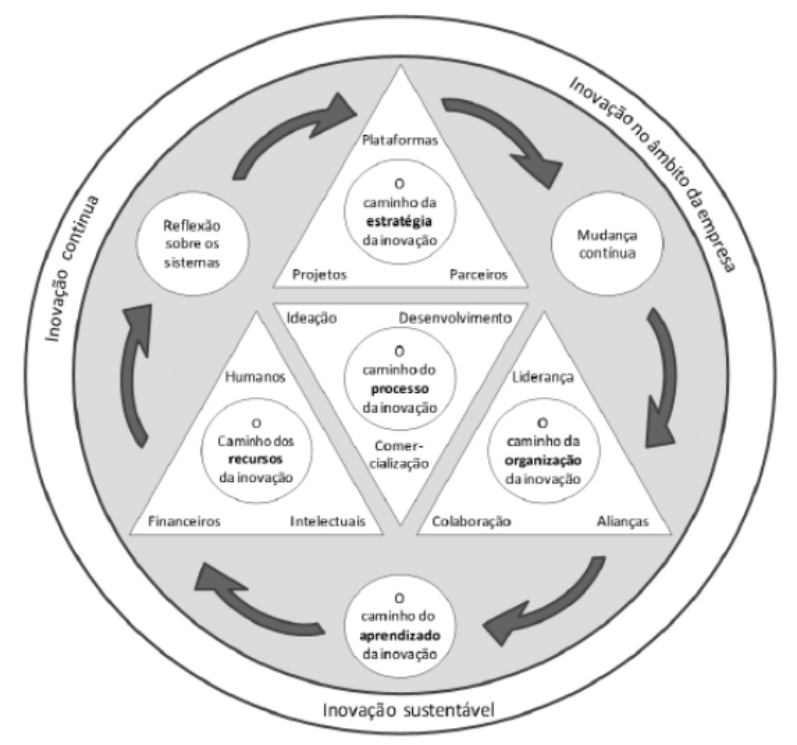

Fonte: Jonash e Sommerlatte (2011).

Adams et al. (2016) apresentam uma revisão da literatura com o objetivo de evidenciar o fenômeno de inovação orientada para a sustentabilidade IOS (SOI Sustainability-oriented Innovation) por meio da identificação, análise e síntese de práticas e processos no nível das empresas, a fim de proporcionar uma espécie de guia para que as mesmas possam evoluir e tornarem-se mais sustentáveis.

O trabalho propõe um modelo de IOS que começa como uma resposta a estímulos regulatórios através de mudanças incrementais no nível da empresa e culmina com uma mudança radical no macro nível sistêmico (onde a empresa atua). O trabalho traz uma questão central: quais são as atividades de inovação que as firmas empregam para se tornarem sustentáveis? Emblematicamente (ADAMS, 2016, p. 182): "Sustainability is not about either/or: rather, sustainability is about becoming". 
O trabalho também se propõe a análise de dimensões da IOS (figura 6). São apresentadas três dimensões. A dimensão técnica/pessoal, a dimensão standalone/integrada e a dimensão insular/sistêmica. Todas elas são consideradas uma transição, um movimento no sentido de tornarem-se mais sustentáveis.

$\mathrm{Na}$ dimensão técnica/pessoal, evidencia-se o status-quo da inovação com um grande foco técnico, com uma visão de inovação voltada ao produto, promovendo ajustes incrementais em práticas para atender os desafios ambientais. Em contraste, essa dimensão agregará também uma visão que repousa sua atenção numa inovação centrada nas pessoas. Sustentabilidade é tratada como um desafio sóciotécnico, afetando um emaranhado de elementos, como tecnologia, regulação, práticas de consumidores e mercados, significado cultural, infraestrutura e cadeia de entrega.

A dimensão stand-alone/integrada trata do posicionamento da empresa, internamente, com relação a sua orientação da inovação para a sustentabilidade, em um caminho de maior integração com atores externos. É o caso, por exemplo, da disseminação das práticas ligadas à análise do ciclo de vida de produtos, que afeta a cadeia de suprimentos de matérias-primas e também a disposição do produto após o uso pelo consumidor.

A terceira e última dimensão, denominada insular/sistêmica, reflete a visão da firma por ela mesma em relação a uma visão mais ampla / holística da sociedade. Ela questiona se inovações são orientadas internamente, endereçando questões internas, ou desenhadas e objetivadas para impactar um sistema socioeconômico mais amplo, além das fronteiras imediatas das firmas e seus colaboradores (stakeholders).

Figura 6: As dimensões da inovação orientada para a sustentabilidade

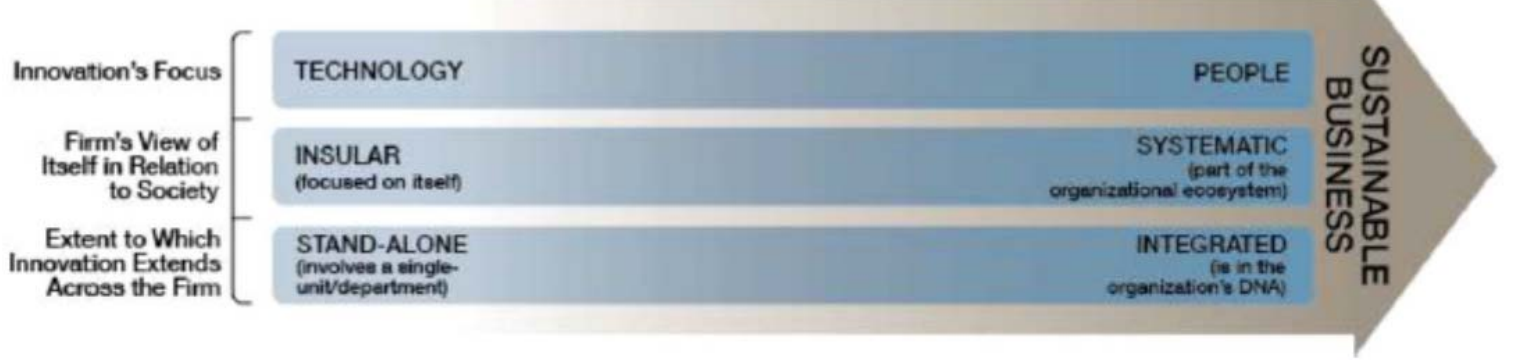

Fonte: Adams et al. (2016) 
Adams et al. (2016) propõem um modelo (figura 7) que incorpora as três dimensões identificadas por eles como fundamentais para a IOS, incluindo elementos relacionados às atividades das IOS que as empresas empregam na implementação dessa orientação no processo de inovação.

Figura 7: Modelo de inovação orientada para a sustentabilidade

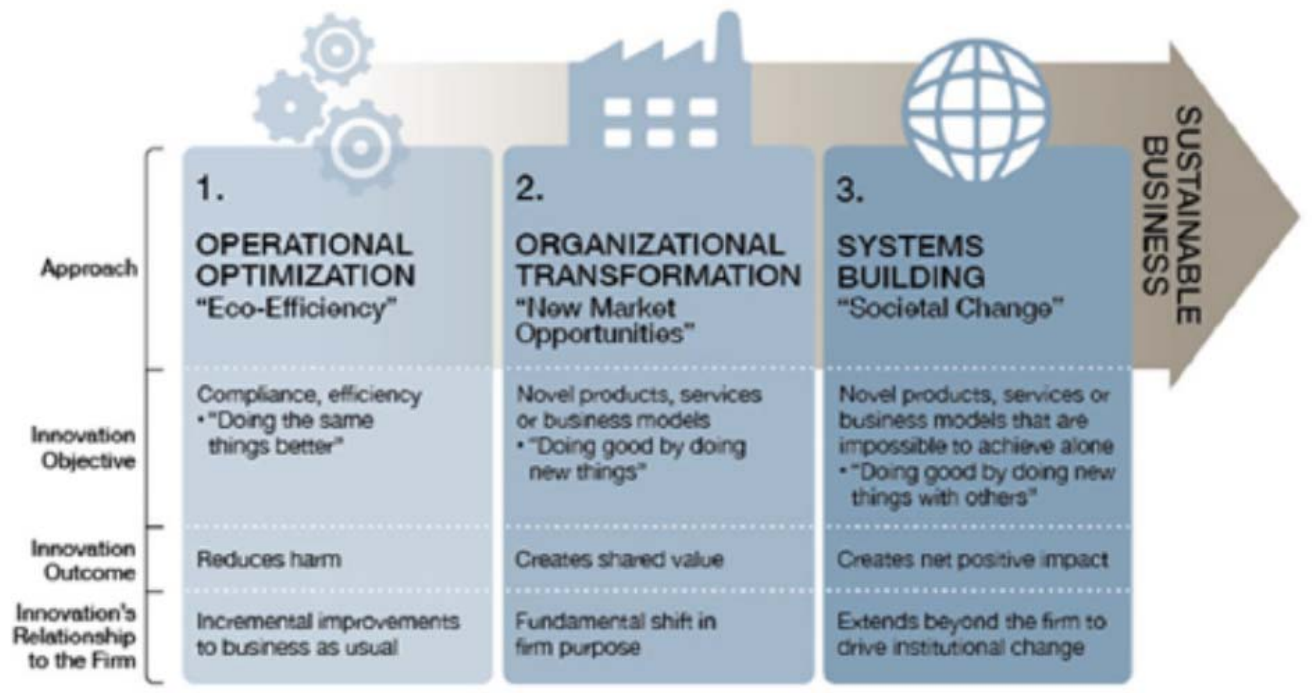

Fonte: Adams et al. (2016)

O modelo descreve três tipos de posicionamentos estratégicos que as empresas podem assumir e mostra uma ideia de evolução desse posicionamento. Um posicionamento inicial, o status-quo, pode ser identificado como uma estratégia de "otimização operacional". Nessa fase, as atividades de inovação voltam-se de maneira eficiente para responder às questões ambientais. Trata-se de fazer as mesmas coisas de maneira melhor. A evolução da inovação será incremental. Um passo posterior e na direção de se tornar mais sustentável, jaz na estratégia de transformação organizacional. Ainda trata-se de algo voltado para dentro da empresa, onde ela busca novas oportunidades e novos mercados. É sobre fazer algo bom por meio de novos produtos. A inovação orientada para a sustentabilidade busca a criação de valor e evidencia uma mudança fundamental no entendimento da importância da inovação para a empresa. O último estágio desse modelo posiciona empresas com uma estratégia de construção de sistemas (de mudança na sociedade). Este, sem dúvida, é o estágio mais completo e ainda visionário e teórico (ou ainda, em construção). Trata-se de fazer novas propostas com os outros colaboradores (acionistas, empregados, comunidades, provedores...). A empresa 
criaria, por meio da inovação, um impacto positivo líquido para a sociedade (avaliadas as dimensões econômica, social e ambiental). A visão de inovação de empresas nesse estágio transcende a própria empresa, e evidencia influências em mudanças institucionais.

O trabalho de Adams et al (2016) ainda apresenta a reflexão sobre categorias para cada estágio proposto. As categorias apresentadas e discutidas são: estratégia; processo de inovação; aprendizado; ligações (linkages) e organização da inovação. A tabela 2 (ADAMS et al. 2016, p. 195, tradução nossa) traz uma síntese dessas categorias.

Tabela 2: Atividades da Inovação Orientada para a sustentabilidade

\begin{tabular}{|c|c|c|c|}
\hline & $\begin{array}{c}\text { Otimização } \\
\text { Operacional: fazendo } \\
\text { mais com menos }\end{array}$ & $\begin{array}{c}\text { Transformação } \\
\text { Organizacional: fazendo } \\
\text { o bom através de novas } \\
\text { coisas }\end{array}$ & $\begin{array}{c}\text { Construção de Sistema: } \\
\text { fazendo o bom através } \\
\text { de novas coisas com os } \\
\text { outros }\end{array}$ \\
\hline Estratégia & $\begin{array}{c}\text { Segue as regulamentações } \\
\text { ou busca ganhos de } \\
\text { eficiência }\end{array}$ & $\begin{array}{l}\text { Imerge sustentabilidade } \\
\text { como uma norma cultural e } \\
\text { estratégica numa forma } \\
\text { lógica que vai através do } \\
\text { tornar-se mais verde }\end{array}$ & $\begin{array}{c}\text { Lógica de ampla } \\
\text { colaboração e investimento } \\
\text { em soluções de sistemas } \\
\text { para derivar novas, e co- } \\
\text { criadas proposições de } \\
\text { valores }\end{array}$ \\
\hline Processo & $\begin{array}{l}\text { Foco sobre inovação } \\
\text { interna e incremental } \\
\text { facilitada pelo uso de } \\
\text { ferramentas }\end{array}$ & $\begin{array}{c}\text { Adota novos valores e } \\
\text { plataformas (por exemplo, } \\
\text { inovação reversa) e novas } \\
\text { práticas de ideação } \\
\text { (exemplo, imitação da } \\
\text { natureza) }\end{array}$ & $\begin{array}{l}\text { Adota novas plataformas de } \\
\text { processos colaborativos com } \\
\text { diversos colaboradores }\end{array}$ \\
\hline Aprendizado & $\begin{array}{c}\text { Exploração do } \\
\text { gerenciamento do } \\
\text { conhecimento existente } \\
\text { para identificar e acessar } \\
\text { conhecimentos relevantes }\end{array}$ & $\begin{array}{l}\text { Engaja mais fortemente os } \\
\text { colaboradores chaves da } \\
\text { empresa (internos e } \\
\text { externos) }\end{array}$ & $\begin{array}{c}\text { Desenvolve habilidades } \\
\text { capazes de perceber coisas } \\
\text { simples (mais escondidas, a } \\
\text { princípio) e aprender com } \\
\text { experimentação de múltiplas } \\
\text { e_novas aproximações }\end{array}$ \\
\hline $\begin{array}{l}\text { Ligações } \\
\text { (Linkages) }\end{array}$ & $\begin{array}{l}\text { Recruta "experts" externos } \\
\text { para novos conhecimentos }\end{array}$ & $\begin{array}{c}\text { Muda o foco de intra- } \\
\text { empresa para colaborações } \\
\text { imediatas entre } \\
\text { colaboradores }\end{array}$ & $\begin{array}{c}\text { Coloca todo o sistema na } \\
\text { mesma sala para } \\
\text { diagnosticar problemas, } \\
\text { entender a complexidade do } \\
\text { sistema e identificar rotas de } \\
\text { mudança }\end{array}$ \\
\hline $\begin{array}{l}\text { Organização } \\
\text { Inovadora }\end{array}$ & $\begin{array}{l}\text { Explora as "capabilities" } \\
\text { existentes de inovação }\end{array}$ & $\begin{array}{c}\text { Dissemina a Inovação } \\
\text { Orientada para a } \\
\text { sustentabilidade através da } \\
\text { organização } \\
\end{array}$ & $\begin{array}{c}\text { Adota novos paradigmas de } \\
\text { negócios }\end{array}$ \\
\hline
\end{tabular}

Fonte: Adams et al. (2016)

No trabalho de Adams et al. (2012), precursor desse modelo, os autores apresentam o paradigma econômico neoliberal predominante que privilegia a maximização do lucro como a dimensão crítica de maior valor nos modelos de negócios das empresas. Para organizações que se aproximam de um modelo de inovação mais sustentável (que segundo o modelo de IOS poderia ser classificadas 
como Transformadores Organizacionais ou ainda Construtores de sistemas), um paradigma emergente é evidente: é necessário um modelo que gere valor social, ambiental bem como econômico. O modelo de Construtores de Sistemas é o mais radical em sua essência, pois requer uma mudança na filosofia de pensar a existência das empresas. Trata-se de repensar o papel do negócio na sociedade. Tal orientação traz a questão sobre a dicotomia de ser sustentável e criar um equilíbrio ambiental, econômico e social. Não por acaso, Adams et al (2012) e Adams et al (2016) evidenciam que tal orientação ainda não pode ser encontrada, na prática, nas organizações e empresas.

Tal dicotomia trazida para discussão também nos remete a uma das reflexões deste presente trabalho, que é o fato de que no status quo das empresas, que se encontram situadas nos estágios um e dois propostos por Adams et al (2016), poderia haver a emergência de conflitos de agência entre os agentes inseridos nas práticas de inovação. Tal conflito surgiria no posicionamento de atores que tentassem, de fato, incorporar os aspectos ambientais e sociais na mesma medida dos aspectos econômicos. Dessa maneira, como seriam tomadas as decisões? Um projeto de inovação altamente e potencialmente lucrativo poderia ser abandonado se seus impactos ambiental e social fossem baixos? Ou ainda, e se as externalidades ambientais fossem altas e não corroborassem a mitigação de problemas sistêmicos? Por exemplo, um dos problemas mais apontados trata-se do padrão de consumo. Por acaso, algum projeto de novo produto preverá uma diminuição de consumo do bem em questão?

No estágio de Transformação Organizacional, Adams et al (2016) apontam que o processo de inovação é geralmente orientado / dirigido por valores pessoais e aspirações de líderes. Nota-se aqui, um reconhecimento da importância da agência. Isso também corrobora e traz a reflexão da possibilidade de conflito de agência, se não houver um alinhamento das aspirações do grupo organizacional e suas estruturas que formam e dão dinâmica às práticas de inovação. Indubitavelmente, o posicionamento das lideranças (altos executivos, diretores e gerentes) é de suma importância para suportar uma estratégia de inovação sustentável, mas um ponto importante é sobre a agência e ação dos outros atores no processo de inovação. São as atividades de outros indivíduos (mais operacionais) que compõem a maioria das atividades relacionadas ao processo de inovação. 
Os trabalhos de Boons et al. (2013) e de Boons e Lüdeke-Freund (2013) também trazem uma reflexão sobre modelos de inovação. O primeiro trabalho trata de uma revisão da literatura sobre modelos de negócios para a inovação sustentável. O segundo trabalho também traz uma revisão sobre inovação sustentável, modelos de negócios e desempenho econômico.

O foco desses trabalhos está na análise dos modelos de negócios. Boons et al (2013) defendem que as inovações orientadas para a sustentabilidade podem ser mais efetivamente criadas e estudadas quando construídas ou analisadas pela lente de modelos de negócios. Os autores afirmam que o uso de tal lente provê uma ferramenta analítica que permite a eles avaliar a interação entre os diferentes aspectos que firmas combinam para criar valor ecológico, econômico e social. Adicionalmente, o conceito de modelo de negócio provê uma ligação entre a empresa/corporação individual e o sistema mais amplo de produção e consumo na qual ela opera.

Boons e Lüdeke-Freund (2013) apresentam quatro elementos que estruturam um modelo de negócio. São eles: a proposta de valor, a cadeia de suprimentos, a interface com o cliente e o modelo financeiro. Eles salientam a necessária articulação do conceito de inovação orientada para a sustentabilidade e também se deparam com a complexidade do conceito e a atual falta de consenso sobre este. Uma das razões apontadas para a variedade e ambiguidade dos conceitos e constructos que se relacionam é o fato da temática estar sendo trabalhada por diversos pesquisadores de diferentes áreas (economia evolucionária, sociologia econômica, inovação econômica, ciência e tecnologia, história etc). Isso leva a diferentes aproximações sobre o conceito.

$\mathrm{Na}$ tentativa de se aproximar do tema "inovação sustentável", Boons e Lüdeke-Freund (2013) propõem três níveis de análises: organizacional; interorganizacional e sociedade. Neste último, discute-se o tema "transições" que reiteradas vezes aparece na literatura sobre sustentabilidade. Os autores também assumem uma posição pragmática para adotarem essa aproximação através de modelos de negócios. Boons e Lüdeke-Freund (2013, p. 11 e 12):

[...] without a successful diffusion in society, eco-innovations are meaningless. In capitalist societies the market is a dominant coordination mechanism where such success is achieved [...] an 
additional challenge for the creation and further development of business towards sustainability is the co-creation of societal and economic profits.

Uma das justificativas para se usar o conceito de modelos de negócios é a possibilidade de, através de sua visão holística de toda a cadeia, ser possível incorporar lógicas diferentes para realidades diferentes. É a constatação básica de que um produto de inovação orientada para a sustentabilidade que se aplica a uma realidade de países desenvolvidos, onde há alto poder aquisitivo dos consumidores, não pode ser empregado para uma realidade de países em desenvolvimento e de baixa renda. A saber, o modelo de negócio e, por conseguinte, o modelo de inovação, deve levar em conta as especificidades para ter impacto econômico, ambiental e social positivos.

Boons e Lüdeke-Freund (2013) definem, através de sua revisão, três modelos de negócios preponderantes no campo de discussão sobre inovação sustentável. Trata-se dos modelos de Inovação Tecnológica, Inovação Organizacional e Inovação social. Os modelos de negócios sustentáveis com foco na inovação tecnológica são aparelhos de mercado que superam as barreiras internas e externas de tecnologias mais limpas. Eles apontam (BOONS e LÜDEKE-FREUND 2013, p. 14):

Thus, sustainable business models with a focus on technological innovation are market devices that overcome internal and external barriers of marketing clean technologies; of significance is the business model's ability to create a fit between technology characteristics and (new) commercialization approaches that both can succeed on given and new markets.

Sobre mudanças no modelo de inovação organizacional (BOONS e LÜDEKEFREUND 2013, p. 15):

Business model change on the organizational level is about the implementation of alternative paradigms other than the neoclassical economic worldview that shape the culture, structure and routines of organizations and thus change the way of doing business towards 
sustainable development; a sustainable business model is the aggregate of these diverse organizational aspects.

Com relação aos modelos de inovação social, os autores apontam que os trabalhos encontrados evidenciam práticas mais voltadas para propósitos sociais e missões. Dessa maneira, poder-se-ia esperar um distanciamento do modelo econômico clássico no qual a maximização dos ganhos financeiros é preponderante. Enquanto inovações tecnológicas são mais inseridas nos modelos atuais (novos produtos, processos e serviços) e as inovações organizacionais são uma forma de autorreflexão das corporações, as inovações sociais são provedoras de soluções para problemas dos outros, i.e., de grupos da sociedade que não possuem recursos ou capability para evoluírem sozinhos (causas sistêmicas).

Outra aproximação sobre a inovação orientada para a sustentabilidade, encontra uma contribuição importante no trabalho de Hallstedt et al (2013) que traz uma análise do processo de inovação de produto. Como será discutido mais adiante nesta seção de fundamentação teórica, aquilo que pode ser concebido como o processo de inovação orientado para a sustentabilidade, engloba inúmeras atividades, que podem ser enquadradas de maneira didática dentro de uma delimitação de estágios, exigindo a interação de diversos atores, ao mesmo tempo, para dar dinâmica ao processo.

Hallstedt et al (2013) trabalham com o modelo de inovação de produto apresentado por Roozenburg e Eakels'(1995) e o modifica com ideias de Sarkis (2003) e ideias próprias.

É importante salientar que o modelo inclui as fases de desenvolvimento do produto e da utilização do mesmo, ou seja, o ciclo de vida do produto. Adicionalmente, discute-se que os aspectos de sustentabilidade necessitam ser integrados ao processo quando o produto está sendo desenvolvido, pois é neste estágio que é possível influenciar os aspectos de como o produto será produzido e utilizado. A figura 8 elucida o modelo. 
Figura 8: Processo de Inovação de produto com o ciclo de vida do produto

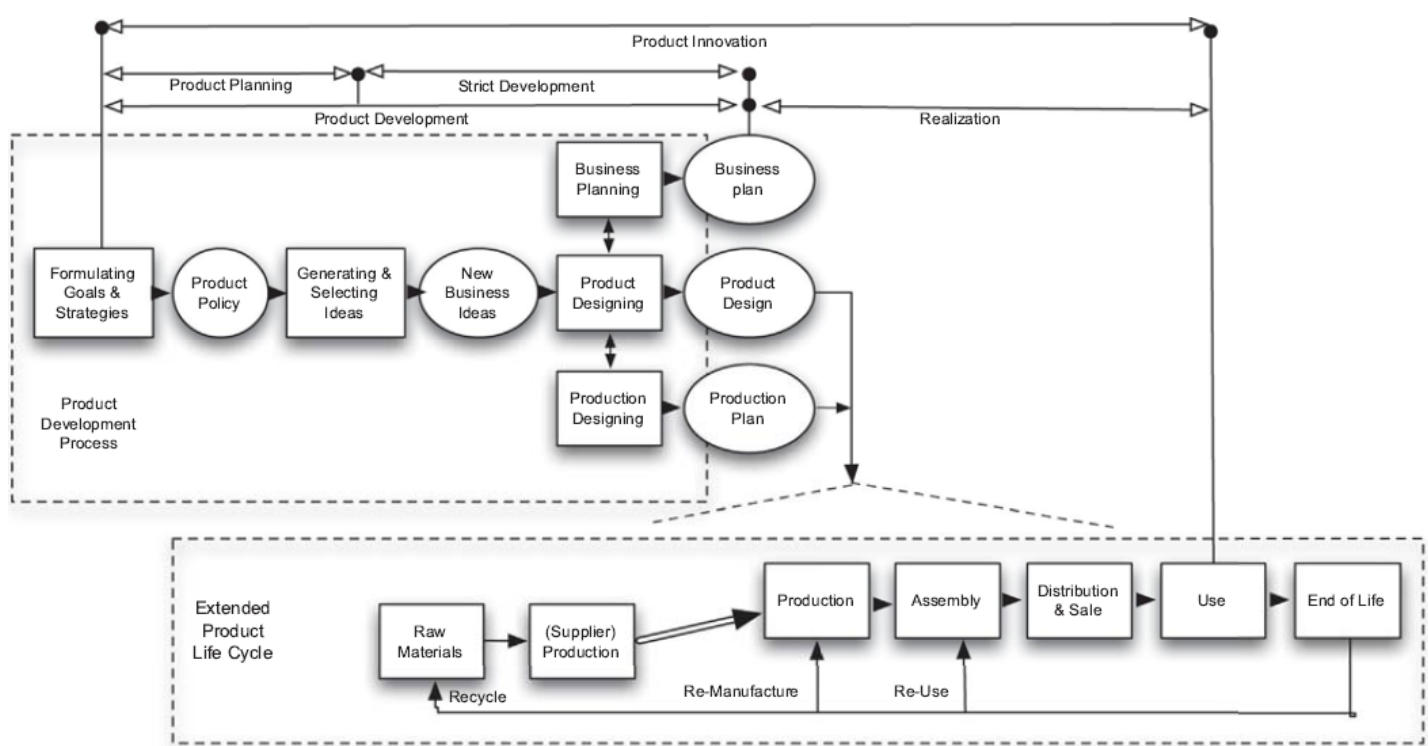

Fonte: Hallstedt et al. (2013), adaptado de Roozenburg e Eekels (1995) e Sarkis (2003)

O trabalho de Hallstedt et al. (2013) sintetiza oito elementos chave para o sucesso da implementação de uma perspectiva estratégica de sustentabilidade para o processo de inovação de produto. Esses elementos são divididos em quatro categorias: organizacional, processos internos, papel/funções (roles) e ferramentas. A tabela 3 traz a descrição de tais elementos bem como em quais categorias eles se encaixam. Na última coluna, alguns comentários foram elaborados pelo autor desta dissertação, a fim de se vislumbrar algumas questões que são centrais neste trabalho de pesquisa.

Ainda Hallstedt et al (2013) também trazem uma contribuição importante ao realizar um trabalho empírico com seis grandes empresas, pertencentes a um mesmo grupo organizacional, fazendo entrevistas orientadas a fim de explorar e avaliar se e como a estratégia de sustentabilidade tem sido implementada nas atividades no dia a dia dos processos de inovação de produtos. Tal aproximação ajudou na estruturação da entrevista feita no estudo de caso deste trabalho. 
Tabela 3: Elementos para uma inovação orientada para a sustentabilidade ${ }^{3}$

\begin{tabular}{|c|c|c|}
\hline Categoria & Elemento & Comentários / Modalidades da estrutura \\
\hline Organizacional & $\begin{array}{l}\text { Assegurar o compromisso da alta gerência através do plano } \\
\text { estratégico de sustentabilidade que é bem comunicado na } \\
\text { companhia; }\end{array}$ & $\begin{array}{l}\text { Quais são as atividades /práticas que garantem tal } \\
\text { compromisso? } \\
\text { Como isso chega e é disseminado ao longo da } \\
\text { estrutura da empresa? } \\
\text { Trata-se de mudar o esquema interpretativo dos } \\
\text { funcionários e espera-se a "agência da alta gerência" }\end{array}$ \\
\hline Processo & $\begin{array}{l}\text { Trazer eficientemente a perspectiva de sustentabilidade nas } \\
\text { fases iniciais dos processos de inovação de produto e alinhá- } \\
\text { los ao longo do processo de design, em ordem de levar esses } \\
\text { aspectos em consideração e considerar critérios baseados } \\
\text { em sustentabilidade com a mesma importância de outros } \\
\text { critérios no processo de desenvolvimento de produto; }\end{array}$ & $\begin{array}{l}\text { Trata-se de incluir novas normas / métricas para a } \\
\text { condução das atividades relacionadas ao processo de } \\
\text { inovação; } \\
\text { Quais os esquemas interpretativos que permitem os } \\
\text { atores darem a mesma importância para critérios } \\
\text { econômicos, sociais e ambientais? }\end{array}$ \\
\hline Processo & $\begin{array}{l}\text { Incluir mais ativamente compradores nas fases iniciais do } \\
\text { processo de desenvolvimento de produto, uma vez que os } \\
\text { compradores podem agregar com relação a questões de } \\
\text { sustentabilidade; }\end{array}$ & $\begin{array}{l}\text { Trata-se de incluir novos recursos na forma de capital } \\
\text { cultural (conhecimento dos atores); }\end{array}$ \\
\hline Processo & $\begin{array}{l}\text { Incluir aspectos sociais ao longo do ciclo de vida e da cadeia } \\
\text { de valor, uma vez que isso afeta a longo prazo a reputação e } \\
\text { imagem da empresa, planos de investimentos, controle de } \\
\text { qualidade e eficiência; }\end{array}$ & Quais métricas e como validá-las? \\
\hline Papéis / Pessoas & $\begin{array}{l}\text { Identificar diferentes níveis de funções para a } \\
\text { responsabilidade das pessoas para a implementação da } \\
\text { sustentabilidade no processo de inovação de produtos }\end{array}$ & $\begin{array}{l}\text { Trata-de agregar recursos; aumentar a resiliência da } \\
\text { equipe; trazer capital cultural diverso; } \\
\text { Há também de se colocar o recurso adequado. Por } \\
\text { exemplo, que ator tem capital cultural especifico para } \\
\text { agregar na discussão de métricas ou aspectos sociais } \\
\text { ao longo da vida de um produto?E sobre os aspectos } \\
\text { ambientais? E sobre a agência dos atores? }\end{array}$ \\
\hline Ferramentas & $\begin{array}{l}\text { Introduzir uma sistemática para construção de competência, } \\
\text { incluindo ações de monitoramento de conhecimento } \\
\text { compartilhado e a reutilização de avaliações com o propósito } \\
\text { de aumentar a competência no campo da sustentabilidade; }\end{array}$ & $\begin{array}{l}\text { Essas revisões das ações já realizadas são de potencial } \\
\text { recursivo para a mudança das práticas e o aprendizado } \\
\text { contínuo. No entanto, como assegurar essa dinâmica? }\end{array}$ \\
\hline Ferramentas & $\begin{array}{l}\text { Incluir ferramentas como guias de decisões; isso poderá } \\
\text { prover um suporte adicional para tomar decisões de longo } \\
\text { prazo numa perspectiva de curto prazo em direção de um } \\
\text { processo de inovação de produto orientado para a } \\
\text { sustentabildade; }\end{array}$ & $\begin{array}{l}\text { Trata-de novas formas que serão 'rotinizadas"; } \\
\text { As ferramentas são importantes, porém, são os atores } \\
\text { que a utilizam. A ferramenta enquanto ferramenta é } \\
\text { virtual. A instanciação da prática é feita pelo ator e } \\
\text { pela relação dele com a ferramenta e a prática } \\
\text { associada ao uso da mesma. }\end{array}$ \\
\hline Ferramentas & $\begin{array}{l}\text { Utilizar ferramentas que incorporem a perspectiva de } \\
\text { "backcasting" desde uma definição de sucesso, desenvolver } \\
\text { produtos que poderiam funcionar como plataformas flexíveis } \\
\text { em direção a produtos mais sustentáveis e ao mesmo tempo } \\
\text { gerar bom retorno sobre investimentos; }\end{array}$ & \\
\hline
\end{tabular}

Fonte: elaborado pelo autor, baseado em Hallstedt et al (2013, p. 283-285)

O trabalho de Varadarajan (2017) traz uma ampla discussão sobre inovação orientada para a sustentabilidade. Na seção 2.1.2, aponta-se a contribuição deste trabalho na discussão sobre a complexidade do conceito de inovação orientada para a sustentabilidade e sua revisão da literatura para se entender os constructos relacionados a essa grande temática. Varadarajan (2017) apresenta o modelo de inovação orientado para a sustentabilidade, representado pela figura 9 . O modelo traz três tipos de inovação e orientação sustentável. Tais tipos se diferenciam de acordo com sua orientação estratégica de inovação. O primeiro tipo (redução de

\footnotetext{
${ }^{3}$ Os comentários desta tabela foram elaborados pelo autor.
} 
recurso/ inovação eficiente) tem o foco em reduzir o uso de recursos e pode ser atingido por um processo mais eficiente. Esse tipo de inovação permite uma categorização entre o uso de recursos renováveis ou não renováveis. O segundo tipo apresentado trata da eliminação de recursos por meio da inovação. Um ponto importante nesse tipo de inovação é que a eliminação de qualquer recurso não acarrete em diminuição de desempenho do produto referência (sem a eliminação do recurso). Uma categorização possível desse tipo de inovação pode ser a eliminação de ingredientes nocivos ao meio ambiente de um determinado produto, a eliminação de um ingrediente veículo (que só é usado para baratear custos) de um produto ou a eliminação da necessidade de se utilizar um produto complementar. Por fim, o terceiro tipo de inovação está relacionado à substituição de um recurso para a manufatura de um determinado produto. Neste caso, uma categorização possível é a substituição de um recurso não renovável por outro renovável; ou a substituição de um recurso não renovável e nocivo ambientalmente, por um produto não renovável, mas menos nocivo; ou a substituição de um recurso não renovável e escasso por um produto não renovável, porém mais abundante; e por fim, a substituição de um recurso virgem por um recurso de reuso extraído pós-uso ou pós-consumo (recurso reciclado). Outra característica desse modelo é a visão do estágio da oportunidade da inovação orientada para a sustentabilidade. O modelo não se limita a pensar na produção de um determinado produto, mas sim em toda a sua cadeia, ou ainda, em todo o seu ciclo de vida.

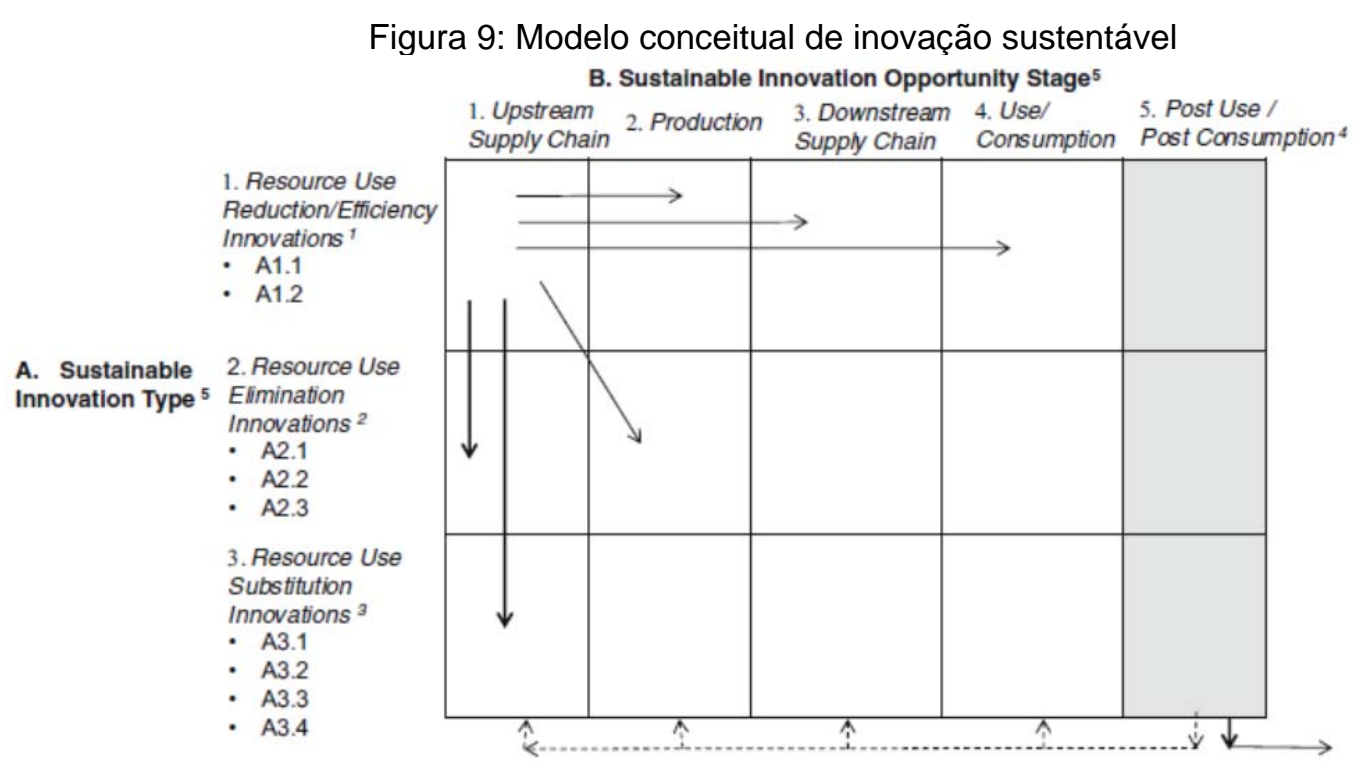

Fonte: Varadarajan (2017) 
O trabalho de Varadarajan (2017) não se limita a trazer o modelo proposto, mas aprofunda-se em questões cruciais que podem ser resumidas em dois questionamentos: o que explica a orientação da inovação para a sustentabilidade?, o que explica as diferenças entre as firmas nessa orientação? Para tal orientação, Varadarajan (2017) se apoia na teoria institucional como apresentado na seção 2.1.1. Adicionalmente, seu trabalho traz um modelo conceitual da inovação orientada para a sustentabilidade, levando em consideração o impacto das instituições e dos efeitos de isomorfismo do campo onde as empresas atuam. Como já discutido no item 2.1.1., o isomorfismo apresentado pelas lentes de DiMaggio e Powell (2005) não trata das práticas instanciadas pelos agentes e tampouco encerram uma abordagem quanto às dinâmicas de poder existentes no campo, que serão objeto deste estudo, analisadas com base na teoria da estruturação. O modelo de Varadarajan está apresentado na figura 10.

Figura 10: Modelo conceitual da orientação das inovações sustentáveis

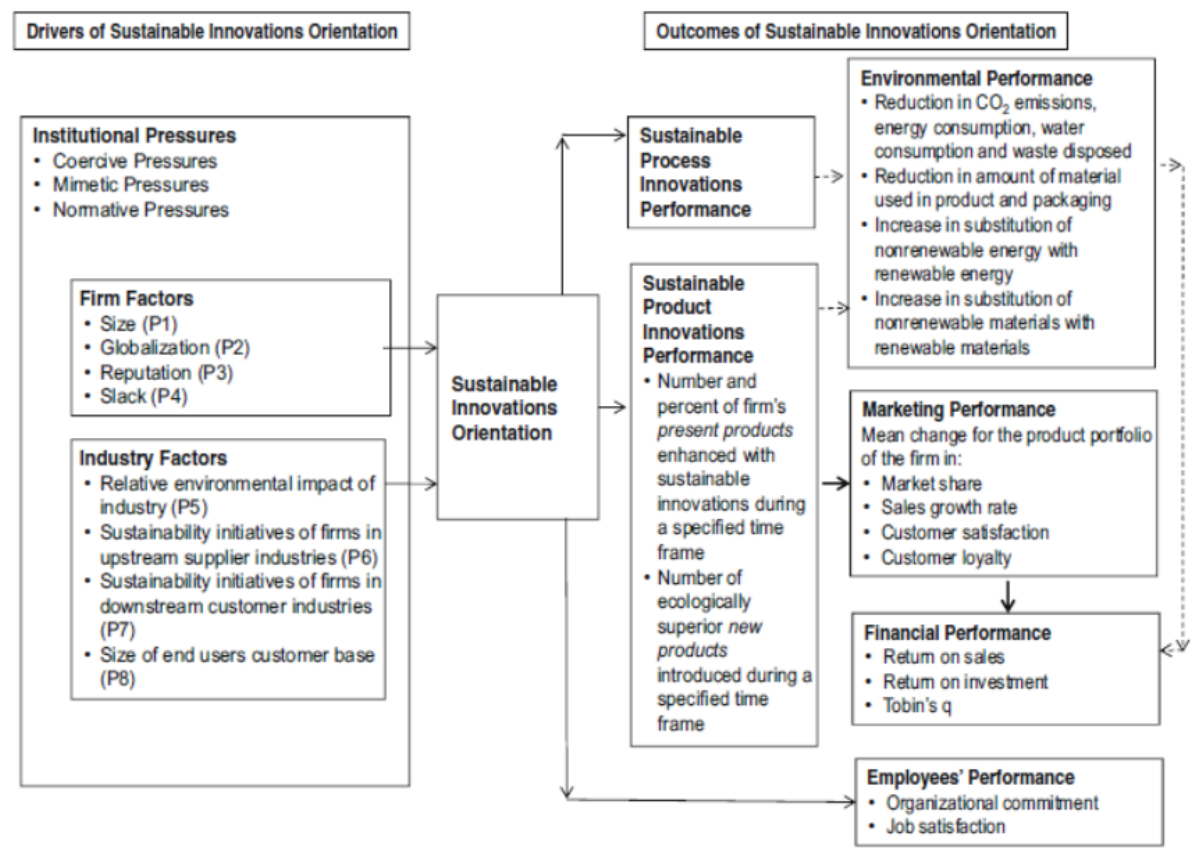

Fonte: Varadarajan (2017)

Por fim, trazemos a contribuição de Coenen e López (2010). Eles identificam e analisam três principais sistemas/estruturas teóricos predominantes sobre 0 discurso da inovação orientada para a sustentabilidade que se relaciona, por conseguinte, com a questão da competitividade e sustentabilidade. São eles: Sistemas Setoriais de Inovação (SSI); Sistemas de Inovação Tecnológica (SIT) e 
Sistemas Técnico-Sociais (STS). Nestes últimos, identifica-se também o conceito de transição, o qual analisa o processo de mudança de modelos organizacionais, bem como as dinâmicas das estruturas sociais imersas entre os campos e atores envolvidos.

É importante se ater nessa abordagem através de sistemas. Estes são complexos e inerentemente baseados em relações de redes sociais. As inovações não se realizam nos eventos singulares ou indivíduos e organizações isolados e nem advêm deles. O entendimento da inovação como um sistema traz como principal característica sua base essencialmente social e de processo que co-evolui (COENEN e LÓPEZ, 2010).

As duas primeiras estruturas (SSI e SIT) podem ser associadas às práticas atuais de inovação no seio do mundo corporativo e sob a ótica da modernização ecológica. A abordagem SSI foca no desempenho da inovação orientada para a sustentabilidade sob o ponto de vista das firmas. Analisa-se a implementação desses sistemas de inovação, processos e práticas na execução dos projetos, tentando-se equilibrar as dimensões de sustentabilidade e colaboradores (stakeholders). Trata-se de uma aproximação sobre as empresas. A abordagem SIT baseia-se na análise da evolução e difusão de tecnologias sustentáveis, bem como na dinâmica de implementação e as novas instituições que surgem e alavancam tais tecnologias. É uma análise mais setorial sobre um tipo de tecnologia e mercado específicos. A dimensão STS foca na análise do processo de transição na sociedade sob a égide da sustentabilidade. $O$ termo transição traz a noção de um sistema mais amplo de interações e co-evolução das novas tecnologias, mudanças nos mercados, novas práticas dos usuários, políticas e discursos culturais e novas instituições governamentais. $O$ trabalho aponta que, das três dimensões e perspectivas analisadas, a STS é a dimensão emergente e que mais apresenta lacunas sobre o seu real processo e dinâmica. 


\subsection{O processo de inovação}

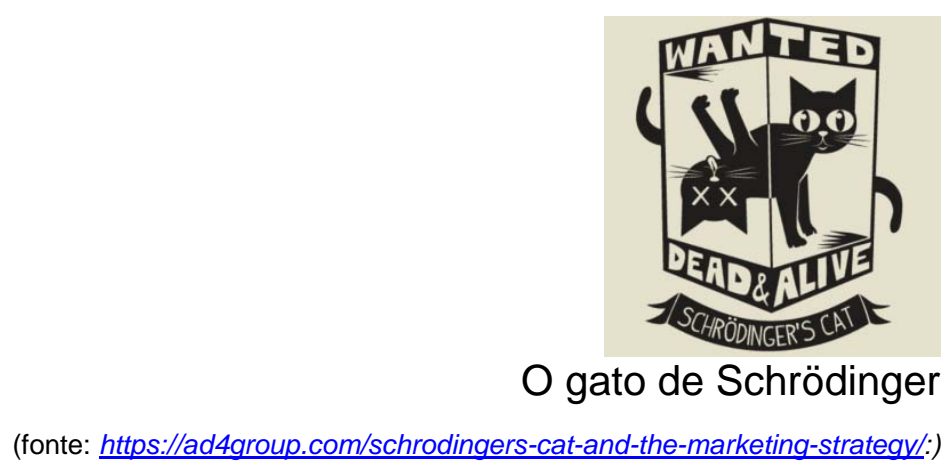

\subsubsection{Indagações iniciais}

A literatura sobre inovação é vasta e vários estudos trazem/propõem uma tipologia para se aproximar desse objeto. Apresenta-se a inovação de produto e processo, inovação exploratória, inovação incremental e radical, inovação de ruptura, inovação tecnológica de ruptura...

A resposta das empresas em direção ao desenvolvimento sustentável pode acontecer de diversas maneiras; uma delas é em relação ao alinhamento de suas práticas de inovação orientada à sustentabilidade. Com relação a esse posicionamento, emerge a questão de como as empresas operacionalizam as práticas e quais são as que podem ser compreendidas como promotoras de sustentabilidade. Outra questão norteadora é: como essa nova orientação modifica (ou não) o próprio processo de inovação? Ou ainda, essa nova orientação modifica as estruturas que condicionam (e são condicionadas no processo recursivo) as práticas dentro do campo inovação?

Adams et al (2012) apontam que enquanto ambas as inovações, tradicional e orientada para a sustentabilidade, endereçam mudanças tecnológicas e inovações em processos, procedimentos operatórios, práticas, modelos de negócios e estruturais mentais (mindset), o que as distingue é sua proposta de integração de aspectos ambientais, sociais e econômicos.

\subsubsection{A complexidade do processo}

A discussão sobre a sustentabilidade muitas vezes recai sobre o avanço tecnológico, como meio através do qual se atingiria a produção de produtos e serviços que diminuem o impacto negativo ao meio ambiente. A aproximação do 
objeto "práticas sociais no processo de inovação orientada para a sustentabilidade" pode revelar o quanto se pode esperar de resultados realmente significativos advindos dessa orientação.

Como descrito por Da Silva et al (2014), a tentativa de se descrever um modelo de gestão de inovação das organizações é algo bastante complexo, pois as várias representações de modelos tendem a enfatizar aspectos específicos dos pilares sobre os quais foram construídos.

Tidd, Bessant e Pavitt (2008) destacam que o desenvolvimento de uma gestão da inovação eficaz perpassa a compreensão de estruturas e comportamentos gerenciais que melhor se ajustem à configuração do negócio.

Os modelos de gestão de inovação apresentam-se num cenário processual, dinâmico e de constante atualização. O trabalho de Da Silva et al (2014) elucida essa característica. A figura 11 mostra o modelo básico apoiado em etapas Stagegate (baseado em Robert G. Copper). A figura 12 (COOPER, 2006) traz uma representação do que é uma etapa Stage-Gate. Tal modelo privilegia o entendimento do processo de inovação como seguindo etapas bem determinadas, no qual cada etapa, necessariamente, cumpre com pré-requisitos que devem ser analisados a fim de possibilitar a passagem de fase (através do gate) para a evolução do projeto. Esse esquema pode gerar a interpretação de um fluxo contínuo de atividades e práticas que não se superpõem. No entanto, versões mais atualizadas desse esquema (figura 13, COOPER 2006), salientam a necessidade de se entender que, em processos reais de inovação, há a superposição das etapas em algum momento e, principalmente, a retroalimentação de uma atividade. Além disso, a depender da complexidade do projeto, haverá mais ou menos etapas no processo de inovação (figura 14, COOPER 2006).

É importante salientar que os estudos sobre modelos de inovação não trazem os detalhes das métricas que direcionam o próprio processo. Assim, para uma empresa que objetiva manter sua competitividade e seu posicionamento estratégico dentro um determinado mercado, é de se esperar que as métricas estejam alinhadas com esses objetivos, por exemplo, o potencial de ganho financeiro, trazido para uma determinada empresa. Dessa maneira, métricas tais como investimento necessário, taxa de retorno, custos fixos e variáveis, desempenho do produto e ciclo de vida fazem parte do processo de inovação e, em alguma medida, concretizam-se como práticas de diversos atores no processo. 
Figura 11: modelo stage-gate de inovação

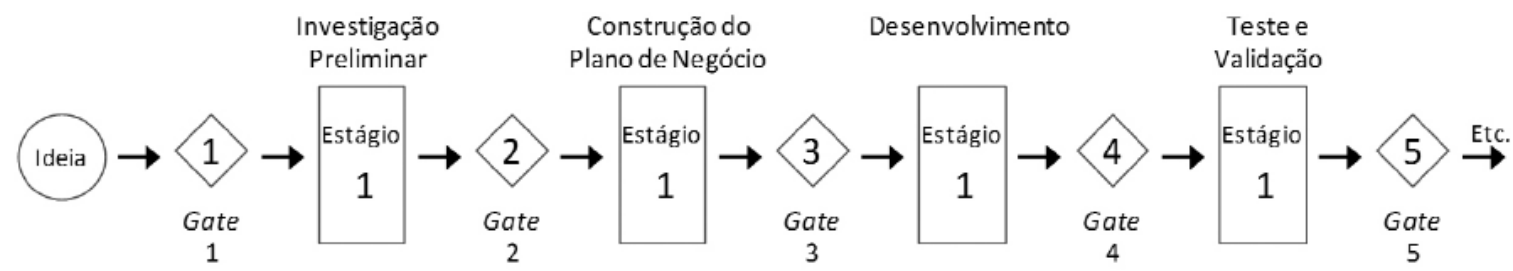

Fonte: Da Silva et al (2014)

Figura 12: Representação de uma etapa stage-gate

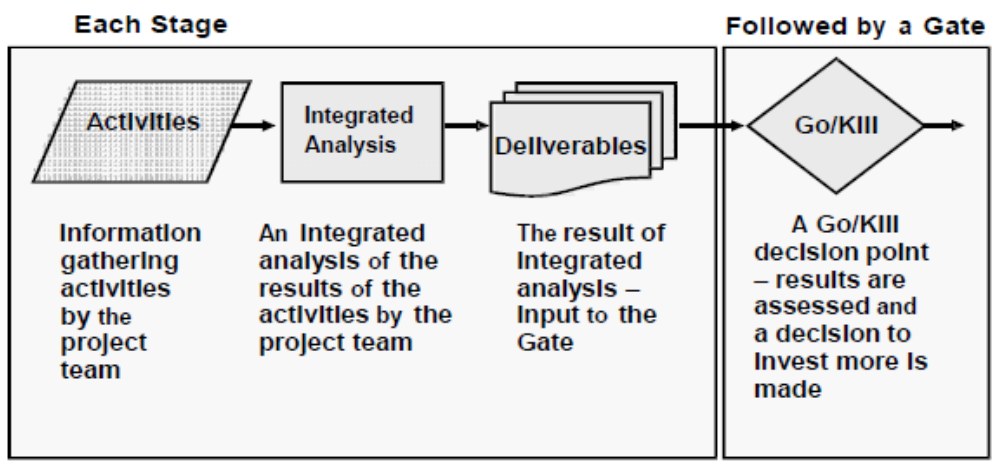

Fonte: Cooper (2006)

Figura 13: Representação das etapas salientando a retroalimentação das atividades envolvidas

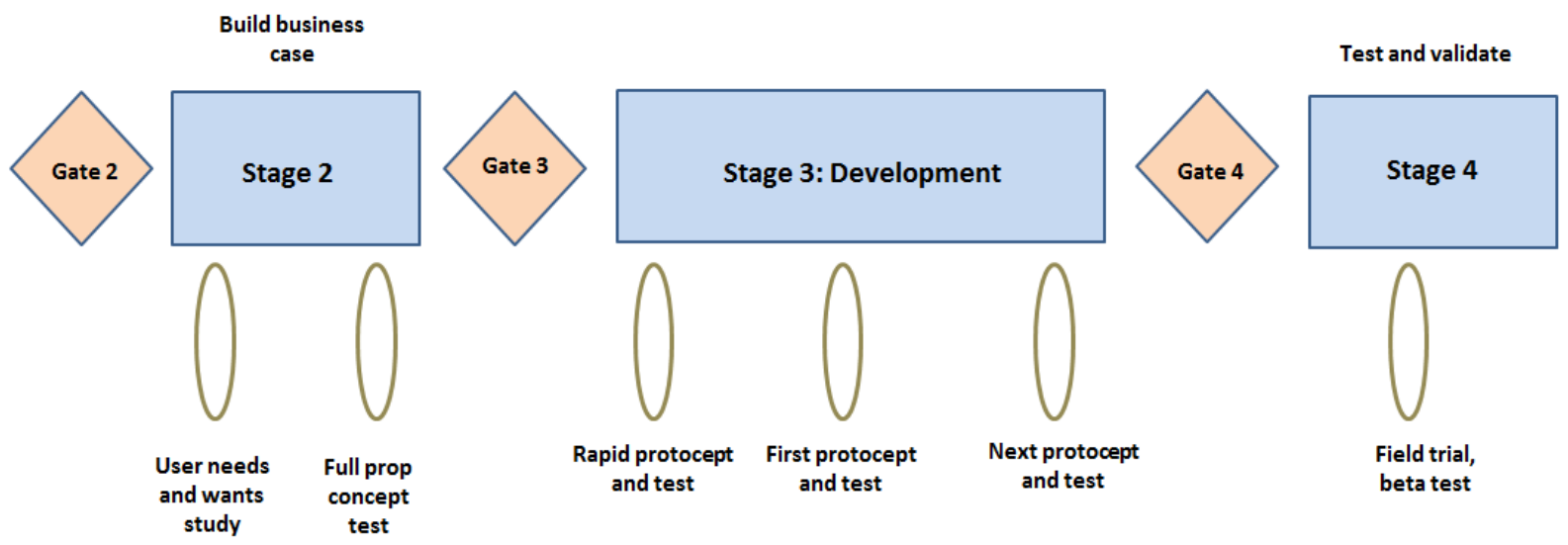

Fonte: Adaptada de Cooper (2006) 
Figura 14: Representação stage-gate para diferentes complexidades de projetos

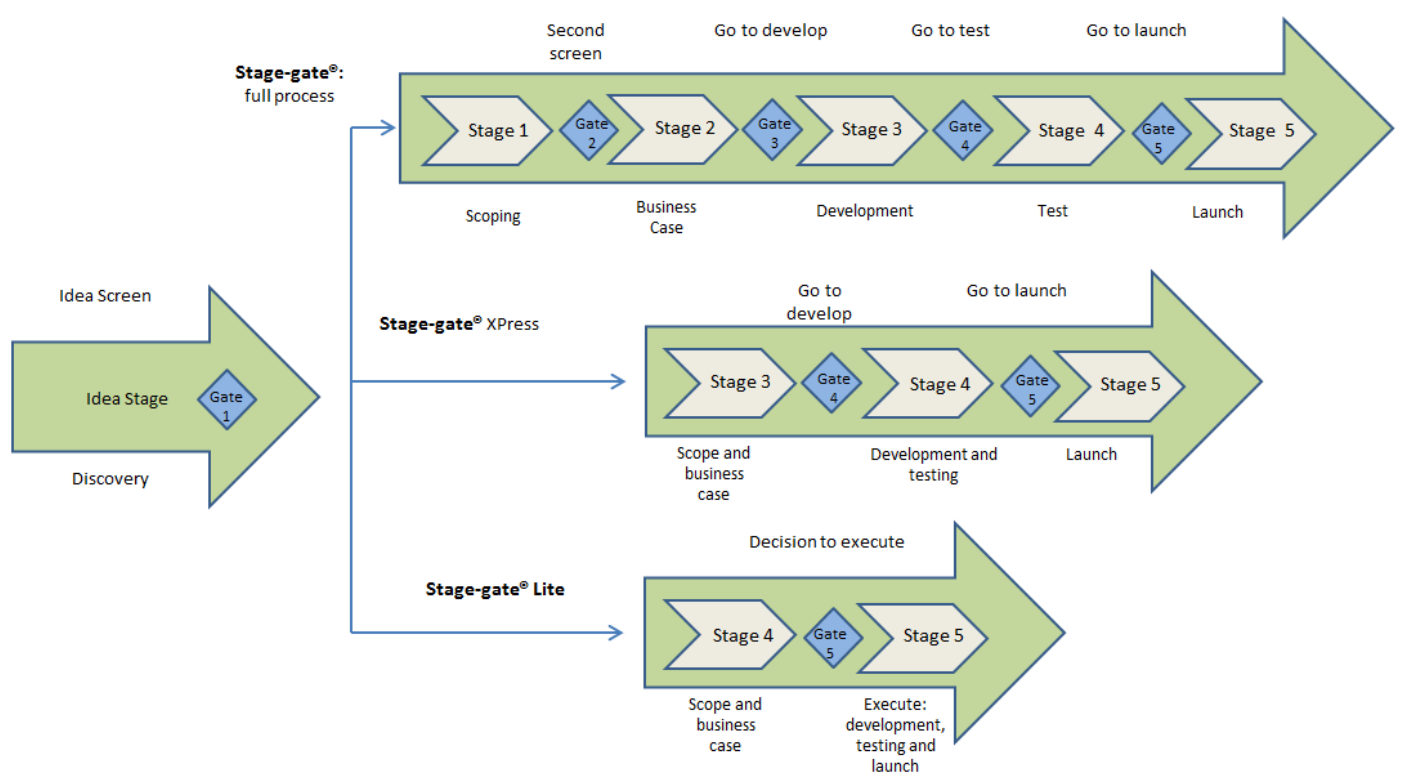

Fonte: Adaptada de Cooper (2006)

Uma limitação desse modelo é que ele pode não trazer claramente todas as funções associadas ao processo de IOS. Esses modelos enfocam a posição de atores geralmente vinculados a uma área de pesquisa e desenvolvimento, e pouco se dá atenção a todos os atores, pertencentes a funções variadas que, por meio de alguma prática, também constituem o processo. Por exemplo, a função da alta gerência, delineando o posicionamento estratégico da empresa; a função de marketing, identificando tendências e necessidades de mercado; a função operacional de manufatura, avaliando a viabilidade industrial; a função comercial dos atores que tentarão implementar o processo da comercialização de determinado produto... Essa questão é de suma importância, porém, às vezes negligenciadas nas avaliações. Deve-se destacar nessa perspectiva é que atores/agentes de áreas diferentes e com capitais culturais diferentes, principalmente, aquilo que entendemos como capital cultural específico (técnico para pesquisadores, habilidade e capital social para atores em contato com clientes e instituições etc) estarão em contato durante as múltiplas práticas do processo. Além do mero contato, esses atores terão de negociar significados, tomar decisões e estarão num campo potencialmente favorável a mudanças. Ainda vale destacar que esses atores estarão no mesmo campo (inovação), ocupando posições diferentes e diferentes capitais e, ao mesmo tempo, fazendo parte de outros campos específicos que influenciam diferentemente 
cada ator (vide seção 2.3.2 para melhor entendimento do que são campo e capital cultural).

\subsubsection{As fases iniciais do processo de inovação}

Após trazer elementos que demonstram a complexidade de um processo de inovação nas seções precedentes, nesta seção, busca-se discutir a delimitação do objeto de pesquisa em questão com base nos elementos teóricos, anteriormente, descritos.

Este projeto de pesquisa quis analisar a relação recursiva entre atores/agentes e estruturas do processo de inovação orientado para a sustentabilidade. Inicialmente, cogitou-se que essa relação seria mais bem compreendida por meio da identificação de práticas com as quais os atores atuam de maneira efetiva. Por isso buscou-se entender como fazer tal identificação. Como será apresentado na seção de metodologia, o estudo de caso mostrou maior riqueza de análise ao deixar que as práticas descritas surgissem naturalmente das entrevistas, levando à inclusão de todas as fases do processo de inovação na coleta de dados e na análise dos mesmos. No entanto, nesta seção, ressalta-se a importância das fases iniciais dos processos de inovação em relação ao intuito de se incluir aspectos de sustentabilidade.

Quando analisa-se o processo de inovação, constata-se que há uma complexidade bastante grande que se evidencia em inúmeras práticas, em várias fases do processo de inovação, com as quais diversos atores de diversas áreas interagem. Dessa maneira, uma questão latente é: como identificar exatamente quais as práticas, e quais os atores envolvidos nas mesmas para analisar essa relação recursiva?

Os trabalhos de Hallstedt et al (2013) e Stok et al (2017) propõem que se analisem os processos de inovação orientados para a sustentabilidade em suas fases iniciais. No modelo stage-gate, identifica-se que um ponto de partida para todo processo de inovação jaz na fase de geração de ideias. A geração de ideias será decisiva e influenciará a qualidade da inovação. Stock et al (2017) cita Charter ${ }^{4}$ (2001) para apontar que considerações ambientais podem ser incluídas nas fases

\footnotetext{
${ }^{4} \mathrm{M}$. Charter, U. Tischner (ed), Sustainable solutions: Developing products and services for the future, Greenleaf Pub, Sheeld, U.k, 2001.
} 
iniciais de geração de ideias como um estímulo para se pensar "fora-da-caixa". Stock et al (2017) também traz a ideia de Gassmann \& Sutter que defendem que (GAASSMANN e SUUTER, $2013^{5}$ apud STOCK et al, 2017, p. 218, tradução nossa):

[...] os estágios iniciais requerem criatividade e muita paciência [...] as fases subsequentes estão mais relacionadas à execução, ou seja, ao longo do processo a criatividade diminui e a implementação se torna mais importante.

Outro ponto que reforça a importância da análise das fases inicias do processo de inovação é o fato de que os impactos sociais e ecológicos dos produtos, sejam eles positivos ou negativos, durante o seu ciclo de vida, são determinados, em sua maioria, por decisões tomadas nas fases iniciais do processo de desenvolvimento de produto (MCALOONE e TAN, 2005).

Adicionalmente ao suporte encontrado na literatura, o autor tem experiência prática na área de inovação de desenvolvimento de produtos e aplicações, e reitera, por meio de suas observações, a importância das fases iniciais de um processo de inovação para endereçar todos os aspectos importantes de um determinado projeto. No caso do desenvolvimento de um produto / processo orientado por uma lógica sustentável, será, nas fases iniciais, que os aspectos econômicos, ambientais e sociais deverão ser apresentados e debatidos.

O próximo tópico tratará da teoria da estruturação, que será o suporte teórico da análise do processo de inovação e da estruturação das práticas instanciadas por seus atores.

\subsection{Teoria da Estruturação}

"É tão verdade serem as circunstâncias a fazerem os seres humanos quanto a afirmação contrária"

(Marx \& Engels, 1974: 49)

\footnotetext{
${ }^{5}$ O. Gassmann, P. Sutter (ed.), Praxiswissen Innovation management: Von der Idee zum Markterfolg, Hanser Verlag, München, 3., 2013.
} 


\subsubsection{Conceitos e definições da teoria da estruturação}

A teoria da estruturação, conforme Giddens (1984), propõe um olhar crítico sobre a história da sociedade a fim de entender o próprio movimento dos grupos sociais, as suas práticas e a legitimação das mesmas, e a possibilidade de construção de novas práticas. Vários elementos dessa teoria são de suma importância para se compreender a dinâmica que envolve atores, estruturas e práticas em um dado campo. Ao apresentar sua teoria, Giddens expõe a necessidade de se compreender as práticas sociais como construídas a partir da relação de três elementos fundamentais: estrutura, sistemas e estruturação (dualidade da estrutura).

Para poder entender a estruturação das práticas através desses elementos supracitados, Giddens traz uma discussão profunda sobre o agente / ator social. Para melhor descrevê-lo, Giddens apresenta o modelo da estratificação do agente (figura 15). A estratificação acontece em três níveis, a saber: a motivação da ação, a racionalização da mesma e o seu monitoramento reflexivo. Para toda a ação instanciada haverá condições não reconhecidas da ação e suas consequências impremeditadas. Nesta introdução dos principais pontos da teoria da estruturação, atém-se aos três níveis de estratificação. A respeito da monitoração reflexiva e racionalização da ação, Giddens afirma (2013, p. 6):

O monitoramento reflexivo da atividade é uma característica crônica da ação cotidiana e envolve a conduta não apenas do indivíduo, mas também dos outros. Quer dizer, os atores não só controlam e regulam continuamente o fluxo de atividades e esperam que os outros façam o mesmo por sua conta própria, mas também monitoram rotineiramente aspectos, sociais e físicos, dos contextos em que se movem. Por racionalização da ação entendo que os atores - também rotineiramente e, na maioria dos casos, sem qualquer alarde - mantêm um contínuo "entendimento teórico" das bases de sua atividade. 
Em relação à motivação da ação, Giddens a identifica muito mais como uma resposta às necessidades que instigam do indivíduo do que uma monitoração contínua da sua ação. Giddens escreve sobre a motivação (GIDDENS, 2013, p. 7) "Ela refere-se mais ao potencial para a ação do que propriamente ao modo como a ação é cronicamente executada pelo agente".

Figura 15: Modelo da estratificação do agente

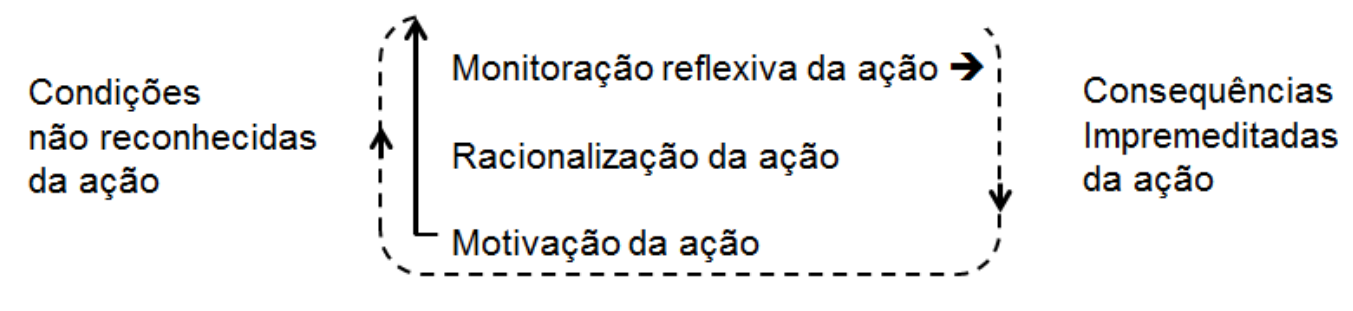

Fonte: Adaptada de Giddens 1984

Ainda com foco no ator social, Giddens dialoga e articula muito a psicanálise para poder entender o indivíduo e o seu posicionamento no mundo (através de suas práticas). Ele identifica e intitula dois tipos de consciência que o indivíduo emprega em suas atividades cotidianas. A primeira trata-se da consciência discursiva do ator social. Tal consciência pressupõe estar o sujeito apto a fazer um relato coerente de suas atividades e das razões que as motivaram. Giddens escreve (2013, p. 51) "consciência discursiva significa ser capaz de pôr coisas em palavras". O segundo tipo de consciência, que é fundamental para a teoria da estruturação, é identificado como consciência prática. Ela faz referência a circunstâncias nas quais as pessoas prestam atenção a eventos que se desenrolam em volta delas de maneira a relacioná-las com sua atividade. Tal consciência prática estaria próxima do monitoramento reflexivo da ação e poderia ser associada ao conceito de préconsciência da psicanálise.

Antes de apresentarmos os pilares da teoria da estruturação, outro conceito intrinsecamente ligado ao indivíduo precisa ser apresentado. Trata-se da agência do ator social. Giddens escreve (2013, p. 10 e 11): 
Agência não se refere às intenções que as pessoas têm ao fazer as coisas, mas à capacidade delas para realizar essas coisas em primeiro lugar (sendo por isso que "agência" subtende poder) [...] Agência diz respeito a eventos dos quais um indivíduo é o perpetrador, no sentido de que ele poderia, em qualquer fase de uma dada sequência de conduta, ter atuado de modo diferente. O que quer que tenha acontecido não o teria se esse indivíduo não tivesse interferido. A ação é um processo contínuo, um fluxo, em que a monitoração reflexiva que o indivíduo mantém é fundamental para o controle do corpo que os atores ordinariamente sustentam até o fim de suas vidas no dia-a-dia.

Giddens define estrutura como regras e recursos, ou conjuntos de relações de transformação, organizados como propriedades de sistemas sociais (marcada pela ausência de sujeito). Um ponto crucial para se compreender o que são "estruturas", é a visão de Giddens de que estruturas (regras e recursos) somente possuem uma existência virtual, isto é, não possuem uma realidade, exceto quando elas se concretizam em atividade. Giddens afirma (GIDDENS, 1989, p.256):

[...] a position I want to avoid, in terms of structure appears as something 'outside' or 'external' to human actions. In my usage, structure is what gives form and shape to social life, but is not itself that form and shape - nor should 'give' be understood in an active sense here, because structure only exists in and through the activities of human agents.

Giddens (2013, p. 20) afirma em relação à estrutura:

A estrutura refere-se, em análise social, às propriedades de estruturação que permitem a delimitação de tempo-espaço em sistemas sociais, às propriedades que possibilitam a existência das práticas sociais discernivelmente semelhantes por dimensões variáveis de tempo e espaço, e Ihes emprestam uma forma sistêmica. 
Os sistemas são relações reproduzidas entre atores ou coletividades, organizadas como práticas sociais regulares (atividades localizadas de agentes humanos, reproduzidas através do tempo e do espaço). Por fim, a estruturação são as condições, governando a continuidade ou transmutação de estruturas e, portanto, a reprodução de sistemas sociais. Giddens (2013, p.29) afirma:

Analisar a estruturação de sistemas sociais significa estudar os modos como tais sistemas, fundamentados nas atividades cognoscitivas de atores localizados que se apoiam em regras e recursos na diversidade de contextos de ação, são produzidos e reproduzidos em interação.

Para o entendimento do conceito de estruturação trazido por Giddens, é necessário apresentar a visão do problema da dualidade da estrutura. A dualidade é a relação entre agentes e estrutura. As propriedades estruturais de sistemas sociais são, ao mesmo tempo, meio e fim das práticas que elas recursivamente organizam. A estrutura não é externa ao indivíduo. Estrutura não é restrição, mas é, sempre, simultaneamente, restritiva e facilitadora. Giddens (2013, p. 31):

A dualidade da estrutura é sempre a base principal das
continuidades na reprodução social através do espaço-tempo. Por
sua vez, pressupõe a monitoração reflexiva (e a integração) de
agentes na durée da atividade social cotidiana.

Giddens (1984) propõe um modelo as estruturas são as propriedades dos sistemas sociais nos quais as práticas ocorrem. Mediando essa relação estruturasistemas, encontram-se as modalidades da estruturação como representadas pela figura 16. A modalidade da estruturação serve para esclarecer as principais dimensões da dualidade da estrutura em interação, relacionando as capacidades cognoscitivas dos agentes a características estruturais. Segundo Giddens (2013, p. 33) "Os atores apoiam-se nas modalidades da estruturação na reprodução de 
sistemas de interação, reconstituindo, justamente por isso, suas propriedades estruturais".

Figura 16: Representação da relação estrutura-prática em interação

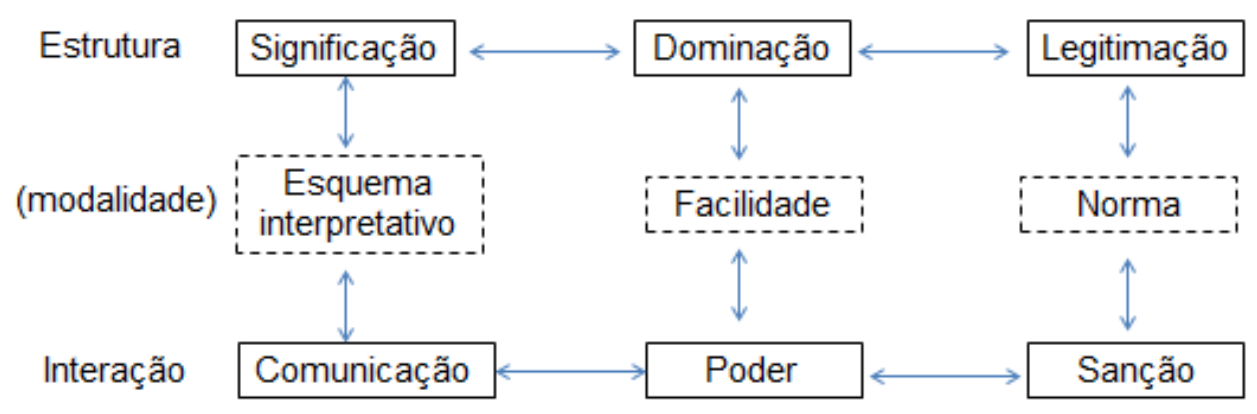

Fonte: Adaptada de Giddens (1984).

A figura 16 sintetiza bem o que é uma prática e sua estruturação. A prática em si, se instancia por meio do ator em interação nos sistemas sociais. Uma prática poderá se instanciar por uma carga de comunicação, um exercício de poder (relacionado ao agente) ou mesmo uma qualidade sancionadora. Obviamente, que uma prática pode se instanciar por todas essas dimensões. Ao realizar / instanciar uma dada prática, o agente está produzindo / reproduzindo estruturas de significação, de dominação e de legitimação para ele próprio e para as coletividades onde está inserido. A reprodução de uma prática ao longo do tempo traz uma carga de significação que poderá ser exposta de maneira discursiva pelo agente por meio de sua cogniscidade. A legitimação de uma prática se dá no tempo, suportada por uma lógica e consciência prática que entende / valida certa atividade.

É importante salientar que as práticas ocorrem dentro dos sistemas sociais e essas legitimam as estruturas. Giddens ressalta a relevância da dimensão temporal da ação prática do indivíduo. A continuidade e legitimação das práticas de reprodução social têm como base a dualidade da estrutura através do espaço-tempo e pressupõem a monitoração reflexiva dos agentes.

Trabalhos recentes, voltados para se compreender a dinâmica das práticas organizacionais, têm usado o arcabouço teórico da teoria da estruturação. Lounsbury e Crumley (2007) discutem a criação de novas práticas em um setor específico, a partir de mudanças propiciadas por diversos agentes num dado campo 
que desafiaram a estrutura vigente e, em vez de legitimarem aquelas práticas vinculadas às condições da estrutura corrente/tradicional passaram, pelo processo recursivo entre estrutura-prática, a delinear o surgimento de novas práticas e estruturas. Orlikowski (2000) traz uma leitura interessante sobre o setor de tecnologia pela ótica estruturacionista de Giddens. Aplicando os conceitos de estrutura, práticas e modalidades, o trabalho de Orlikowski (2000) delineia-se demonstrando diferenças na assimilação de novas práticas propiciadas por um novo recurso tecnológico, por diferentes atores com diferentes perspectivas. Parte deste trabalho se inspirou nessa adaptação, proposta por Orlikowski (figura 17), para discutir, inicialmente, a inovação orientada para a sustentabilidade pela ótica da teoria da estruturação.

Figura 17: As práticas através da estrutura

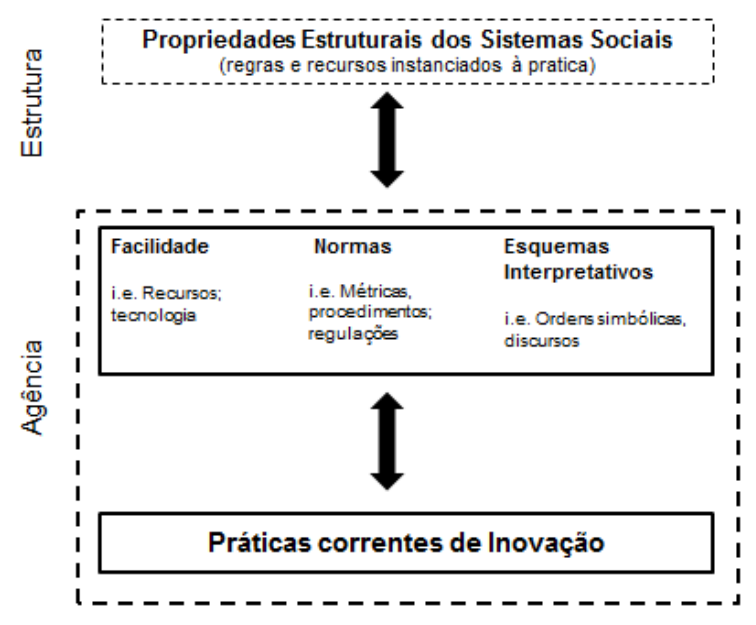

Fonte: adaptada de Orlikowski 2000

\subsubsection{A definição do âmbito de análise}

Uma questão importantíssima para se aproximar de um objeto dinâmico como as práticas do processo de inovação é a escolha do âmbito de análise, ou ainda, do nível de análise. Este último referente a uma análise de nível macro ou micro. Num trabalho acadêmico é necessário que se faça um recorte adequado e claro do objeto para, assim, se aproximar do mesmo. No entanto, o próprio recorte é uma diminuição da totalidade do fenômeno que esse estuda. Por exemplo, no nível macro da inovação orientada para a sustentabilidade, o entendimento da inovação 
como um campo institucional seria útil na identificação dos atores inseridos neste campo e para se entender os movimentos existentes nele. Uma vez que este trabalho teve como foco a análise das práticas dos indivíduos nos processos de inovação e sua interação com as estruturas, a teoria da estruturação foi a lente adotada, não significando, porém, que outras análises não fossem possíveis, a partir de outras lentes teóricas, como a teoria dos campos de Fligstein e McAdam (2012), por exemplo.

Objetivamente, este trabalho analisou a estruturação das práticas do processo de IOS. Ainda que isso possa parecer algo bem delimitado, não o é, pois como visto na fundamentação teórica sobre inovação, inúmeras práticas/atividades compõem o movimento do processo de inovação. A totalidade dessas práticas e como elas se articulam representam o fluxo do processo. A teoria da estruturação é uma base teórica para analisar as práticas. No entanto, a análise da totalidade das práticas demandaria a utilização de outros referenciais teóricos que articulassem as práticas aos sistemas sociais mais amplos onde elas também se concretizam. Tal articulação não foi realizada neste trabalho para manter-se o foco na estruturação das práticas.

\subsection{Teoria da estruturação e inovação orientada para a sustentabilidade}

Diego no conocía la mar. El padre, Santiago Kovadloff, lo llevó a descubrirla.

Viajaron al sur.

Ella, la mar, estaba más allá de los altos médanos, esperando.

Cuando el niño y su padre alcanzaron por fin aquellas cumbres de arena, después de mucho caminar, la mar estalló ante sus ojos. Y fue tanta la inmensidad de la mar, y tanto su fulgor, que el niño quedó mudo de hermosura.

Y cuando por fin consiguió hablar, temblando, tartamudeando, pidió a su padre:

—_Ayúdame a mirar! (GALEANO, 2012, p.3)

Neste último tópico de fundamentação teórica, procura-se articular o objeto do presente trabalho com a teoria da estruturação. A base teórica dessa abordagem 
encontra-se no campo da sociologia e seu emprego em trabalhos de outras áreas é ainda incipiente. O próprio Giddens (GIDDENS, 1984) reconhece que suas ideias, suporte da teoria da estruturação, não configuram e nem trazem bases metodológicas para outros trabalhos, ou seja, a utilização das ideias estruturais da teoria da estruturação para entender um determinado fenômeno, ou se aproximar de algum objeto de pesquisa, se dá de maneira empírica. Alguns trabalhos encontrados na literatura dão suporte a esse posicionamento (JONES, O. et al 2000; ORLIKOWSKI, W. J. 2000; LOCK, M. J. 2015; HUNG, S. C. 2004).

Jones et al (2000) e Hung (2004) se aproximam do objeto "processo de inovação" através da lente da teoria da estruturação. Ambos apontam a fragilidade de se pensar o objeto de inovação com o conceito stage-to-stage. Hung (2004) traz duas aproximações gerais para o processo de inovação. Uma visão voluntarista que depende da ação de atores (agência), e uma visão determinista que enxerga o processo de inovação dentro de um contexto de estruturas institucionalizadas, nas quais as ações dos atores são socialmente moldadas. Em sua posição, a aproximação mais precisa do processo de inovação não é o conceito de stage-tostage, mas sim, a visão de um processo dinâmico, conceito de contínua mudança ao longo do tempo. A dualidade da estrutura no processo de inovação jaz, justamente, nessa perspectiva das ações potenciais de mudança (voluntarista/agência) e as ações rotineiras engendradas pelas estruturas. Hung (2004) propõe um modelo (Technology path, figura 18) para descrever a estruturação do processo de inovação que é historicamente construída pela relação recursiva entre ação (agentes) e estruturas.

Figura 18: Relações recíprocas entre ação e estrutura (regras e recursos) no caminho tecnológico (technology path)

the path of action

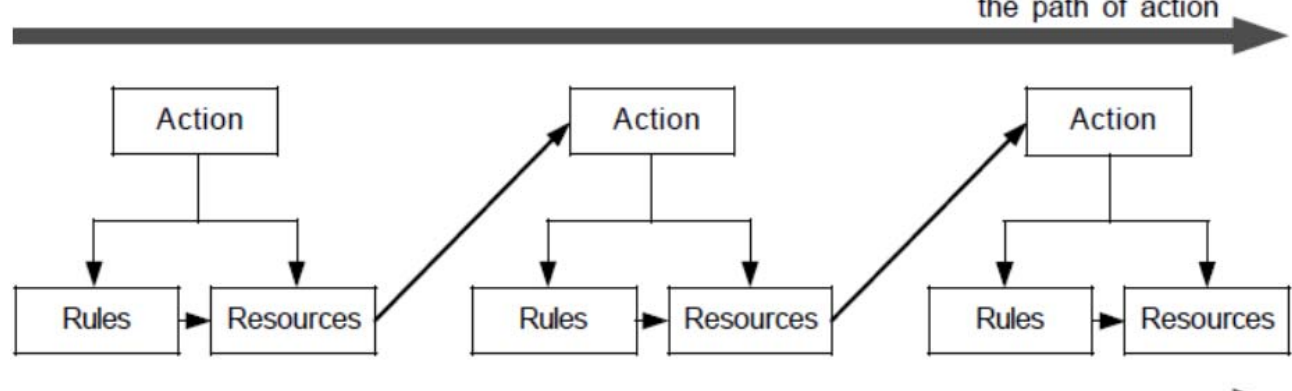

the path of structure

Fonte: Hung (2004) 
Hung (2004) reforça duas formas de análises para entender o processo de estruturação da inovação: a dimensão da ação (que se tratando de inovação está mais relacionada à desordem e à mudança) e a dimensão da estrutura (um conceito de ordem e estabilidade). O autor examina o processo de inovação como "estrutura $\rightarrow$ Através da ação" e "ação $\rightarrow$ através da estrutura". Três proposições são realizadas: primeiro, a ação é vista como algo criativo e um processo acumulativo; segundo, as estruturas se traduzem como regras e recursos envolvidos na inovação; e, terceiro, há relações recíprocas entre ação e estrutura.

Jones et al (2000) afirmam que a lente da teoria da estruturação para se aproximar do processo de inovação permite analisar sua complexidade e a relação paradoxal entre ação e estrutura. Esta visão rejeita a ideia de que estruturas sociais possuem uma realidade objetiva que é separada dos padrões diários da interação social. É possível afirmar que, as estruturas organizacionais, que dão dinâmica ao processo de inovação, são formadas pelas atividades dos atores e pelos seus mais bem incorporados esquemas interpretativos, e pela influência de seus valores e interesses. Este último é um ponto importantíssimo para este trabalho, pois a inovação orientada para a sustentabilidade incorpora valores e significados novos ao próprio ato do fazer inovação uma vez que se posiciona na tentativa de equilibrar externalidades ambientais e sociais.

Apoiado pela teoria da estruturação e tomando alguns elementos de representação do trabalho de Orlikowski (2000), as práticas associadas à inovação tradicional (voltada para a manutenção da competitividade) podem ser entendidas através da figura 19.

Nessa representação, os atores ou agentes envolvidos no processo de inovação reproduzem práticas dentro dos sistemas sociais nos quais estão inseridos. Tais práticas ocorrem em determinada posição no espaço e no tempo (vide proposição de Hung (2004) na qual a ideia da dimensão temporal tem maior representatividade). Mediando as estruturas e os sistemas sociais, encontram-se as modalidades da estrutura que servem para esclarecer as principais dimensões da dualidade da estrutura em interação, relacionando as capacidades cognoscitivas dos agentes a características estruturais. 
Figura 19: Práticas correntes em inovação e sua estrutura

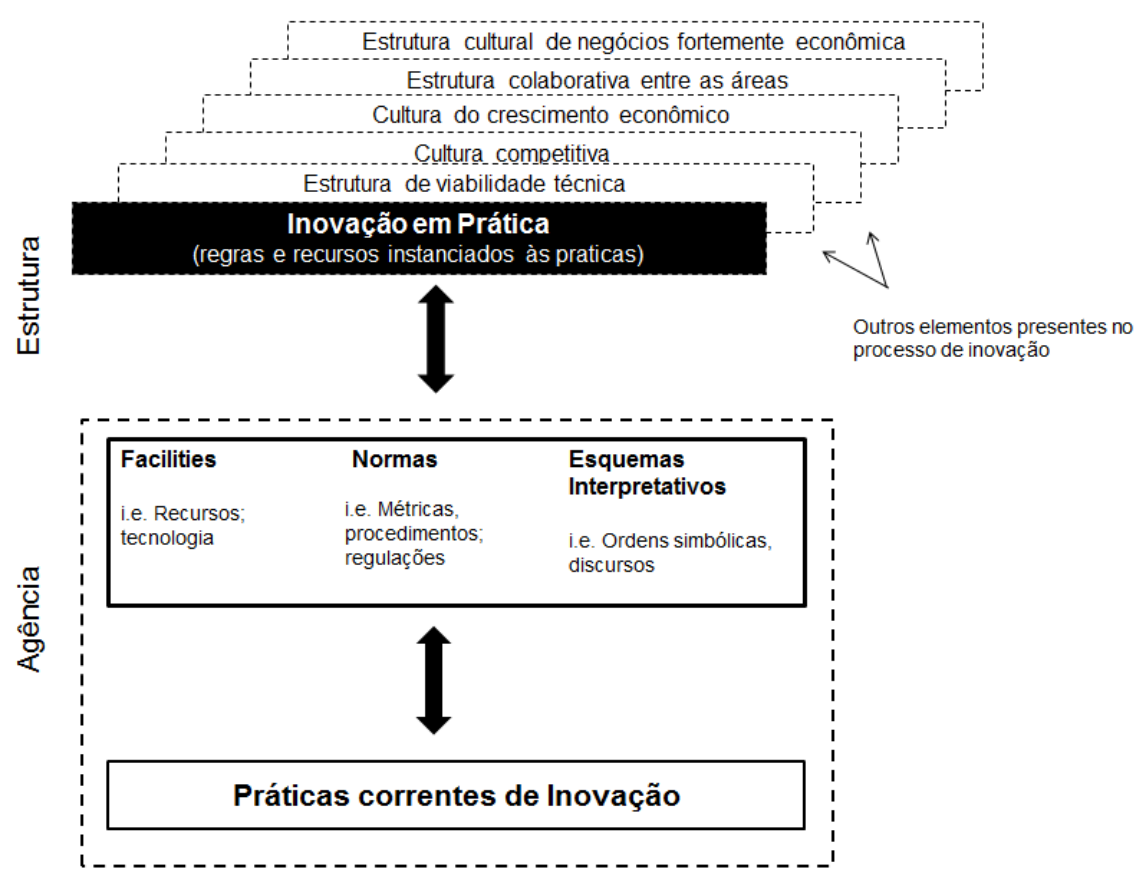

Fonte: elaborado pelo autor

Ao mesmo tempo em que há um destaque para a estrutura da inovação em prática, há outros elementos que co-habitam e influenciam a estruturação das práticas. Na figura 19, esquematicamente, apontam-se alguns desses elementos que terão características, ora de estuturas (regras), ora de modalidades das mesmas. Propõe-se que esquemas interpretativos, normas e mesmo recursos materiais (facilities) ligados a uma cultura competitiva, a uma visão de crescimento econômico, a análise de viabilidade técnica etc, estarão presentes na estruturação das práticas em inovação. Em suma, vários elementos atuam, ao mesmo tempo, dentro de um sistema social de relações específicas (processo de inovação, por exemplo) e, não raras as vezes, estão em posição confrontante. A reprodução de práticas em sistemas sociais legitimam essas estruturas e recursivamente se estabelecem, contendo em si um potencial de mudança. Em maior ou em menor medida, ao longo do processo de inovação, serão aquelas estruturas que darão forma e se instanciarão nas práticas dos múltiplos agentes.

Serão analisadas agora duas representações (figura 20) propostas das práticas estruturadas para a inovação orientada para a sustentabilidade segundo a teoria da estruturação. No esquema proposto, vê-se que na inovação orientada para 
a sustentabilidade há estruturas no campo econômico, social e ambiental e o equilíbrio entre elas geraria um produto inovador de cunho sustentável. No entanto, essa aproximação (figura 20a) é utópica e parte de uma premissa que as estruturas, nos diferentes campos, engendram similar impacto e influência nas práticas nos sistemas sociais. Portanto, essa representação simplista não permite a observação do movimento real do fenômeno inovação orientada para a sustentabilidade, pois não se tem clareza de quais são as estruturas dos campos sociais e ambientais e quais práticas elas engendrariam dentro das múltiplas-práticas do campo inovação orientada para a sustentabilidade. A representação da figura 20b mostra, de maneira diferente, o que se imagina ser o status quo do processo de inovação para sustentabilidade atual.

Nesse esquema, a dimensão estrutural do campo econômico engloba todas as modalidades estruturais e, por conseguinte, está legitimado em todas as práticas concernentes à inovação orientada para a sustentabilidade. Já as estruturas sociais e ambientais apenas permeiam parte da totalidade das práticas envolvidas no processo. É dizer que não existem condições estruturais legitimadas sociais e ambientais que deem conta ou que exerçam influência em todas as práticas. Dessa maneira, haverá/há um desequilíbrio nas práticas que tenderão a reproduzir o campo econômico. Ou ainda, no processo de dualidade da estrutura, não existem estruturas que engendrem práticas orientadas ao campo social e ambiental, ao mesmo tempo em que a não existência dessas práticas não legitimam o próprio campo social e ambiental. $\mathrm{E}$ ainda o que pode acontecer é que algumas práticas que poderiam ser entendidas dentro de normas do campo estrutural ambiental, por exemplo, o cálculo do ciclo energético (ou ciclo de carbono) de um produto, serão vistas dentro da lógica das estruturas econômicas e não na das estruturas ambientais. Ou seja, várias práticas que são ditas e associadas a estruturas ambientais e sociais, são ainda atreladas ao econômico mediante o grande impacto que este exerce sobre o modo de vida das pessoas e em suas práticas dentro de sistemas sociais. 
Figura 20: Representação das práticas em inovação orientada para a sustentabilidade

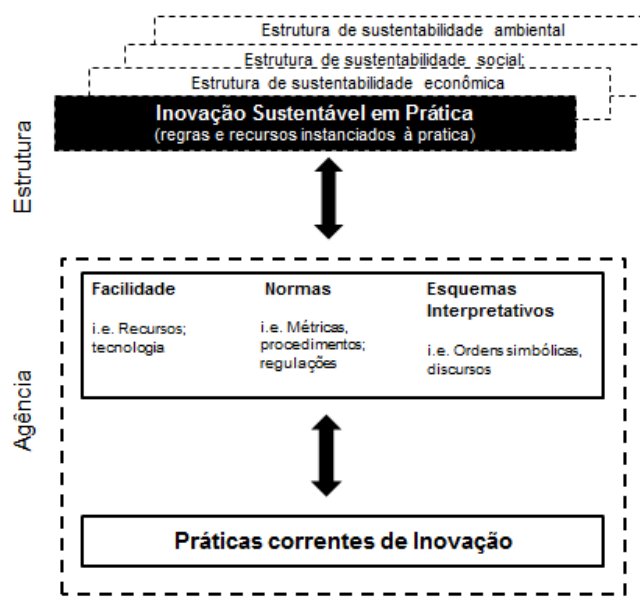

a

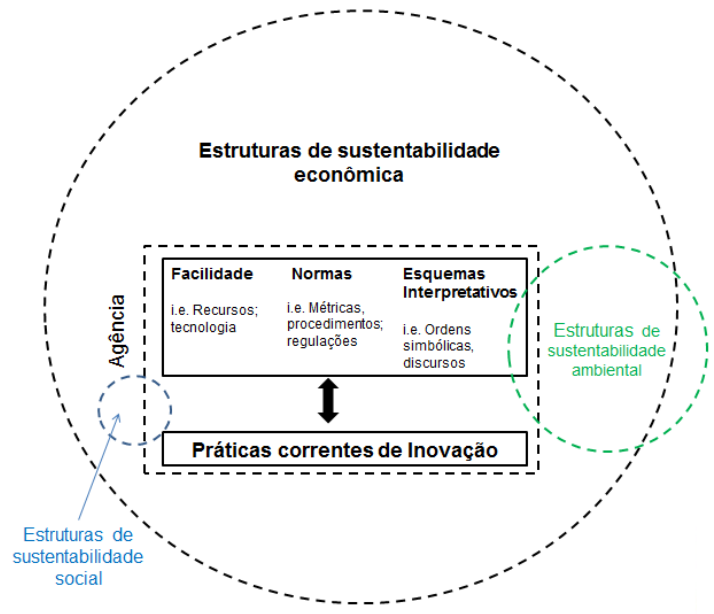

b

A) Práticas correntes em inovação orientada para a sustentabilidade (modelo ideal); B) Práticas correntes em inovação orientada para a sustentabilidade e o alcance das estruturas

Fonte: elaborado pelo autor

\subsection{Uma síntese}

A teoria da estruturação (GIDDENS, 1984) abre um leque de possibilidades de análises que incorporam a ação do agente no sistema social, sua relação com as estruturas, o sistema de poder e mecanismos de legitimação de práticas de inovação. Sob a perspectiva da teoria de Giddens, a análise das práticas de processos de inovação orientada para a sustentabilidade ganha um arcabouço mais completo que sob óticas clássicas ou que tangenciavam apenas alguns dos elementos dessa teoria.

Adotar a teoria da estruturação como lente teórica para análise da inserção das organizações em rotas para a sustentabilidade leva a uma comparação com outras lentes teóricas que tratam da inovação, identificando fragilidades nas mesmas. As teorias que tratam da inovação, sem considerar as diversas relações entre agente, estrutura, relações de poder e mecanismos de legitimação de práticas sociais, descrevem, por meio de muitos discursos, um cenário inanimado, em que pouca atenção é direcionada aos indivíduos. É como dizer que uma empresa se movimenta em determinada direção estratégica, pois o mercado está orientado nessa direção. Embora, facilmente seria percebido que o mercado é constituído de consumidores, isso não traz a profunda discussão sobre quem são esses atores e 
como eles, por meio de suas práticas, legitimam as estruturas e têm suas práticas alteradas por essas mesmas estruturas.

Analisar os processos e práticas de inovação sob a ótica da teoria da estruturação não está a salvo de limitações, no entanto. Dificuldades relacionadas à complexidade de aplicação do modelo extraído de Giddens, para análise dos processos de inovação, nas organizações, são agravadas pelo fato de que a proposta de aplicação desse modelo acontece em um campo, cujos conceitos ainda estão em definição, como é o campo da sustentabilidade. Analisar a dinâmica do movimento que ocorre quando as áreas responsáveis pelo desenvolvimento de inovação recebem diretrizes, para redirecionarem seus projetos, para projetos com foco em inovação orientada para a sustentabilidade, a partir da lente da teoria da estruturação, é, portanto, um desafio que se apresenta em duas frentes: a teórica e a empírica. 


\section{ABORDAGEM METODOLÓGICA}

A abordagem metodológica deste trabalho buscou aproximar-se do objeto inovação orientada para a sustentabilidade, por meio da análise da interação recursiva entre atores / estruturas dos processos de inovação. Para tanto, e configurando parte desta pesquisa exploratória, elaborou-se uma ampla revisão bibliográfica sobre inovação orientada para a sustentabilidade, estreitando-se a lente de análise para processos de inovação. Em seguida, a revisão apresentou a teoria da estruturação como suporte teórico para análise do objeto de pesquisa.

A revisão bibliográfica apresentou a orientação para a sustentabilidade adotada pelas empresas. No entanto, os trabalhos que confirmam tal orientação trazem uma análise macro. Uma vez que este trabalho quis analisar a estruturação das práticas instanciadas no processo de inovação e vislumbrar a dualidade da estrutura (agente / estruturas), optou-se pela estratégia de pesquisa de estudo de caso (seção 3.2).

Com relação à abordagem metodológica, duas ressalvas são importantes. Inicialmente, quando a metodologia estava sendo desenvolvida, tinha-se a intenção de identificar algumas práticas específicas e analisá-las. Porém, durante a aplicação da pesquisa, a identificação e análise de tais práticas mostraram-se de pouco valor; afinal, o processo de inovação inclui várias práticas ou atividades cotidianas e a escolha de uma prática específica poderia representar uma diminuição da totalidade do processo de inovação. Há de se salientar, que este trabalho entende prática como uma atividade padrão, realizada pelo indivíduo em seu cotidiano (JARZABKOWSKI, 2005), sem perder de vista as propriedades de recursividade com a estrutura, já amplamente, tratadas na revisão da literatura. Assim, a participação em uma reunião de projeto é uma prática que um indivíduo engendra. Escrever a ata da mesma reunião ou a realização de um teste de laboratório também é entendido como práticas. Enfim, o processo de inovação envolverá vários atores que interagirão e engendrarão inúmeras práticas. Dessa maneira, a decisão por descrever a estruturação das práticas de inovação em seu conjunto mostrou-se muito mais atraente e permitiu uma aproximação mais ampla com o objeto de pesquisa. Obviamente, alguns resultados (obtidos mediante os estudo de caso) mostram e evidenciam práticas. Porém, neste caso, suportado pela teoria da 
estruturação, discute-se como acontece a estruturação dessas práticas que são, de fato, instanciadas por indivíduos.

Outra mudança realizada no decorrer do projeto e que é fruto de uma melhor aproximação com o objeto "práticas instanciadas no processo de inovação orientado para a sustentabilidade" foi não colocar foco nas etapas iniciais do processo de inovação, mas sim, deixar que o foco emergisse das interações com os entrevistados. Desse modo, buscou-se saber em quais etapas surgem os aspectos de sustentabilidade (se surgem) e como surgem, e foi confirmada uma forte tendência de isso ocorrer nas etapas iniciais, conforme respostas dos atores entrevistados (também suportada pela revisão da literatura, seção 2.2.3).

\subsection{O processo de revisão da literatura}

A revisão da literatura realizada não constitui uma revisão sistemática da literatura, pois o amplo alcance desse tipo de abordagem ultrapassa o objetivo desta dissertação. Porém, para realizar tal trabalho utilizou-se como guia o estudo de Okoli e Schabram (2010) que apresenta etapas cruciais de uma revisão sistemática da literatura. Primeiramente, definiu-se a proposta da busca e a pergunta a que tal revisão queria responder, como descritas abaixo:

Proposta da revisão: entender como os modelos de inovação orientados para sustentabilidade lidam com a incorporação de práticas de sustentabilidade (se as incorporam) e qual o papel da agência ${ }^{6}$ nesses modelos.

Pergunta da revisão: quais são os modelos de inovação orientada para a sustentabilidade atuais e como eles incorporam a prática ou agência dos atores?

Para fazer a busca, a base de dados utilizada foi a plataforma Scopus e as expressões e palavras chave (em inglês) foram as seguintes: Sustainable innovation models; Innovation AND sustainability; Innovation Process; Innovation, models and processs; sustainability OR sustainable; Eco-innovation; Sustainability-oriented

\footnotetext{
${ }^{6}$ Agência (Giddens, 2013): “Agência não se refere às intenções que as pessoas têm em fazer as coisas, mas à capacidade delas para realizar essas coisas em primeiro lugar (sendo por isso que agência subtende poder...). "Agência" diz respeito a eventos dos quais um indivíduo é o perpetrador, no sentido de que ele poderia, em qualquer fase de uma dada sequência de conduta, ter atuado de modo diferente".
} 
innovation; framework; pattern. Tais expressões e palavras chave foram combinadas por meio das possibilidades avançadas de pesquisa da base de dados Scopus. Como período de busca, decidiu-se limitar a busca de trabalhos a partir de 2006, pois evidenciou-se um aumento das publicações em relação a essa temática na última década. Esse trabalho de busca foi realizado entre setembro e outubro de 2017. A configuração final de busca utilizada é como segue:

TITLE (sustain* AND innovat* AND (model* OR process* OR framework*)) AND $(P U B Y E A R>2006)$

Tal busca resultou em 260 trabalhos. Ao final, por critérios de escolha (somente papers relacionados à inovação e ao processo de inovação em empresas) focou-se em 41 artigos e 5 revisões. Outros textos, antes contatados, também foram considerados e incorporados na seção da fundamentação teórica.

\subsection{Estudo de caso}

A abordagem do estudo de caso foi utilizada com o objetivo de descrever a relação recursiva entre atores e estruturas de processos de inovação e comparar essas relações. A princípio, nos baseamos em Stake (2006) para entender se poderíamos compreender os casos analisados dentro de uma perspectiva de casos múltiplos. Neste sentido, o processo de inovação foi o nosso quintain, ou seja, o fenômeno em sua totalidade do qual quisemos nos aproximar através deste estudo. Ainda que os casos apresentem características similares que corroboram para uma abordagem de casos múltiplos (STAKE, 2006), assume-se que cada caso foi considerado uma unidade de análise desse estudo, uma vez que os casos são referentes a um mesmo grupo corporativo (empresa Longue Durée ${ }^{7}$ ).

\subsubsection{Descrição dos casos de inovação}

Este trabalho conseguiu a permissão da empresa Longue Durée para realizar o estudo de caso. A empresa pediu para ser identificada com um nome fantasia. Tal empresa é um grupo multinacional do ramo químico e é constituída de várias GBU's

\footnotetext{
${ }^{7}$ Longue Durée é o nome fictício da empresa que compõe o estudo de caso
} 
(Global Business Unities) com fábricas e centros de inovação espalhados pelo mundo. Foram escolhidos dois grupos para serem analisados. Estes, são formados por pessoas que trabalham na área de pesquisa e inovação da Longue Durée ou ainda pessoas que, em algum momento, se envolvem nos projetos de inovação (o caso de pessoas, trabalhando na área de marketing ou na área de desenvolvimento de negócios). Para bem poder analisar o estudo de caso, segue a descrição dos dois casos com maiores informações a respeito do campo de atuação de cada unidade de análise (caso 1 e caso 2).

\section{Caso 1:}

O primeiro caso selecionado trata de pessoas ligadas diretamente a uma unidade de negócios específica da empresa. Tal unidade de negócios produz correntemente matérias primas para indústrias do setor automobilístico. A presença de seus produtos é disseminada globalmente pela cadeia de valor da indústria e uma das principais forças motrizes da unidade de negócio são os produtos de inovação que conferem ganhos ou benefícios em termos de eficiência energética para os veículos como um todo (através dos componentes dos veículos). A utilização dos produtos dessa unidade de negócio encontra legitimidade institucional por meio de legislações referentes ao consumo de combustível de veículos (diversas legislações ao redor do mundo, respeitando as regras de cada região). A equipe que compõe a área de inovação dessa unidade de negócio é composta por mais de 50 pessoas em várias regiões do mundo. O principal centro técnico e de desenvolvimento de inovação encontra-se na Europa. Mediante a robustez dessa estrutura de inovação, foi possível identificar 10 atores que aceitaram participar das entrevistas. Outras pessoas, que também fazem parte da unidade de negócios, foram contatadas, propiciando material e embasamento prático que também foram levados em consideração, metodologicamente, seguindo as premissas do método da observação participante (seção 3.2.2.2). O detalhe da identificação dos atores é apresentado na seção 3.3.2. 


\section{Caso 2:}

O segundo caso selecionado trata de pessoas que trabalham na área de inovação corporativa, mais precisamente, na área de pesquisa e inovação relacionada à biotecnologia. Isso quer dizer que tal área de inovação não está diretamente ligada a nenhuma unidade de negócios, sendo caracterizada por uma atuação transversal com acesso a todas as unidades de negócios. É importante ressaltar que, este caráter de uma estrutura transversal de biotecnologia e acesso a todas as unidades de negócio faz com que a força motriz dos desenvolvimentos seja desenvolver inovações biotecnológicas para todas as unidades de negócios (inclusive a unidade correspondente ao estudo de caso 1) que se interessem e onde, obviamente, existam oportunidades. Dessa maneira, a força motriz em termos de mercado, dependerá de cada produto em questão. Por exemplo, um desenvolvimento de inovação tecnológica, que esteja focado para a unidade de negócio do caso 1, estará também sujeito à lógica instaurada no mercado automobilístico do qual a unidade demandante faz parte. Por outro lado, uma inovação voltada para outra unidade de negócio, por exemplo, uma unidade que tenha seus produtos direcionados ao mercado alimentício, estará sujeita a outras estruturas e forças motrizes no campo de atuação. Isso trará impacto à estruturação da inovação dessa equipe corporativa (caso 2). Tal área de biotecnologia possui sua estrutura física e principais pesquisadores e outros colaboradores situados no Brasil. A equipe que compõe essa estrutura conta com mais de 10 pessoas (entre pesquisadores e outros colaboradores). Para este estudo de caso, três pessoas foram entrevistadas, assim como outras pessoas foram ouvidas de maneira indireta (observação participante). O detalhe da identificação dos atores entrevistados está contido na seção 3.3.2.

Por fim, salienta-se que a empresa Longue Durée apresenta uma orientação de inovação comum a todas as áreas e equipes, independentemente de serem corporativas ou ligadas, diretamente, às unidades de negócios. Tal alinhamento garante a similaridade necessária para que se compare os casos. No entanto, as especificidades de cada área existem e merecem atenção para se analisar a estruturação das práticas nos processos de inovação orientados para a sustentabilidade. 


\subsubsection{Método de coleta de dados}

\section{Entrevistas em profundidade}

Foram elaboradas e aplicadas entrevistas semi-estruturadas e em profundidade, segundo recomendado por Silverman (1993). Para tanto, os seguintes procedimentos foram adotados:

o Identificação dos atores;

- Elaboração do roteiro;

o Validação do roteiro;

o Execução das entrevistas;

As entrevistas foram gravadas e transcritas; notas ao longo das entrevistas também foram redigidas. O caso 1 contou com dez entrevistados e o caso 2 com três. Tal diferença se justifica pelo tamanho das respectivas áreas de inovação (tabela 4).

\section{Observação participante}

A observação participante tem sido empregada em vários campos de estudos como estratégia metodológica de coleta de dados. Como apontam Serva e Junior (1995), tal estratégia permite que o processo de coleta de dados aconteça no próprio ambiente natural de vida dos observados e uma potencial qualidade de elementos acerca dos fenômenos seja alcançada. É importante salientar que a aplicação de tal método foi possível, pois o autor tem atuação contínua na empresa investigada, na área de inovação. Dessa maneira, a observação participante contou especialmente com um foco do pesquisador no período compreendido durante a fase de preparação do roteiro das entrevistas em profundidade e de sua realização. Adicionalmente às pessoas que foram entrevistadas, a atuação como observador participante, resultou do trabalho cotidiano do autor e sua relação que ultrapassa o contato com as pessoas das áreas de inovação dos casos 1 e 2, e atinge outras unidades de negócios, outras áreas corporativas e também colaboradores externos. As reflexões e dados prevenientes da análise de observação participante foram registradas em algum meio de anotação físico (caderno de anotações) ou eletrônico (computador). O pesquisador atuou como um insider e, ao mesmo tempo, como um 
outsider, com a necessária aproximação ao objeto, mas com a consciência de que deveria seguir um roteiro, baseado na revisão de literatura previamente elaborado, conforme recomendam Serva e Junior (1995). A construção da narrativa dos resultados obtidos na elaboração do estudo de caso (seções 4 e 5) conta com a observação participante realizada durante este trabalho.

\subsubsection{Os atores}

Uma parte crucial das entrevistas em profundidade está na identificação dos atores a serem entrevistados e no entendimento da posição que cada um ocupa no processo de inovação. A seleção adequada refletirá uma potencial profunda análise sobre o objeto de pesquisa, possibilitando o alcance do objetivo da dissertação.

Durante a identificação dos atores que seriam entrevistados, buscou-se encontrar pessoas que ocupassem a posição de pesquisadores, técnicos, gerentes e diretores (envolvidos diretamente com o processo inovação). Adicionalmente, buscou-se também encontrar pessoas que não estivessem diretamente ligadas à área de inovação, mas que fizessem parte do processo de inovação na sua totalidade (pessoas da área de marketing e da área de negócios). O detalhamento dos atores identificados encontra-se na tabela 4.

Tabela 4: Atores entrevistados

\begin{tabular}{|c|c|c|c|}
\hline Casos & Cargo & Tipo de Interação & $\begin{array}{l}\text { Tempo da } \\
\text { Entrevista }\end{array}$ \\
\hline 1 & Diretora $\left.R \&\right|^{\star 8}$ & Entrevista & $100 \mathrm{~min}$ \\
\hline 1 & Gerente R\&I & Entrevista & $50 \mathrm{~min}$ \\
\hline 1 & Diretor de Negócio & Entrevista & $60 \min$ \\
\hline 1 & Engenheira de Processo R\&l & Entrevista & $65 \mathrm{~min}$ \\
\hline 1 & Líder de Projeto R\&I & Entrevista & $70 \mathrm{~min}$ \\
\hline 1 & Engenheira de Aplicação R\&l & Entrevista & $75 \mathrm{~min}$ \\
\hline 1 & Técnico de Aplicação R\&l & Entrevista & $70 \mathrm{~min}$ \\
\hline 1 & Técnico de Aplicação R\&I & Entrevista & $65 \mathrm{~min}$ \\
\hline 1 & $\begin{array}{c}\text { Gerente Ideação R\&I / Engenheira de } \\
\text { Processo R\&I }\end{array}$ & Entrevista & $90 \min$ \\
\hline 1 & Gerente de Marketing & Entrevista & $70 \min$ \\
\hline 1 & Gerente Técnico \& Marketing & Observação Participante & Não se aplica \\
\hline 1 & Pesquisadora & Observação Participante & Não se aplica \\
\hline 2 & Analista & Entrevista & $75 \min$ \\
\hline 2 & Pesquisadora & Entrevista & $80 \mathrm{~min}$ \\
\hline 2 & Pesquisadora & Entrevista & $75 \mathrm{~min}$ \\
\hline 2 & Gerente R\&I & Observação Participante & Não se aplica \\
\hline
\end{tabular}

Fonte: Elaborado pelo autor.

\footnotetext{
${ }^{8}$ R\&I, do inglês Research \& Innovation
} 
As figuras 21 e 22 mostram a visão do organograma e posição dos atores dentro das áreas respectivas em que atuam. Tal demonstração gráfica da hierarquia é comum em várias empresas e também o é para a empresa Longue Durée.

Figura 21: Disposição hierárquica dos entrevistados do caso 1

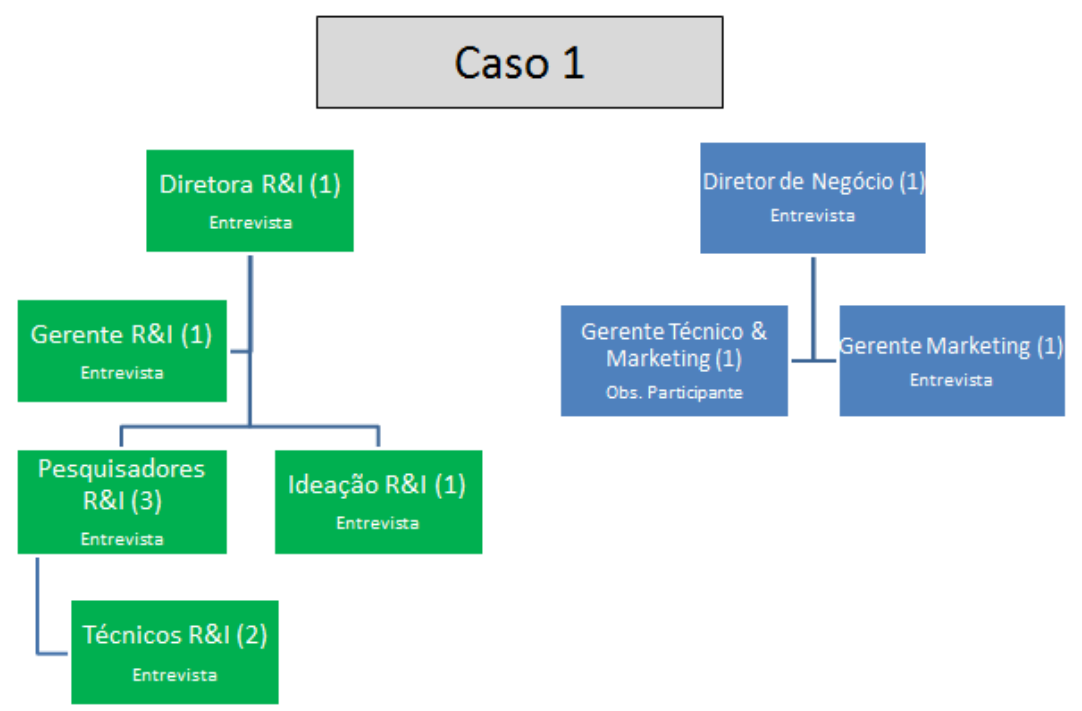

Fonte: Autor

Figura 22: Disposição hierárquica dos entrevistados do caso 2

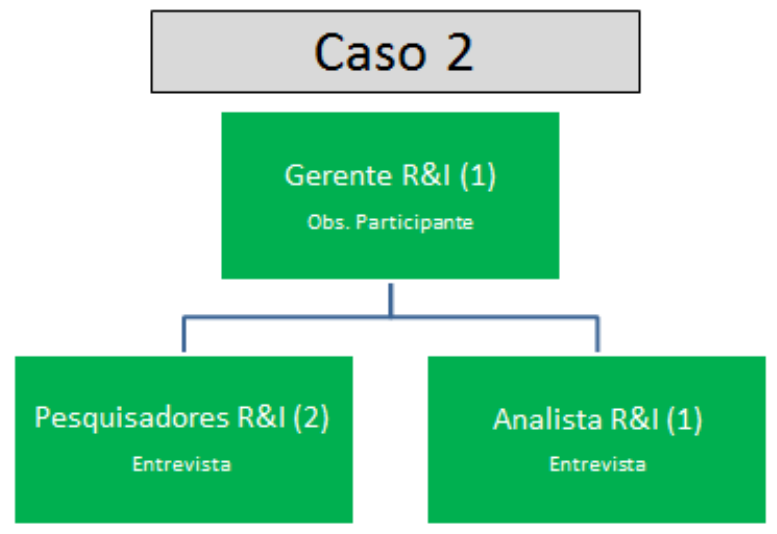

Fonte: Autor

\subsubsection{Roteiro das entrevistas}

O roteiro abaixo (tabela 5) traz as questões que foram abordadas com os entrevistados. Tal roteiro semiestruturado é fruto de um pré-roteiro que foi elaborado e testado com alguns pesquisadores (atores) e que, posteriormente, ganhou essa 


\section{versão final após importantes contribuições dos entrevistados e da discussão entre orientadora e orientando. O questionário foi traduzido para o inglês (anexo $A$ ), pois a maioria dos entrevistados é formada por estrangeiros.}

Tabela 5: Roteiro das entrevistas

\begin{tabular}{|c|c|c|c|}
\hline & Perguntas & Ideias Chaves & Autores \\
\hline A & $\begin{array}{l}\text { O que vem à sua cabeça sobre o tema sustentabilidade? } \\
\text { O que é sustentabilidade para você? }\end{array}$ & $\begin{array}{l}\text { Teoria da Estruturação } \\
\text { (TE); } \\
\text { Sustentabilidade; }\end{array}$ & $\begin{array}{l}\text { GIDDENS (1984); } \\
\text { BURSZTYN, BURSZTYN } \\
(2012)\end{array}$ \\
\hline B & Qual a importância da sustentabilidade? & $\begin{array}{l}\text { TE (esquemas } \\
\text { interpretativos); }\end{array}$ & GIDDENS (1984) \\
\hline C & $\begin{array}{l}\text { A sustentabilidade é um tema harmonioso? Há } \\
\text { contradições nessa temática? }\end{array}$ & $\begin{array}{l}\text { TE (esquemas } \\
\text { interpretativos); } \\
\text { Sustentabilidade fraca } \\
\text { ou forte; }\end{array}$ & $\begin{array}{l}\text { GIDDENS (1984); } \\
\text { BURSZTYN, BURSZTYN } \\
\text { (2012); JACKSON (2013) }\end{array}$ \\
\hline D & $\begin{array}{l}\text { Quais são os principais temas que a discussão sobre } \\
\text { sustentabilidade traz pra você? }\end{array}$ & $\begin{array}{l}\text { TE (esquemas } \\
\text { interpretativos); } \\
\text { Sustentabilidade fraca } \\
\text { ou forte; }\end{array}$ & $\begin{array}{l}\text { GIDDENS (1984); } \\
\text { BURSZTYN, BURSZTYN } \\
\text { (2012); JACKSON (2013) }\end{array}$ \\
\hline E & $\begin{array}{l}\text { Quais são os obstáculos / desafios para alcançar a } \\
\text { sustentabilidade? }\end{array}$ & $\begin{array}{l}\text { TE (esquemas } \\
\text { interpretativos); } \\
\text { Isomorfismo } \\
\text { Institucional; } \\
\text { Alinhamento para a } \\
\text { sustentabilidade; } \\
\end{array}$ & $\begin{array}{l}\text { GIDDENS (1984); } \\
\text { BURSZTYN, BURSZTYN } \\
\text { (2012); JACKSON (2013), } \\
\text { SACHS (2015) }\end{array}$ \\
\hline $\mathbf{F}$ & $\begin{array}{l}\text { Sua empresa (e / ou unidade de negócio) se preocupa } \\
\text { com sustentabilidade? Qual o grau de comprometimento } \\
\text { da sua empresa com a sustentabilidade)? Pode dar } \\
\text { exemplos? }\end{array}$ & $\begin{array}{l}\text { TE (esquemas } \\
\text { interpretativos); } \\
\text { Isomorfismo } \\
\text { Institucional; } \\
\text { Alinhamento para a } \\
\text { sustentabilidade; }\end{array}$ & $\begin{array}{l}\text { GIDDENS (1984); } \\
\text { DIMMAGIO e POWELL } \\
\text { (2005); BURSZTYN, } \\
\text { BURSZTYN (2012); }\end{array}$ \\
\hline G & O que é inovação? & $\begin{array}{l}\text { Inovação; } \\
\text { TE (esquemas } \\
\text { interpretativos); }\end{array}$ & $\begin{array}{l}\text { TIDD, BESSAN e PAVITT } \\
\text { (2008); SACHS (2015); } \\
\text { VARADARAJAN (2017); } \\
\text { PORTER (1995), } \\
\text { SCHUMPETER (1939) } \\
\end{array}$ \\
\hline H & O que é necessário para fazer inovação? & $\begin{array}{l}\text { Inovação; } \\
\text { TE (esquemas } \\
\text { interpretativos); }\end{array}$ & $\begin{array}{l}\text { GIDDENS (1984); ADAMS } \\
\text { et al. (2016), HALLSTEDT } \\
\text { et al. (2013) }\end{array}$ \\
\hline $\mathbf{I}$ & Qual a relação entre sustentabilidade e inovação? & $\begin{array}{l}\text { Inovação e } \\
\text { Sustentabilidade; } \\
\text { TE (esquemas } \\
\text { interpretativos); }\end{array}$ & $\begin{array}{l}\text { GIDDENS (1984); } \\
\text { BURSZTYN, BURSZTYN } \\
\text { (2012); JACKSON (2013) }\end{array}$ \\
\hline $\mathbf{J}$ & $\begin{array}{l}\text { Em sua opinião, qual o papel da inovação para a sua } \\
\text { empresa? }\end{array}$ & $\begin{array}{l}\text { Inovação; } \\
\text { Campos; } \\
\text { TE (esquemas } \\
\text { interpretativos); }\end{array}$ & $\begin{array}{l}\text { GIDDENS (1984); TIDD, } \\
\text { BESSAN e PAVITT (2008); } \\
\text { SACHS (2015); } \\
\text { VARADARAJAN (2017); } \\
\text { PORTER (1995), } \\
\text { SCHUMPETER (1939) }\end{array}$ \\
\hline K & $\begin{array}{l}\text { No processo de inovação da sua empresa, quais são os } \\
\text { principais objetivos? Quais são as principais métricas? }\end{array}$ & $\begin{array}{l}\text { Inovação; } \\
\text { Sustentabilidade; } \\
\text { Esquemas } \\
\text { Interpretativos; } \\
\text { Normas e métricas; }\end{array}$ & $\begin{array}{l}\text { COOPER (2006); } \\
\text { GIDDENS (1984); } \\
\text { VARADARAJAN (2017), } \\
\text { HALLSTEDT et al. (2013) }\end{array}$ \\
\hline $\mathbf{L}$ & $\begin{array}{l}\text { Sua empresa (e / ou unidade de negócio) busca promover } \\
\text { a sustentabilidade através da inovação? Como? }\end{array}$ & $\begin{array}{l}\text { Inovação; } \\
\text { Sustentabilidade; } \\
\text { TE (esquemas } \\
\text { interpretativos); }\end{array}$ & $\begin{array}{l}\text { GIDDENS (1984); } \\
\text { DIMMAGIO e POWELL } \\
\text { (2005); BURSZTYN, } \\
\text { BURSZTYN (2012); }\end{array}$ \\
\hline M & $\begin{array}{l}\text { Em que momento do processo de inovação a } \\
\text { sustentabilidade é discutida? }\end{array}$ & $\begin{array}{l}\text { Processo de inovação; } \\
\text { Sustentabilidade; } \\
\text { Práticas (TE); }\end{array}$ & $\begin{array}{l}\text { COOPER (2006); } \\
\text { GIDDENS (1984); } \\
\text { VARADARAJAN, } \\
\text { HALLSTEDT et al. (2013); }\end{array}$ \\
\hline
\end{tabular}




\begin{tabular}{|c|c|c|c|}
\hline & Perguntas & Ideias Chaves & Autores \\
\hline $\mathbf{N}$ & $\begin{array}{l}\text { Como incluir a sustentabilidade nos processos de } \\
\text { inovação? }\end{array}$ & $\begin{array}{l}\text { Processo de inovação; } \\
\text { Sustentabilidade; } \\
\text { Práticas (TE); }\end{array}$ & $\begin{array}{l}\text { VARADARAJAN (2017); } \\
\text { HALLSTEDT et al. (2013); } \\
\text { ADAMS et al. (2016); } \\
\text { SACHS (2015); }\end{array}$ \\
\hline $\mathbf{o}$ & $\begin{array}{l}\text { Existem práticas no dia a dia do fazer inovação que } \\
\text { ajudam a incluir a sustentabilidade na condução do } \\
\text { projeto? Quais são essas práticas? }\end{array}$ & $\begin{array}{l}\text { Práticas (TE); } \\
\text { TE (esquemas } \\
\text { interpretativos); } \\
\text { Inovação; } \\
\text { Sustentabilidade; }\end{array}$ & $\begin{array}{l}\text { GIDDENS (1984); } \\
\text { GIDDENS (2013); } \\
\text { ORLIKOWSKY (2000); } \\
\text { JONES et al. (2000); } \\
\text { HUNG (2004); STOCK et } \\
\text { al. (2017); }\end{array}$ \\
\hline $\mathbf{P}$ & $\begin{array}{l}\text { Qual o papel de cada pessoa no processo de inovação, } \\
\text { em relação à sustentabilidade? }\end{array}$ & $\begin{array}{l}\text { Agência (TE); } \\
\text { Inovação; } \\
\text { Sustentabilidade; }\end{array}$ & $\begin{array}{l}\text { GIDDENS (1984); } \\
\text { GIDDENS (2013); } \\
\text { ORLIKOWSKY (2000); }\end{array}$ \\
\hline $\mathbf{Q}$ & $\begin{array}{l}\text { Existem métricas / normas / diretrizes na condução de } \\
\text { projetos de inovação relacionadas à sustentabilidade? }\end{array}$ & Normas e métricas (TE); & $\begin{array}{l}\text { GIDDENS (1984); } \\
\text { GIDDENS (2013); } \\
\text { ORLIKOWSKY (2000); }\end{array}$ \\
\hline $\mathbf{R}$ & $\begin{array}{l}\text { Qual é a sua influência em promover uma inovação } \\
\text { orientada para a sustentabilidade? }\end{array}$ & $\begin{array}{l}\text { Agência (TE); } \\
\text { Sustentabilidade; }\end{array}$ & $\begin{array}{l}\text { GIDDENS (1984); } \\
\text { GIDDENS (1989); } \\
\text { GIDDENS (2013); }\end{array}$ \\
\hline $\mathbf{s}$ & $\begin{array}{l}\text { No seu trabalho, na sua GBU, como você está ajudando a } \\
\text { sustentabilidade? Qual o problema que você está } \\
\text { atacando? }\end{array}$ & $\begin{array}{l}\text { Sustentabilidade; } \\
\text { TE (esquemas } \\
\text { interpretativos); }\end{array}$ & $\begin{array}{l}\text { GIDDENS (1984); } \\
\text { BURSZTYN, BURSZTYN } \\
\text { (2012); JACKSON (2013) }\end{array}$ \\
\hline $\mathbf{T}$ & $\begin{array}{l}\text { O seu dia a dia é cheio de atividades... Práticas... Em } \\
\text { quais delas você endereça a sustentabilidade? }\end{array}$ & $\begin{array}{l}\text { Práticas (TE); } \\
\text { TE (esquemas } \\
\text { interpretativos); }\end{array}$ & $\begin{array}{l}\text { GIDDENS (1984); } \\
\text { GIDDENS (1989); } \\
\text { GIDDENS (2013); }\end{array}$ \\
\hline $\mathbf{u}$ & $\begin{array}{l}\text { Nas práticas mais importantes para o seu trabalho em } \\
\text { inovação, quais são as mais relevantes que você precisa } \\
\text { cumprir? }\end{array}$ & $\begin{array}{l}\text { Práticas (TE); } \\
\text { TE (esquemas } \\
\text { interpretativos); }\end{array}$ & $\begin{array}{l}\text { GIDDENS (1984); } \\
\text { GIDDENS (1989); } \\
\text { GIDDENS (2013); }\end{array}$ \\
\hline
\end{tabular}

Fonte: Elaborado pelo autor

\subsubsection{Método para análise das entrevistas}

A escolha de como se avaliar o material das entrevistas é de suma importância para se extrair a potencial riqueza do movimento do fenômeno que se observa. Uma abordagem possível acontece através da analise temática das entrevistas. Segundo Fereday e Muir-Cochrane (2006), a análise temática é uma ferramenta metodológica poderosa para ajudar na interpretação dos resultados provenientes da entrevista. Dado o fato de que as entrevistas contém um conteúdo considerável de subjetividade (tanto por parte dos entrevistados, como pela do entrevistador), é importante uma estratégia adequada que valide e sustente a discussão e conclusões a que se pretende ao final de um projeto de pesquisa. Duas abordagens recorrentes na aproximação da análise temática são a abordagem temática indutiva e a abordagem dedutiva. A primeira baseia-se numa categorização que emerge dos dados coletados. Os temas não são levantados a priori e qualquer 
interpretação é a posteriori (BOYATZIS, 1998)."Uma "boa categoria" é aquela que captura a riqueza qualitativa do fenômeno" (BOYATZIS, 1998, p. 1). A segunda baseia-se na estruturação prévia de um modelo que permita a interpretação das entrevistas a posteriori. Nesta estruturação, já se visualizam e se descrevem as possíveis categorias que se pretende analisar.

Para a tratativa dos dados coletados das entrevistas, foi utilizado o método indutivo de Corley \& Gioia (2004), seguindo-se três níveis de informação. Em primeiro, o denominado de temas de primeira ordem, que consistem em elementos que surgiram das entrevistas como respostas dos entrevistados. A análise de tais elementos facilita o refino e identificação de uma segunda categorização, identificada como conceitos de segunda ordem. Estes conceitos configuram um maior nível de abstração, ou ainda maior nível de mediação (termo definido no item 5.3), sendo uma maneira de categorizar os elementos da ação prática que surgiram por uma consciência discursiva dos entrevistados, no momento das respostas aos questionamentos. Por fim, visando à descrição da estruturação das práticas em inovação, identificaram-se 4 categorias agregadas que permitiram a proposição de um modelo de estruturação (figura 24, na seção 5).

É importante salientar que tal tratativa foi utilizada a fim de se apresentar e articular os tópicos e principais aspectos que emergiram das entrevistas. No entanto, para análise do conteúdo, propriamente dito, e para a discussão dos resultados, foram utilizados os princípios e conceitos da teoria da estruturação (detalhados na seção de fundamentação teórica). 


\section{RESULTADOS E OBSERVAÇÕES INICIAIS}

Primeiramente, como já exposto no tópico sobre metodologia, a revisão bibliográfica contribuiu para os resultados deste projeto de pesquisa. A partir dela, é possível afirmar que várias empresas têm a disposição de afirmar que o produto (seja produto ou serviços) das suas inovações é orientado para a sustentabilidade. Disso deriva o termo que está sendo utilizado neste trabalho: inovação orientada para a sustentabilidade, ou simplesmente, IOS (ADAMS, 2016).

Esta seção, intitulada resultados e observações iniciais, tem o objetivo de expor os resultados e iniciar a discussão dos mesmos, com o respaldo da teoria da estruturação. A seção seguinte (5) traz uma análise em profundidade sobre os resultados obtidos, tentando articulá-los com o objetivo do projeto. Este comentário se faz necessário para esclarecer a posição deste autor que não enxerga uma separação clara entre resultados e discussão em um tipo de pesquisa exploratória e qualitativa que tem como foco os indivíduos e suas práticas. Dessa maneira, a presente seção, além de trazer os resultados mais explícitos deste trabalho, também traz certo nível de discussão.

\section{Tópicos Emergentes}

Inicialmente, a figura 23 demonstra o agrupamento temático realizado sobre o material das entrevistas, suportado pelo método indutivo de Corley \& Gioia (2004). Doze conceitos de segunda ordem foram identificados através dos temas que emergiram explicitamente durante as entrevistas. A análise de cada conceito permitiu a identificação / proposição de quatro categorias agregadas que contêm esses conceitos. Em seguida, são discutidas as quatro categorias e cada conceito associado de segunda ordem. Para suporte dessa discussão inicial, trechos das falas dos entrevistados são apresentados. As tabelas de 6 a 17, contendo as falas, apresentam as indicações EC1 e EC2 que são referentes aos Casos 1 e 2, respectivamente. As letras que aparecem, em seguida das indicações EC1 ou EC2, nas referidas tabelas representam as perguntas que foram aplicadas e geraram essas respostas (tabela 5). A articulação entre conceito de segunda ordem, categoria e falas é realizada com suporte da teoria da estruturação. 
Figura 23: Resultados da avaliação temática das entrevistas

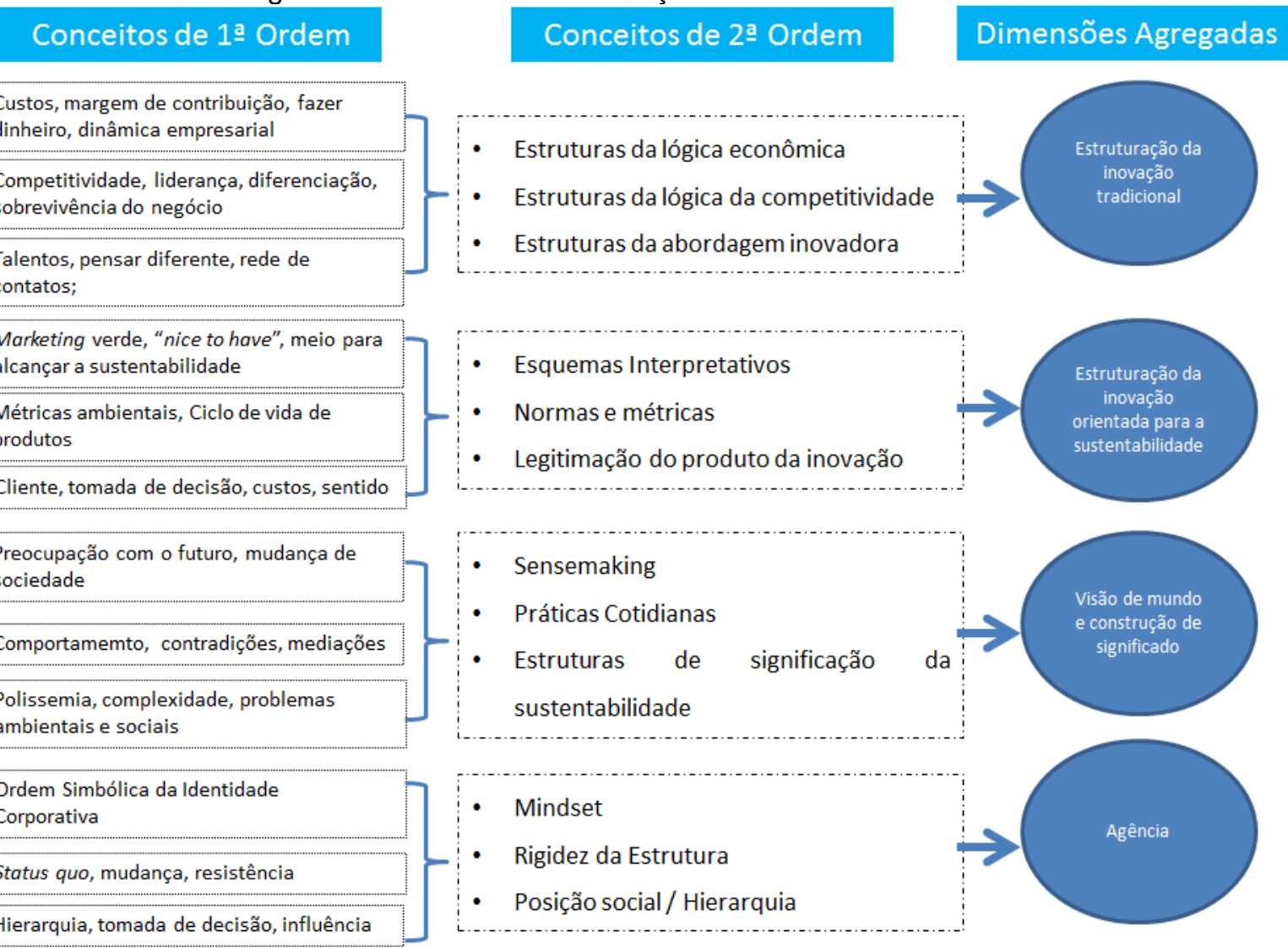

Fonte: Autor

\subsection{Estruturação da inovação tradicional}

A primeira categoria apresentada está identificada como "Estruturação da inovação tradicional". Trata-se da dinâmica de estruturação das práticas daquilo que poderia ser identificado como o status quo do fazer inovação. Os conceitos de segunda ordem que compõem a categoria dizem respeito a uma lógica econômica, de competitividade e de estruturas de abordagem inovadora, esta última, ligada em como fazer inovação, como achar e propor soluções inovadoras, mas de forma tradicional.

\section{Estruturas da lógica econômica}

O questionário semiestruturado buscou trazer à tona o entendimento dos atores sobre o fazer inovação, processo do qual eles são parte e o legitimam. 0 conceito de segunda ordem "estruturas da lógica econômica" emergiu dos discursos dos atores sociais quando eles exprimiram o porquê do fazer inovação (relacionado 
às questões $\mathrm{J}, \mathrm{K}$ e $\mathrm{L}$ do roteiro - tabela 5). É interessante o posicionamento direcionado ao outro. A inovação é vista como uma atividade alheia ao indivíduo, pertencente à empresa. É a empresa que faz a inovação e não os indivíduos que instanciam as práticas (falas 1, 2, 3 e 4 na tabela 6).

Tabela 6: Extratos das falas referentes às estruturas da lógica econômica

\begin{tabular}{|c|c|}
\hline Falas & ESTRUTURAÇÃO DA INOVAÇÃO TRADICIONAL I Estruturas da lógica econômica \\
\hline $\begin{array}{c}1 \\
\text { EC1-H }\end{array}$ & $\begin{array}{l}\text { It's clear that innovation for private companies is linked, of course, to make money in a } \\
\text { sustainable way, of sustainable solution to new technologies to the customers, to provide } \\
\text { this technology. It's clear that innovation in a more general sense is also to make, to } \\
\text { build some bricks of knowledge, for the scientific community in order to help the humans, } \\
\text { to say, to continue this kind of evolution and developing new technology for the future, } \\
\text { just to be clear. }\end{array}$ \\
\hline $\begin{array}{c}2 \\
E C 1-K\end{array}$ & A empresa faz inovação para se manter no topo. Manter sua liderança. \\
\hline $\begin{array}{c}3 \\
\text { EC1-J }\end{array}$ & $\begin{array}{l}\text { It's to grow and to make sure that the company grows in a business perspective. } \\
\text { Sustainable growth. It's not a growth for the next } 1 \text { to } 5 \text { years. It's a growth for the next } \\
\text { centuries, potentially. But innovation has to be very broad in the sense that is not only } \\
\text { focused on one point. It's not only product innovation. For me innovation is making sure } \\
\text { that you can continue to grow, for your business perspective, and you have the } \\
\text { sustainable growth. }\end{array}$ \\
\hline $\begin{array}{c}4 \\
\text { EC1-K }\end{array}$ & $\begin{array}{l}\text { É vender. } \\
\text { A inovação na empresa é dirigida sobre o mercado. Primeiro sobre o mercado. É uma } \\
\text { lógica econômica, que não tem nada a ver com a parte de desenvolvimento sustentável } \\
\text { (para mim). }\end{array}$ \\
\hline $\begin{array}{c}5 \\
\text { EC1-N }\end{array}$ & $\begin{array}{l}\text { Today, one way is through the tool "A" (which is a formality). In the end an idea will work } \\
\text { as more sustainable as possible... But the costs metrics are the first ones. It's more } \\
\text { important [...] main practices put focus on economics and performance of the product. } \\
\text { Sustainability it's the last. It's only environmental issue. }\end{array}$ \\
\hline $\begin{array}{c}6 \\
E C 2-G\end{array}$ & $\begin{array}{l}\text { Inovação é criar um novo produto, uma nova solução para o mercado que não exista ou } \\
\text { complementar aquilo que exista e, uma vez, que a gente tá dentro da empresa e a gente } \\
\text { é cobrado pra isso, a gente já tem que saber que aquela inovação vai trazer lucro, vai } \\
\text { trazer ativos para o segmento. É isso que a gente vê como inovação. }\end{array}$ \\
\hline
\end{tabular}

As estruturas da lógica econômica na estruturação da inovação tradicional são muito latentes. Com o apoio da teoria da estruturação, identifica-se, por meio dos extratos, o que chamar-se-ia de esquemas interpretativos da lógica econômica. A inovação é vista como uma atividade que tem por finalidade principal, para a 
empresa, o "fazer dinheiro" (falas 1 e 6, tabela 6), e, fazer dinheiro requer legitimar essa prática de fazer dinheiro ao longo do tempo, nos dizeres da fala 2, trata-se de "se manter no topo... manter sua liderança". Outra característica da lógica econômica é a crença do crescimento econômico (fala 3, tabela 6). Tal crescimento é um objetivo claro da empresa e a inovação é um dos meios para tal finalidade. É interessante notar que a expressão crescimento sustentável apareça. $O$ questionamento foi introduzido para cada ator, mediante a explicação do objetivo do projeto. Dessa maneira, foi observado o posicionamento de alguns atores ao descreverem a estrutura da lógica econômica como uma busca por sustentabilidade econômica da empresa. A empresa, em questão, possui uma ferramenta (que neste trabalho será referenciada como ferramenta "A") de tomada de decisões, para projeto de inovação, que apresenta como foco, endereçar questões de sustentabilidade sobre cada projeto. A análise dessa ferramenta poderia ser feita através da teoria da estruturação a fim de entender como se dá a estruturação das práticas que envolvem tal ferramenta. No entanto, somente haverá de se registrar que tal ferramenta foi recorrentemente citada, representando uma legitimação dos esquemas interpretativos dos atores que veem nessa ferramenta algo que, de certa maneira, legitima certas práticas com a finalidade de se discutir a sustentabilidade no processo de inovação. É um ponto interessante da análise que, embora tal ferramenta $(A)$ possa ser vista como parte integrante da estruturação de práticas voltadas para a sustentabilidade no processo de inovação, observa-se que as estruturas da lógica econômica são mais profundamente enraizadas e, por assim dizer, mais legitimadas. A fala 5 (tabela 6 ) representa bem essa observação quando o ator social respondeu como seria possível incluir práticas que ajudariam a incorporar mais aspectos de sustentabilidade ao processo de inovação.

Ao final, nota-se que o objetivo econômico das empresas, que é gerar capital através de produtos e serviços, justifica ou legitima também uma orientação da área de inovação para se alcançar tal objetivo. Muitas práticas serão engendradas, a fim de se verificar a possibilidade de se conseguir um produto que traga lucro para a empresa. Dessa maneira, será latente a preocupação com margem de contribuição, custos etc, no desenvolvimento de uma inovação. Ou melhor, seja qual for o produto da inovação, é através de uma lógica econômica que seu sucesso será legitimado, a saber, que um produto será deveras produzido e comercializado. Um produto que não é vendido, não alcança legitimidade e, consequentemente, não será produzido. 
Ainda neste quesito, um produto ideal será aquele que permite uma diferenciação entre outros produtos do mercado (muitas vezes fruto da inovação) e que traga boa margem de contribuição para a empresa (diferença entre o preço comercializado e os custos para produzi-lo).

\section{Estruturas da lógica da competitividade}

O conceito de segunda ordem "Estruturas da lógica da competitividade" também emergiu de maneira latente durante as entrevistas. Tal constatação encontra ressonância na argumentação, apresentada na fundamentação teórica em que a inovação tem como objetivo a manutenção da empresa, ou ainda, a sobrevivência da mesma dentro do mercado em que ela opera.

Tal finalidade é evidenciada e reproduzida pela consciência discursiva dos atores que trabalham com inovação em ambos os casos (unidades de análise). Através da teoria da estruturação, pode-se dizer que existem regras e recursos que se instanciam em práticas cujas finalidades são o posicionamento da empresa e sua atuação de mercado. Alguns esquemas interpretativos fazem a ligação de várias estruturas que atuam ao mesmo tempo, as quais são identificadas, neste estudo, como múltiplas estruturas. A fala 7 (tabela 7) articula como se dá a legitimação de um produto desenvolvido pela área de inovação (que é aprovado pelo cliente), uma vez possível produzi-lo e obter alta margem de contribuição para a empresa (estruturas da lógica econômica). Ainda pondera-se que a legitimação de sucesso vem de um isolamento / garantia da inovação, a partir de propriedades intelectuais (patentes) que garantirão à empresa um bom período de lucratividade.

Muitas vezes, pode ser um pouco abstrato o conceito de que a estrutura é o conjunto de regras e recursos que se organizam de maneira recursiva e se instanciam por meio dos indivíduos em suas práticas (Giddens, 1984). No caso dessas estruturas da lógica da competitividade, algumas regras que, a priori, não são tão abertamente expostas, ganham entonação pela consciência discursiva dos atores. Assim, pelos extratos, poder-se-ia elucubrar as seguintes regras, seguindo os exemplos sugeridos por Giddens (1984):

O que é inovação? 
Regra $1 \rightarrow$ "é a sobrevivência da empresa" (fala 8, tabela 7)

Regra $2 \rightarrow$ "é ter bons negócios, porque nós somos capazes de nos diferenciar de nossos competidores" (fala 9, tabela 7);

Regra $3 \rightarrow$ "é manter a liderança dentro do mercado onde estamos atuando" (fala 10, tabela 7).

Tabela 7: Extratos das falas referentes às estruturas da lógica da competitividade

\begin{tabular}{|c|c|}
\hline Falas & $\begin{array}{l}\text { ESTRUTURAÇÃO DA INOVAÇÃO TRADICIONAL / Estruturas da lógica da } \\
\text { competividade }\end{array}$ \\
\hline $\begin{array}{c}7 \\
E C 1-U\end{array}$ & $\begin{array}{l}\text { I need to deliver results that it means the customer must approve the product and we } \\
\text { can produce the product and gain high marging. Also, I need to delivery IP } \\
\text { (intellectual properties) results aiming to protect our technology from competitors. }\end{array}$ \\
\hline $\begin{array}{c}8 \\
\text { EC1-J }\end{array}$ & $\begin{array}{l}\text { É a sobrevivência da empresa. A gente vive num mundo que é super competitivo. Se } \\
\text { a gente não faz isso, sob o aspecto inovação, a empresa perde. } \\
\text { Cada vez mais o cliente demanda um produto "especial". Então, se a empresa não } \\
\text { avança e não se mexe nesse sentido de inovação e de desenvolvimento sustentável, } \\
\text { forçosamente ela vai pagar em um dado momento. Todos os clientes demandam } \\
\text { isso. E tudo isso é bem concorrencial, onde é necessário se diferenciar por esses } \\
\text { aspectos. É a sobrevivência do grupo. }\end{array}$ \\
\hline $\begin{array}{c}9 \\
\text { EC1-J }\end{array}$ & $\begin{array}{l}\text { Ok, first of all, for sure, to have good business, because we are able to differentiate } \\
\text { ourselves every time versus our competitors, and offering every time good solutions } \\
{[\ldots] \text { to arrive first to offer good solutions for our customer, and in this case, when we }} \\
\text { create, I would say good barriers, good IP and so on, we can protect the company } \\
\text { versus the competition, and then to be able to resist and to maintain the continuity of } \\
\text { the company for the } \\
\text { And second, innovation ask to be sustainable, if you do the innovation in this way you } \\
\text { contribute really to continues to improve the sustainability of our processess, and our } \\
\text { technologies and our products. }\end{array}$ \\
\hline $\begin{array}{c}10 \\
E C 1-J\end{array}$ & It's key! To keep leadership in the market where you are playing. \\
\hline $\begin{array}{c}11 \\
\text { EC1-U }\end{array}$ & $\begin{array}{l}\text { A única coisa que nós somos cobrados para fazer é aumentar a eficiência, é a } \\
\text { excelência operacional de produção, entregar as amostras, e tentar fazer a inovação } \\
\text { tecnológica. É a grande missão que nós temos. }\end{array}$ \\
\hline
\end{tabular}

Obviamente, que tais regras não especificam claramente quais práticas se estruturam a partir delas. Porém, a dinâmica entre as múltiplas estruturas permite avaliar que ter bons negócios, ter eficiência operacional (fala 11, tabela 7) e ter alta 
margem de contribuição, estruturarão práticas de contabilização de ganhos, custos, vendas etc.

Ao final, essas estruturas da lógica da competitividade se apresentam muito bem legitimadas e, possivelmente, não são questionadas. O nível máximo de uma prática rotineira é a sua instituição, ou mesmo, sua legitimação pelas regras mais claras com uma característica de sanção e poder. Ou seja, é uma obrigação que não precisa ser apresentada como tal. Portanto, a estruturação de um projeto de inovação, que traga entre seus principais parâmetros os ganhos e custos envolvidos, uma projeção de negócios (business case) bem como a posição de tal tecnologia perante os competidores, é algo óbvio para os atores envolvidos.

\section{Estruturas da abordagem inovadora}

As estruturas da abordagem inovadora dizem respeito à dinâmica de criação. Obviamente, as estruturas já discutidas (lógica econômica e lógica da competitividade) interferem e impactam o desenvolvimento tecnológico em si. Este conceito de segunda ordem revela como os atores veem o processo da criação / invenção da inovação. Vale ressaltar que a solução tecnológica será muito específica a depender da tecnologia envolvida e do mercado onde a empresa atua. Por abordagem tecnológica, entende-se, neste trabalho, a maneira pela qual a empresa se posicionará para desenvolver a inovação. Uma empresa do mercado automobilístico terá que cumprir certas regras e responder a uma estruturação bem diferente de uma empresa do ramo alimentício, por exemplo. Práticas específicas surgirão de estruturas específicas de cada mercado. A título de reflexão, o setor automobilístico engendrará práticas que se estruturam por determinadas modalidades da estrutura, como exemplo, as normas técnicas de segurança. Atores instanciarão práticas que derivam dessas normas e de legislações (sanções) específicas. Ainda que paralelamente possa-se imaginar a mesma situação no mercado alimentício, de fato serão outras regras e legislações que encontrarão, nas práticas instanciadas por atores dessas companhias, suas legitimidades. 
Tabela 8: Extratos das falas referentes às estruturas da abordagem inovadora

\begin{tabular}{|c|c|}
\hline Falas & $\begin{array}{c}\text { ESTRUTURAÇÃO DA INOVAÇÃO TRADICIONAL I Estruturas da abordagem } \\
\text { inovadora }\end{array}$ \\
\hline $\begin{array}{c}12 \\
\text { EC1-H }\end{array}$ & $\begin{array}{l}\text { To make a good innovation we need talents, we need people, teams. Teams of } \\
\text { people that really able to work together, but specially has creative "organ", have a } \\
\text { good environment to delivery. So, the people are fundamental, without people we } \\
\text { cannot innovate. Brilliant brains. We need money, because we need investments, so } \\
\text { if we want to make some trials, we need equipment. And we need good network. I } \\
\text { would say sources of information, that depending of the network that can be very } \\
\text { differentiated. That could be the university, or you have special customers, } \\
\text { associations, from literature, from papers, from internet, big data analysis. So, } \\
\text { information. Channels to achieve, to gather a lot of information. It could useful to have } \\
\text { in the people, also the variety of people, not only people having the same mindset, } \\
\text { but it could be in this case having diversity and inclusion is something very important. } \\
\text { So, to offer vey kind of mindset. To offer different points of views. And then, there is } \\
\text { the last important topic, to be lucky. To get the real, the clever idea in the right } \\
\text { moment. }\end{array}$ \\
\hline $\begin{array}{c}13 \\
\mathrm{EC} 1-\mathrm{H}\end{array}$ & $\begin{array}{l}\text { It's more to get an idea. Make connections from this on. Ideas come from different } \\
\text { ways. From discussion with different people. All of this is necessary to make } \\
\text { innovation. }\end{array}$ \\
\hline $\begin{array}{c}14 \\
\text { EC2-H }\end{array}$ & $\begin{array}{l}\text { A inovação está muito mais ligada de novo ao fator humano, fator de entender o que } \\
\text { o outro ainda não entende e que ele quer colocar isso em prática. Hoje mesmo com } \\
\text { a experiência que temos no laboratório de biotecnologia é muito mais fácil } \\
\text { operacionalizar uma inovação do que você inovar em relação a temas. } \\
\text { Operacionalizar é "mamão com açúcar"... Fácil. }\end{array}$ \\
\hline $\begin{array}{c}15 \\
\text { EC2-H }\end{array}$ & $\begin{array}{l}\text { Pessoas dispostas a pensar diferente. Acho que em primeiro lugar, porque não } \\
\text { adianta você..., É difícil colocar na cabeça dos outros, então se a pessoa não está } \\
\text { aberta a escutar, aberta ao novo, aberta a pensar não sai a inovação... E acho que } \\
\text { curiosidade em coisas novas. Querer fazer novo e fazer diferente. E pra fazer novo e } \\
\text { diferente você tem que aprender coisas novas por que se você tiver o mesmo } \\
\text { conhecimento que você tinha antes, você vai fazer as mesmas coisas. } \\
\text { São esses dois pontos, tanto estar com a mente aberta, tanto ter novos } \\
\text { conhecimentos, procurar novas formações para conseguir fazer diferente. }\end{array}$ \\
\hline $\begin{array}{c}16 \\
\text { EC1-H }\end{array}$ & $\begin{array}{l}\text { First, you need people that believe in it. Then you have to find other. People that will } \\
\text { be the first to test, try to implement it. In another to get them, your innovation has to } \\
\text { make sense. }\end{array}$ \\
\hline
\end{tabular}

Neste conceito de segunda ordem, evidenciou-se, nas respostas dos atores que, embora em ambos os casos, os mercados e orientação tecnológica estivessem 
de certa maneira bem definidos, o mais importante na abordagem inovadora foi apresentado como estruturas relacionadas ao indivíduo / ator social da inovação. Mais do que a consciência da existência de métricas, normas e sanções de cada mercado (e isso parece algo dado e não passível de fácil mudança), a grande diferença em fazer inovação, no que tange à abordagem tecnológica, está relacionada ao individuo. Trata-se do emprego de capital (cultural, social, técnico etc) de cada indivíduo; a saber, de como o capital cultural específico e a maneira como ele (indivíduo) se posiciona na arena, mercado onde atua, pode, potencialmente, possibilitar o surgimento de ideias, a comprovação das mesmas e ser a diferença no fazer a inovação.

As falas apresentadas trazem esses elementos, colocando no fator humano, especial de cada indivíduo, a principal estrutura da abordagem inovadora. Tais falas dialogam bastante com a agência do ator (outro conceito de segunda ordem) e, principalmente, com a subcategoria identificada como mindset.

A operacionalização da inovação também requer elementos econômicos (alocação de recursos financeiros) que apareceram modestamente (fala 12, tabela 8). Existe aparente contradição neste esquema, pois se há uma ideia que não pode ser verificada pela alocação de recursos materiais (comprovação da inovação em laboratório, por exemplo), o fator humano não faz a diferença. Por outro lado, a limitação é superada, especialmente por um posicionamento: se a ideia e a proposição de inovação são boas (e isso deriva do ator social), a operacionalização e os recursos serão destinados para o avanço da inovação. Obviamente, isso dependerá de cada caso, mas não se pode negligenciar a quantidade de capital financeiro e a alocação de recursos disponíveis na estruturação da abordagem inovadora. Adicionalmente, a alocação de recursos financeiros pode ocorrer na contratação de um recurso humano que tenha as habilidades e capitais necessários para uma dada área específica da inovação.

\subsection{Estruturação da inovação orientada para a sustentabilidade}

A seguir, são detalhados os conceitos de segunda ordem que surgiram das interações com os atores e que possibilitaram a identificação do processo de estruturação de novas práticas. De antemão, não se consegue validar a legitimação de muitas práticas, porém, o que se observa a partir da teoria da estruturação é o 
surgimento de princípios estruturantes que aportam elementos aos esquemas interpretativos dos agentes. Neste estudo, muito mais do que validar ou identificar as práticas que poderiam ser vistas como orientadas para a sustentabilidade no processo de inovação, buscou-se entender e identificar elementos de estruturação. A legitimação e a criação de práticas é um processo mais lento e recursivo oriundo da dualidade da estrutura.

\section{Esquemas interpretativos}

O elemento de segunda ordem identificado como esquema interpretativo é bem rico e abrangente. De certa maneira, ele traduz a incipiente questão plural da sustentabilidade e sua complexidade (ver também as estruturas de significação da sustentabilidade). No que diz respeito especificamente a fazer inovação, identificamse alguns pontos importantes daquilo que é enxergado como sustentabilidade no fazer inovação. É evidente, pelos extratos das falas, a ligação da sustentabilidade e inovação com a preocupação quanto aos recursos naturais. Trata-se do aspecto ambiental e da constatação da escassez de recursos para manter a dinâmica da sociedade onde vivemos. As falas 17 e 18 (tabela 9) trazem claramente a preocupação com a escassez de recursos e os problemas ambientais da sociedade de alto consumo contemporânea. A objetivação da consciência discursiva revela preocupação em aumentar a eficiência de produção, a fim de minimizar o impacto ambiental. Uma das maneiras de se concretizar isso seria por meio da inovação. Esse posicionamento poderia ser visto como um esquema interpretativo que legitima a inovação com foco na redução da utilização de recursos, ou mesmo no aumento da eficiência de processos. Tal legitimação ajudará na estruturação de práticas, nas quais, por exemplo, se calcule o ciclo de vida de um determinado produto, a fim de se obter dados sobre seu processo e eficiência. A prática instanciada para fazer esse cálculo terá sua estruturação através desse esquema interpretativo, mas também por meio de normas e métricas que se instanciam como regras que o indivíduo precisar aplicar.

As falas 19, 21 e 23 (tabela 9) trazem uma evidente tensão entre esses esquemas interpretativos e a grande influência da estruturação da inovação tradicional. Nesta afirmação, a inovação sustentável precisa cumprir certas "regras" que a legitimariam, a saber: não aumentar os custos e os preços e garantir a 
margem de contribuição desejada pela empresa. Ou seja, a lógica econômica está presente e influencia a estruturação da inovação orientada para a sustentabilidade. Ainda, a utilização de uma ferramenta de tomada de decisão sustentável (ferramenta A) é tensionada pela sua dupla função de apontar o nível de sustentabilidade de um produto de inovação e a sua vantagem econômica (redução de recursos versus otimização dos custos), sendo que sua sustentabilidade está muito mais ligada à vantagem econômica em um primeiro plano.

Por fim, nota-se o posicionamento crítico nas falas 20 e 21 (tabela 9). Primeiramente, um posicionamento crítico de que a inovação não é suficiente para alcançar a sustentabilidade, mas sim um meio necessário. Tal posicionamento se mostra mais amplo, trazendo à tona a questão de sustentabilidade como um direito humano de cada cidadão de ter uma vida digna. Em segundo lugar, uma crítica à maneira como a empresa posiciona sua área de inovação, revelando que aquela não enxerga a sustentabilidade como um fator determinante para guiar o processo de inovação. Posiciona-se, aparentemente, que a empresa endereça tais assuntos e ainda poderia ser considerada mais ativamente comprometida nestes tópicos, se comparada com outras empresas do mercado, porém, para aquilo que se vislumbra como sustentabilidade e que, neste caso, tem muito a ver com um posicionamento individual no mundo (ver o conceito de segunda ordem sensemaking), a empresa ainda precisaria evoluir. 
Tabela 9: Extratos das falas referentes às estruturas dos esquemas interpretativos

\begin{tabular}{|c|c|}
\hline Falas & $\begin{array}{l}\text { ESTRUTURAÇÃO DA INOVAÇÃO ORIENTADA PARA A } \\
\text { SUSTENTABILIDADE / Esquemas interpretativos }\end{array}$ \\
\hline $\begin{array}{c}17 \\
\text { EC1-A }\end{array}$ & $\begin{array}{l}\text { If I have to synthetize, in a very scientific way is to try minimize, or to reduce the } \\
\text { entropy or the energy of the world. This is if I have to synthetize. Because the } \\
\text { concept is that everything is going to consume, to be consumed, this works to } \\
\text { everybody, for us, for animals, the vegetables and so on... the world is becoming } \\
\text { old and old and to the fact that is consuming. So how we can slow down this } \\
\text { consuming? So, the humans are making things that can accelerate, this kind of } \\
\text { consumption, and then making faster this consume of energy, so for this reason, } \\
\text { for me, sustainability is to try to slow down. It's not possible to say to put to zero, } \\
\text { but to try really to slow down as much as possible in order to minimize the } \\
\text { consumption of the planet. So in this case, means to be efficient to use energy } \\
\text { and try to recycle, to use raw materials and try to recycle, everything in order to } \\
\text { try not to "disperse" but in order to close the system. So, In terms of } \\
\text { thermodynamics things and now we talk about entropy and we try to have a } \\
\text { system that could be conservative in a way. }\end{array}$ \\
\hline $\begin{array}{c}18 \\
\text { EC1-I }\end{array}$ & $\begin{array}{l}\text { It's to try to find solutions, that really under the sustainability issues, so that } \\
\text { means that when you find the solution you have to challenge yourself if this } \\
\text { solution you are optimizing the energy, water consumption, } \mathrm{CO}_{2} \text { emission, the } \\
\text { impact of chemicals, the environment. So, you, we have the tool ("A") system } \\
\text { also to make this kind of LCA of the solution that we are trying to develop. So, if } \\
\text { the solution is aligned with this kind of analysis, ok. We can continue and go } \\
\text { ahead and so on, if really there is something in conflict, the idea... usually we } \\
\text { don't go ahead with this kind of innovation. So, sustainable innovation is not } \\
\text { innovation and sustainability, for me is sustainable innovation. This is the ideal } \\
\text { innovation. }\end{array}$ \\
\hline $\begin{array}{c}19 \\
\text { EC1-F }\end{array}$ & $\begin{array}{l}\text { I see that when the business comes back, sustainability is the last part. In big } \\
\text { words, we all talk about sustainability but sustainability shouldn't increase the } \\
\text { costs, shouldn't increase the prices. So, that means that in words is there, in } \\
\text { mindset is partially there. I would say "in" the company, but not yet enough within } \\
\text { the company. }\end{array}$ \\
\hline $\begin{array}{c}20 \\
\text { EC1-I;L }\end{array}$ & $\begin{array}{l}\text { Innovation is not enough to sustainability, that's for sure. } \\
\text { There is a lot of mindset behind sustainabilty, people are more important than } \\
\text { innovation, and innovation is part of it because... to work, to make sure that we } \\
\text { are going to different direction to what do you do today, we have to do something } \\
\text { different, and innovation is to do something different. Innovation is not to grow, is } \\
\text { not consume more, is to make sure that we have a minimum sustainable } \\
\text { development for the life. } \\
\text { [...] At least, it's taking it into account ... It's not what's gonna make you take a }\end{array}$ \\
\hline
\end{tabular}




\begin{tabular}{|c|c|}
\hline & $\begin{array}{l}\text { decision for a project, but at least, it's regarded. We look at it. What's the impact } \\
\text { in the sustainable development? What's the impact in the sustainability? We ask } \\
\text { ourselves the questions. This is better than others. It's part of the project } \\
\text { management. It's not a decision make yet, that's why I say yeah... it's nice, we } \\
\text { look at it, but it's not the art of the development. }\end{array}$ \\
\hline $\begin{array}{c}21 \\
\text { EC1-D }\end{array}$ & $\begin{array}{l}\text { We have no brainstorming about sustainability. It's more to make the risk } \\
\text { analysis. It's also about to challenge, challenge the idea to get some specific } \\
\text { target (reduce production costs, for instance). } \\
\text { [...] We have the tool guys (experts) that analyse the sustainable aspects of the } \\
\text { project / idea, but it's much more related to reduction of resources to maximize } \\
\text { production costs (less raw material /less energy / less water and so on). }\end{array}$ \\
\hline $\begin{array}{c}22 \\
\text { EC1-I }\end{array}$ & $\begin{array}{l}\text { A gente vive numa época que forçosamente a gente deve tentar. Nossa maneira } \\
\text { de trabalhar é condicionada pelo ambiente por uma época. Isso quer dizer que a } \\
\text { gente vai fazer uma inovação onde a gente coloca, a conservação de energia, a } \\
\text { espécie social etc, isso não é compatível (se não colocar esses elementos), não } \\
\text { é inovação, por que senão é uma inovação que vai morrer rapidamente. A gente } \\
\text { pode criar uma coisa boa, mas que vai morrer rapidamente porque não é viável. } \\
\text { O que vai fazer com que uma inovação tenha valor, é que ela seja durável. E ela } \\
\text { pode durar por que ela está de acordo com o seu ambiente, de acordo com sua } \\
\text { época. Nossa época, nos impõe tomar conta disso, e não é possível outro } \\
\text { momento. Para mim é isso. Está ligado forçosamente. }\end{array}$ \\
\hline $\begin{array}{c}23 \\
\text { EC2-M }\end{array}$ & $\begin{array}{l}\text { Pro nosso trabalho qualquer início de projeto tem a ver com sustentabilidade } \\
\text { porque todos os nossos processos se eles não foram sustentáveis, na medida } \\
\text { em que você vai reduzir o consumo de agua, ou você vai trazer... O processo em } \\
\text { si, ele por si só comparado com o processo químico ele tem que ser sustentável } \\
\text { senão não vale a pena, não vai mudar um processo se ele não traz uma } \\
\text { sustentabilidade. E ao mesmo tempo a gente aprende que na hora de } \\
\text { apresentar esse projeto pra uma GBU, por exemplo, esse não pode ser o tópico } \\
\text { principal. Se eu bato o martelo que o projeto é bom porque ele é muito bom em } \\
\text { sustentabilidade eu não vendo. Eu preciso mostrar o mercadológico pra BU. } \\
\text { Olha, o seu custo vai ser menor, você vai reduzir tempo de produção... entende? } \\
\text { Então é importante pra gente mas eu não posso usar esse argumento pra } \\
\text { vender, se não eu não vendo... }\end{array}$ \\
\hline
\end{tabular}

\section{Normas e métricas}

A modalidade da estrutura relacionada a normas e métricas é um aspecto importante da estruturação das práticas. Ela traz consigo aspectos de significação, sanção e legitimação da prática que será instanciada pelos atores. 
Tabela 10: Extratos das falas referentes às normas e métricas

\begin{tabular}{|c|c|}
\hline Falas & $\begin{array}{c}\text { ESTRUTURAÇÃO DA INOVAÇÃO ORIENTADA PARA A SUSTENTABILIDADE I } \\
\text { Normas e métricas }\end{array}$ \\
\hline $\begin{array}{c}24 \\
\text { EC1-Q }\end{array}$ & $\begin{array}{l}\text { In this case we have to evaluate the chemicals, if we use carcinogenic, or some } \\
\text { chemicals that can have any impact in the people or in the environment. We analyse } \\
\text { the consumption of water, the consumption of energy. We analyse the possible gain } \\
\text { in terms of } \mathrm{CO}_{2} \text { emissions, or reciclability in the case of processess, if it's possible to } \\
\text { recycle the things in order to minimize the effluents. Minimize the possible impact of } \\
\text { the effluents in the environment. So, all this kind of things has to be taken into } \\
\text { consideration. }\end{array}$ \\
\hline $\begin{array}{c}25 \\
\text { EC1-M }\end{array}$ & $\begin{array}{l}\text { Quite in the beginning. For instance to make an NBO (opportunity description and } \\
\text { preparation before an idea becomes a project) it's necessary to make the tool } \\
\text { analysis... For the Kick off of the project that's sure! }\end{array}$ \\
\hline $\begin{array}{c}26 \\
\text { EC1-N }\end{array}$ & $\begin{array}{l}\text { Today, one way is through the tool (which is a formality). In the end an idea will } \\
\text { worked as more sustainable as possible. But the costs metrics are the first ones... It's } \\
\text { more important. }\end{array}$ \\
\hline $\begin{array}{c}27 \\
\text { EC1-M }\end{array}$ & $\begin{array}{l}\text { Acho que não é no começo. Não é na ideia. Depois da ideia, ao longo do processo é } \\
\text { discutido. A sustentabilidade surge quando você pode medir, tem métrica... Tem que } \\
\text { ter métrica para avaliar. Para a ideia, no pontapé inicial, acho que não é discutido. }\end{array}$ \\
\hline $\begin{array}{c}28 \\
\text { EC1-N }\end{array}$ & $\begin{array}{l}\text { A partir do momento que tem métrica, algum estudo, algo prático mesmo. Assim } \\
\text { você pode avaliar. Com uma referência, no final você pode avaliar se algo é } \\
\text { sustentável ou não. Se não é difícil. }\end{array}$ \\
\hline $\begin{array}{c}29 \\
E C 1-Q\end{array}$ & $\begin{array}{l}\text { Se a gente pensa sobre métricas, há a ferramenta "A", que é um pouco leve. E em } \\
\text { segundo é o custo proporcional. A margem de contribuição. É isso. No final, é isso } \\
\text { que se passa. Existe a margem de contribuição que vai "acordar" as coisas. Quando } \\
\text { você vê que o custo proporcional aumentou devido ao aumento do consumo de } \\
\text { água, ou consumo de gás, é isso. E isso é o indicador que Ihes interessa "margem } \\
\text { de contribuição". Finalmente, o verdadeiro problema não é atacado. "Ah, eu tenho } \\
\text { um processo que consome muito gás... Então, a gente vai fazer um projeto por que a } \\
\text { margem de contribuição não é boa. Então, não é porque consome muito gás, mas } \\
\text { porque a margem de contribuição é ruim". }\end{array}$ \\
\hline $\begin{array}{c}30 \\
\text { EC2-O }\end{array}$ & $\begin{array}{l}\text { Eu acho isso, no laboratório de biotecnologia faz parte do nosso escopo, mas eu } \\
\text { acho que uma coisa que é capaz de puxar assim, e parametrizar melhor, pra que } \\
\text { puxe essa inovação sustentável, é por exemplo, quando a unidade de negócio X, o } \\
\text { conselho de direção fala: "até } 2020,50 \% \text { do nosso portfólio tem que ser de fontes } \\
\text { renováveis", então cria uma métrica, com base nisso você tem que forçar todas as } \\
\text { pessoas, subordinadas, e todos os pesquisadores envolvidos, a correr atrás disso. } \\
\text { Então, eu acredito que isso seja uma sinalização assim do Board, do conselho de } \\
\text { direção que tem essa capacidade de aprovação, e uma vez que você cria essas }\end{array}$ \\
\hline
\end{tabular}




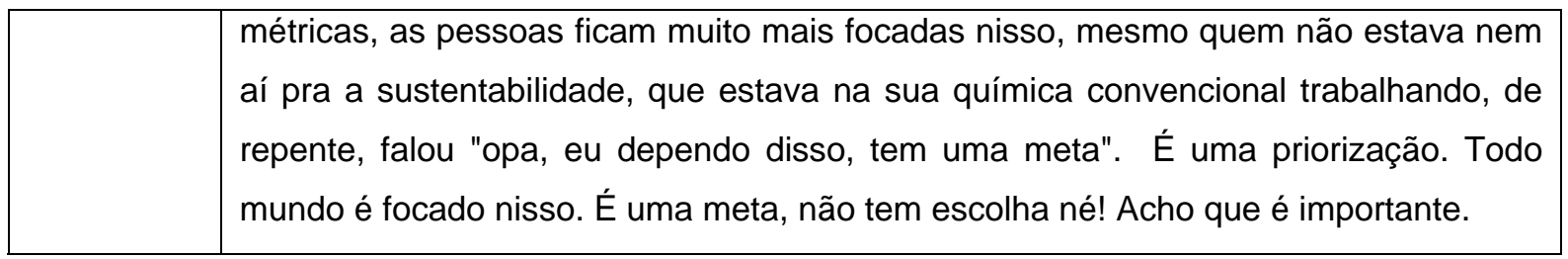

No processo de estruturação da inovação orientada para a sustentabilidade, este conceito de segunda ordem foi bastante latente. Uma primeira observação está no seu aspecto de significação com relação à inovação. De maneira simples e direta, para um produto de inovação ser considerado melhor em sustentabilidade, é preciso que haja métricas. É preciso demonstrar que tal produto, mediante algumas métricas, apresenta um caráter mais sustentável do que outro. Neste quesito, evidencia-se que as métricas ligadas aos aspectos ambientais são mais latentes na consciência discursiva dos atores. Nos extratos abaixo, observa-se que os atores entendem que métricas tais como, pegada de carbono, consumos de água e energia, reciclabilidade etc, permitem identificar e posicionar um produto em detrimento a outro no que tange os aspectos de sustentabilidade. Ainda mais, há o posicionamento de que sem métricas não é possível analisar e fazer uma inovação sustentável. De certa maneira, pode-se traçar o paralelismo de que, enquanto na inovação tradicional as métricas principais estão relacionadas à margem de contribuição a qual dependerá dos custos de produção, na inovação orientada para a sustentabilidade haverá maior preocupação com as métricas ambientais. No entanto, como a fala 25 aporta (tabela 10), as métricas econômicas são mais importantes.

Outra análise importante que deriva desse conceito de segunda ordem é em relação ao momento no qual os aspectos de sustentabilidade são discutidos no processo de inovação. Como suportado na fundamentação teórica, as fases iniciais do processo de inovação são cruciais para a incorporação dos aspectos da sustentabilidade. Mais do que confirmar essa indagação, notou-se que a empresa incorpora tal posicionamento. Embora não se veja isso de maneira unânime naquilo que poderia ser chamado de fase de ideação, as etapas iniciais incorporam a discussão dos aspectos de sustentabilidade.

Outro aspecto identificado trata da descrição de uma prática bem específica na condução dos projetos de inovação que está relacionado à utilização de uma ferramenta $(A)$ de tomada de decisão que traz elementos de sustentabilidade. Essa 
ferramenta e a prática derivada da sua utilização foram bastante reconhecidas pelos atores. Embora tal ferramenta seja reconhecida como uma prática que ajuda a incorporar elementos de sustentabilidade na condução da inovação, ela não escapa às críticas como as falas 25 e 28 (tabela 10x) revelam. Uma aproximação sobre esse conflito poderia ser entendida como a tensão derivada entre a lógica econômica e a estruturação dessa prática que, à priori, estrutura-se sobre aspectos de sustentabilidade ambiental.

\section{Legitimação do produto da inovação}

Este conceito de segunda ordem muito se relaciona com o que se entende, neste estudo, como nível de mediação. Para a compreensão do que é exposto nos próximos parágrafos, define-se nível de mediação como a distância (não física) entre a ação projetada da inovação e a sua legitimação através do usuário do produto da inovação. Este conceito foi definido pelo autor a partir da teoria e será discutida mais profundamente na seção 5.3 .

As falas 31 e 32 (tabela 11) trazem esse aspecto de legitimação. As áreas de inovação podem desenvolver produtos que sejam, de fato, mais sustentáveis (através das métricas já apresentadas), porém, é necessária sua legitimação ao longo da cadeia de valor, e isso ultrapassa e complexifica o processo de inovação. Sendo assimPor exemplo, se um produto sustentável (por diversos atributos) não encontra sua legitimação mais genuína que seria seu consumo, ele não será produzido. A vivência nas inúmeras práticas que esse processo histórico engendrará nos atores envolvidos, não levará à legitimação de práticas sustentáveis da inovação, servindo muito mais como barreiras ao surgimento e estruturação de novas práticas no processo de inovação. Muito mais do que isso, a não legitimação de tais práticas, é de certa maneira a legitimação das práticas da inovação tradicional que se estrutura por lógicas econômicas e de competitividade, onde as métricas mais evidentes são a margem de contribuição e os custos. 
Tabela 11: Extratos das falas referentes à Legitimação do produto da inovação

\begin{tabular}{|c|l|}
\hline Falas & $\begin{array}{l}\text { ESTRUTURAÇÃO DA INOVAÇÃO ORIENTADA PARA A SUSTENTABILIDADE I } \\
\text { Legitimação do produto da inovação }\end{array}$ \\
\hline 31 & $\begin{array}{l}\text { Eu acho que no sentido, por exemplo, da empresa, eles sempre encaminham pra } \\
\text { gente, essa questão. da própria ferramenta (A). Que tem de ser o mais sustentável } \\
\text { possível, mas do ponto de vista do mercado né, com clientes você vê que isso não } \\
\text { tem tanto valor, é muito difícil, principalmente, pra gente que trabalha com alguns } \\
\text { mercados um pouco mais "comoditizados" como solventes, papel e celulose. É difícil } \\
\text { eles pensarem nisso, é sempre... "ah, isso é um produto bastante sustentável só que } \\
\text { ele tem uma performance melhor que um produto convencional de uma química } \\
\text { convencional", e isso sim tem um valor, realmente pros clientes. Se eu disser que } \\
\text { simplesmente, é só sustentável e que tem uma performance inferior, a gente vê que } \\
\text { existem grandes barreiras. Assim, não é simplesmente ser sustentável, não é só } \\
\text { simplesmente o marketing, ele tem sempre que vir encaminhado com uma questão } \\
\text { de performance mesmo, porque senão eu vejo que não tem abertura da maioria dos } \\
\text { mercados. }\end{array}$ \\
\hline EC2-I & $\begin{array}{l}\text { Primeiro por que se a gente continuar fazendo da forma que a gente faz hoje, você } \\
\text { não faz sustentabilidade. Por que de fato, o problema hoje é esse. E o segundo, que } \\
\text { se você não trouxer soluções que sejam aceitas pelas pessoas, elas também não } \\
\text { vão fazer aquilo só porque é sustentável. Então, se você não trouxer algo inovador } \\
\text { que seja aceito pela população que vai ser implementada de uma certa forma, você } \\
\text { não vai atingir a sustentabilidade. Então, não adianta um produto que é sustentável } \\
\text { se ninguém vai usar, não adianta nada. Então, a inovação ela tem é que tanto trazer } \\
\text { coisas inovadoras mas que também sejam implementadas. }\end{array}$ \\
\hline
\end{tabular}

\subsection{Visão de mundo e construção de significados}

Uma das categorias agregadas que foi identificada trata-se da visão de mundo e construção de significados de e para cada indivíduo. Tal categoria é de suma importância, pois revela alguns pressupostos básicos da ação do agente social. Os conceitos de segunda ordem que formam tal categoria são: sensemaking, práticas cotidianas e estruturas de significação da sustentabilidade.

\section{Sensemaking}

Primeiramente, o constructo escolhido para representar este conceito é vastamente discutido nas áreas de pscicologia e comportamento organizacional e dialoga com outros vários temas tais como identidade, sense-breaking, sense-giving 
etc. Resumidamente, sensemaking traz a indagação de "como indivíduos interpretam as pistas dos ambientes externos e internos quando eles constroem uma identidade situada?" (ASHFORTH e SCHINOFF, 2016). Trata-se de entender como o ator social conjuga uma visão mais ampla dos seus ambientes para entender e agir em um determinado contexto. Sensemaking permite aos indivíduos suportarem condições de ambiguidade, de equívocos ou de dinamismo. O processo pode ser desencadeado por questões organizacionais, ou ainda, simplesmente, por eventos que induzam os indivíduos a se questionarem sobre o que está acontecendo ao redor deles, levando-os a procurar informações que lhes são relevantes para suas identidades (ASHFORTH e SCHINOFF, 2016).

Este conceito de segunda ordem traz alguns aspectos muito interessantes a respeito do posicionamento individual acerca do mundo. A seção traz elementos plurais que estão presentes na vida e no cotidiano dos indivíduos e que emergiram de seus posicionamentos discursivos a respeito da temática sustentabilidade.

Nota-se uma profunda reflexão e capacidade cognitiva em relação ao posicionamento num nível macro que é o de sociedade. Sensemaking tem a ver com a consciência discursiva dos indivíduos que apontam o que faz sentido para eles. Trata-se de um sentido holístico de vida e mesmo filosófico-ontológico (fala 34, tabela 12, onde se discute a finitude e transitoriedade da vida). Pautado pelo roteiro semiestruturado que trouxe perguntas sobre a importância da sustentabilidade, respostas que demonstram uma preocupação com o planeta, com uma visão de futuro, do bem viver, preocupação com gerações futuras, cuidado com o planeta, mostram a abrangência desse conceito. São evidentes os aspectos sociais e ambientais nessa perspectiva (falas 33, 34 e 37, tabela 12).

Essa dimensão também traz um autoquestionamento sobre as ações (atividades práticas) dos indivíduos em suas vidas (pessoais e profissionais). A fala 35 (tabela 12) traz essa preocupação e corrobora a discussão de que esse ambiente de debates é emergente e, de certa maneira, compõe um processo de estruturação corrente que, neste trabalho, é intitulado de estruturação da inovação orientada para a sustentabilidade.

Por fim, a fala 36 (tabela 12) coloca em evidência a contradição estrutural da sociedade e, de maneira bem individual, posiciona-se e reconhece que é necessário mudar a sociedade. Para isso, aponta a necessidade de dar um passo para trás na 
sociedade do consumo de massa e viabilizar a distribuição de riquezas na sociedade.

Tabela 12: Extratos das falas referentes ao Sensemaking

\begin{tabular}{|c|c|}
\hline Falas & VISÃO DE MUNDO E CONSTRUÇÃO DE SIGNIFICADOS I Sensemaking \\
\hline $\begin{array}{c}33 \\
\text { EC1-A }\end{array}$ & $\begin{array}{l}\text { How we can deal with sustainability to make people live better, especially in the area, } \\
\text { where we know that there are a lot of troubles... regarding weather, clima. }\end{array}$ \\
\hline $\begin{array}{c}34 \\
E C 1-A\end{array}$ & $\begin{array}{l}\text { For me sustainability is a world where the main objective and what is important to } \\
\text { sustainability is to make sure that the planet is gonna be there in } 20 \text { years, } 50 \text { years } \\
\text { for childrens, for our childrens for childrens of our childrens and make sure that we do } \\
\text { not destroy everything, we don't destroy all resources and make sure that life } \\
\text { continues in the good level. With the good level that it means everyone has access to } \\
\text { water, everyone has access to what he needs for life. Sustainability is durability and } \\
\text { it's now and in the future. }\end{array}$ \\
\hline $\begin{array}{c}35 \\
E C 1-B\end{array}$ & $\begin{array}{l}\text { Because people usually see the things in an own period of life, that is very short, that } \\
\text { could be the entropy in the best situation in } 80 \text { years. But we are transiting in the } \\
\text { world for a very "instant", we respect the life of the world. So, for me is important } \\
\text { because we can provide the contribution, because we know, if everybody thinks the } \\
\text { same no one acts to try to give a contribution. We will never achieve this kind of } \\
\text { things. So, if we want really to provide, a contribute and let our planet in a good } \\
\text { condition to our son, children and the other people coming after us, is something that } \\
\text { we have to put in place every day. It's something that you make every day. In terms of } \\
\text { cultural approach, behavior... not the cultural, but I would say behavior approach. }\end{array}$ \\
\hline $\begin{array}{c}36 \\
E C 1-C\end{array}$ & $\begin{array}{l}\text { There are contradictions for me. In the sense that today we are more in the full } \\
\text { consumer world and if we want to go to sustainability, so that it means that we have } \\
\text { the minimum that you need and you have good life, we will need to think about our } \\
\text { culture and where we work and where we are today, where we manage the planet, } \\
\text { and continues consumption is not a good 'flying in the future". So, we have to review } \\
\text { the way we were and that means that may be a step back in the evolution in a certain } \\
\text { point of time for one generation or two and we have to accept that. It's the } \\
\text { contradiction in the way we are living today. It's not a contradiction per se } \\
\text { sustainability. Sustainability is that where everyone is happy and etc... and few things } \\
\text { that high level, high salary down a little bit... it's not ... whatever you want... it's a little } \\
\text { bit of contradiction in that and if you want to avoid to go back to the middle age soon, } \\
\text { to make sure that planet... sure, we need to make a step back in consumption... to be } \\
\text { more reasonable, but to everyone not only the low, to share the resources and to } \\
\text { share the money, and to review our way of working and to review exactly the politics } \\
\text { where we are. }\end{array}$ \\
\hline
\end{tabular}



issues in the moment, the global warming, how to lead with all climate events, how do we "clean" the human activities. What we can do on that... It's really questioning myself on what I can do either in my personal life but also in my professional life. So it's not so easy I think to find a solution that are impacting one because personally in my daily life I try to have some small actions on that, but I'm not sure that it's really impactful.

\section{Práticas Cotidianas}

Esta dimensão, intitulada práticas cotidianas, emergiu de exemplos dados sobre as condições contraditórias das práticas individuais cotidianas que envolvem um contexto de sustentabilidade. Trata-se de mostrar como se dá a estruturação de práticas que apresentam um nível de mediação menor. Conforme anteriormente explicado, mediação deve ser compreendida como a distância entre a ação realizada e o efeito da sua projeção/intenção. Por exemplo, na fala 38 (tabela 13), primeiramente, decidir entre, utilizar o carro, ou não, como meio de transporte, é mediado somente pela ação que se instancia, ou seja, ir de carro ou utilizar outro meio de transporte. Um nível de mediação maior jaz no efeito esperado em se tomar uma decisão específica. Decidir usar o carro com a intenção de ser mais barato num contexto específico evidencia o êxito de tal decisão pela quase imediata preservação do capital. No entanto, tomar o transporte público porque ele faz menos mal para o planeta pode ser de difícil constatação prática. Neste caso, o que é referido não é uma conta global, mas sim a conta prática que dialoga com uma análise macro. Se, somente um indivíduo faz isso, seu impacto é diminuto na conta do impacto sobre o planeta.

O que é interessante desse conceito de segunda ordem é a apelação para exemplos práticos aos quais os atores sociais recorreram para, de certa maneira, comprovar os seus argumentos discursivos. $O$ fato de expor os diversos elementos presentes em uma tomada de decisão, aparentemente simples (ir de carro ou transporte público), evidencia as múltiplas estruturas que causam dinâmicas aos sistemas sociais e que produzem/reproduzem as rotinas sociais.

Outro exemplo de evidente estruturação das práticas cotidianas diz respeito à coleta seletiva e à destinação correta de resíduos nas práticas rotineiras na vida dos 
indivíduos. A fala 39 (tabela 13) é riquíssima ao trazer três elementos: tempo e disponibilidade do indivíduo, legitimação da prática por meios materiais e custos. $\mathrm{O}$ primeiro elemento mostra certa rigidez da estrutura (ver a análise do conceito de segunda ordem intitulado "rigidez da estrutura" que compõe a categoria agregada "agência"), ou seja, o tempo que se questiona é o tempo para fazer a triagem do lixo. Obviamente, as práticas correntes que estariam relacionadas à não destinação adequada do lixo encontra sua legitimação mediante vários aspectos da estrutura. Muito provavelmente, a ação pragmática de não separar o lixo encontra, na experiência do indivíduo, uma quase certeza da praticidade de se juntar todo o lixo e colocá-lo para fora de casa. Uma vez que a triagem exigiria um maior nível de atenção na instanciação da prática, isso é visto como uma barreira. Serão necessárias mudanças na prática e na sua legitimação através de repetidas ações até que isso se torne uma nova prática. O segundo elemento corrobora para essa tensão. De fato, o simples ato de fazer a triagem não representa a totalidade da coleta seletiva. Quando me refiro à legitimação da prática por meios materiais, refirome à organização do bairro ou da cidade em permitir / facilitar a disposição desse lixo reciclável. Se é muito mais fácil colocar todo o lixo junto e isso ser disposto no mesmo lugar, essa ação é mais fácil de ser legitimada (por facilidade e comodidade do indivíduo), porém, se não há ações que permitam a coleta seletiva, como por exemplo, a disposição de lixos específicos nas proximidades das residências, coleta organizada pelos bairros ou prefeituras, será muito mais difícil legitimar a triagem feita em casa. Tal característica da estruturação pode ser entendida com modalidade da teoria da estruturação de "facilities", quer dizer, a estrutura material / recurso / meio pelo qual a prática se instancia. O terceiro elemento desse extrato traz uma questão da estrutura da lógica econômica. $O$ fato de um produto de caráter sustentável ser mais caro dificulta a disseminação da sua legitimação. Neste caso, o conjunto de capital econômico mais a consciência do indivíduo ocuparão um lugar de grande influência nos esquemas interpretativos e estruturaram a prática relacionada à tomada de decisão.

Por fim, a fala 40 (tabela 13) também corrobora a influência da estrutura da lógica econômica nas tomadas de decisões sobre consumo. O relato coloca em evidência outro conceito de segunda ordem que é identificado como "mindset" / mentalidade e será discutido na categoria agregada de agência. 
Tabela 13: Extratos das falas referentes às práticas cotidianas

\begin{tabular}{|c|c|}
\hline Falas & ISÃO DE MUNDO E CONSTRUÇÃO DE SIGNIFICADOS / Práticas Cotidianas \\
\hline & $\begin{array}{l}\text { You can imagine: you don't use your car, it's good for the planet but sometimes you } \\
\text { want to do that because is good for your wallet. }\end{array}$ \\
\hline$E C 1-E$ & $\begin{array}{l}\text { First of all it's about TIME. Example: to do the split of garbage among glasses, metal, } \\
\text { plastic and so on. Till now to make the split is still very difficult and time for make the } \\
\text { separation in adequate way. It's also a constraint that sustainable products are more } \\
\text { expensive, and we are still driven by costs when we are buying something. } \\
\text { Sometimes is very difficult to find the sustainable way to do the things. For instance in } \\
\text { simple attitudes, take the car or take the bus!!! } \\
\text { It's a question of costs for the companies and costs for the humans. In the end how to } \\
\text { sell the sustainability? }\end{array}$ \\
\hline $\begin{array}{c}40 \\
E C 2-E\end{array}$ & $\begin{array}{l}\text { Hoje é a questão de comportamento mesmo. O comportamento hoje ainda está } \\
\text { muito mais ligado à quantidade e custo, tanto para produção quanto para consumo. } \\
\text { [...] Hoje a preocupação maior ainda é., você olha primeiro o preço depois olha do } \\
\text { que ele é feito, e depois você vê se ele é reciclável ou não. } \\
\text { [...] Comportamento é bem complicado. Ainda somos muito guiados por quantidade e } \\
\text { custo e isso limita a discussão sobre sustentabilidade. Hoje quando você vai falar } \\
\text { sobre a temática, independente de qualquer coisa, ainda a pergunta é "quanto que } \\
\text { vai custar isso?" Muita gente fala de uma maneira pragmática do conceito de } \\
\text { sustentabilidade em a gente como consumidor, mas sem sombras de dúvidas, } \\
\text { quando você tem } 10 \text { opções de bolacha diferente numa prateleira você olha primeiro } \\
\text { o preço e depois você olha se a embalagem é reciclada. Acho que ainda a gente } \\
\text { cobra muito e faz pouco. }\end{array}$ \\
\hline
\end{tabular}

\section{Estruturas de significação da sustentabilidade}

Este conceito de segunda ordem é de suma importância. Ele evidencia o complexo emaranhado de conotações que circunda o constructo sustentabilidade. Com esta denominação, atribuída de "estuturas de significação da sustentabilidade", retrata-se a complexidade que o tema traz, as inúmeras aproximações possíveis, as contradições... O fato de diferentes atores trazerem diferentes temáticas para discussão mostra o quão abrangente pode ser o tema e quão útil a noção de polissemia pode se apresentar. As falas trazem relatos relativos a temas sobre consciência ambiental, a problemática do desenvolvimento econômico e economia circular (falas 42, 45 e 49 respectivamente na tabela 14). Em seguida, destacam-se alguns aspectos que emergiram desse conceito de segunda ordem. 
Tabela 14: Extratos das falas referentes às estruturas de significação da sustentabilidade

\begin{tabular}{|c|c|}
\hline Falas & $\begin{array}{c}\text { VISÃO DE MUNDO E CONSTRUÇÃO DE SIGNIFICADOS / Estruturas de } \\
\text { significação da sustentabilidade }\end{array}$ \\
\hline $\begin{array}{c}41 \\
\text { EC2-A }\end{array}$ & $\begin{array}{l}\text { Sustentabilidade é conseguir agregar valor não monetário para o mundo. É conseguir } \\
\text { realmente trabalhar para atingirmos um mundo melhor. Uma sociedade melhor para } \\
\text { as pessoas e gerações futuras. }\end{array}$ \\
\hline $\begin{array}{c}42 \\
\text { EC1-B }\end{array}$ & $\begin{array}{l}\text { Sometimes is more your consciousness. We do it because you know that is good for } \\
\text { the planet. But sometimes we estimate that there are too much constraints to do that, } \\
\text { even if we have to save the planet. To be very honest about that, sometimes we go in } \\
\text { vacation very far, for our pleasure, we take the car, we take the plane with high } \\
\text { contribution, negative contribution to the planet (footprint), ok? But we can only go in } \\
\text { vacation by train just } 100 \mathrm{~km} \text { far, every times is equilibrium about that. So, sometimes } \\
\text { we take decision that is negative impact but it's also for our good life that we take it. }\end{array}$ \\
\hline $\begin{array}{c}43 \\
\text { EC1-C }\end{array}$ & $\begin{array}{l}\text { Everybody has different definitions of sustainability, ok? So, that depends of what you } \\
\text { put in, ok first. Secondly I will say sustainability to be a broader implemented has to } \\
\text { make sense for an economic point of view or at least people have to agree that there } \\
\text { will not be have the same... the same payback. }\end{array}$ \\
\hline $\begin{array}{c}44 \\
\text { EC1-D }\end{array}$ & $\begin{array}{l}\text { Resources scarcity is very important to me. So, water, fossil fuels, food, whatever, the } \\
\text { population is growing continuously. We can't ask to people in Africa or south America } \\
\text { not to have a better life, a different life, we can't ask. We have to change more in } \\
\text { Europe and resources scarcity is one thing. There are a lot of topics in sustainability. } \\
\text { For that is green gases emissions, it's renewable energy. [...] Coming back, local } \\
\text { sourcing, rather than we are consuming is produced in China, we can pay a little bit } \\
\text { more if it's something that is better, that it means } \mathrm{CO}_{2} \text {. And there is a very big one it's } \\
\text { human after that... In sustainability, we have to regard that human, the well-being of } \\
\text { all the humans and not only ourselves. So, that means be a little bit more work as a } \\
\text { team than any individuals. }\end{array}$ \\
\hline $\begin{array}{c}45 \\
\text { EC1-U }\end{array}$ & $\begin{array}{l}\text { The most important is what I said in the beginning: Growing, growing is not possible. } \\
\text { We have to understand if we want to make a sustainable planet, we have to probably } \\
\text { review our way of consumption, and don't want to consume more, and don't create } \\
\text { more business, but when we talk about sustainable growth is for some specific } \\
\text { companies. If you go macroscopically we may not continue to grow like we do today. }\end{array}$ \\
\hline $\begin{array}{c}46 \\
\text { EC1-I }\end{array}$ & $\begin{array}{l}\text { There is a lot of marketing involved. Sometimes it's very difficult to analyse and know } \\
\text { what is sustainable or not. Take the example of lithium battery for electric car. How is } \\
\text { the disposal of batteries...? Is this more sustainable or not? It will depend of the } \\
\text { energy source. It's about the total cycle analyses, and where to get this information? }\end{array}$ \\
\hline
\end{tabular}




\begin{tabular}{|c|c|}
\hline $\begin{array}{c}47 \\
\text { EC2-C }\end{array}$ & $\begin{array}{l}\text { Tem muita coisa relativa. Cada pessoa relativiza. O tema ainda está longe de ser } \\
\text { harmonioso. Tem muitas contradições, e a sustentabilidade deve servir para } \\
\text { amenizar, trazer ganhos para a sociedade. Hoje estamos muito mais perto da } \\
\text { confusão do que da harmonia. A sustentabilidade vai muito além de jogar lixo no } \\
\text { chão ou reciclar coisas... isso é óbvio que faz parte de mudança de mindset, mas } \\
\text { algo que a gente ainda faz de uma forma pragmática, muita gente ainda não entende } \\
\text { o porquê e como isso vai impactar durante muito tempo na vida das pessoas. }\end{array}$ \\
\hline $\begin{array}{c}48 \\
\text { EC2-E }\end{array}$ & $\begin{array}{l}\text { Isso é bem abrangente. Eu acho que as pessoas veem a sustentabilidade como um } \\
\text { freio no desenvolvimento. Então, historicamente se acostumou a fazer um } \\
\text { desenvolvimento destrutivo e aí a sustentabilidade parece que vai frear o } \\
\text { desenvolvimento e não embalar na mesma. E não é fácil implementar, todo mundo } \\
\text { acha lindo mas ninguém implementa. A limitação é que sustentabilidade é vista como } \\
\text { atraso econômico. }\end{array}$ \\
\hline $\begin{array}{c}49 \\
\text { EC1-A }\end{array}$ & $\begin{array}{l}\text { Sustainability goes into circular economy, meaning a world where everything could be } \\
\text { re-used. Meaning our consumption, raw material could decrease quite a lot. Ideally } \\
\text { we should recycle any product and for that we need product, I don't think we would be } \\
\text { able to stop the consumption of any raw material. So to me, is circular economy. }\end{array}$ \\
\hline
\end{tabular}

A fala 41 (tabela 14) sintetiza um posicionamento que surgiu e encontrou ressonância em vários entrevistados, que se permitiria entendê-lo como posição utópica, de reflexão moral. Neste caso a sustentabilidade seria a busca por um mundo melhor. A busca por uma sociedade melhor para as gerações futuras. Seria agregar "valor não monetário" para o mundo. Obviamente, não se interessa discutir o que pode significar isso, mas, pelo contrário, é interessante trazer à tona quão ampla e individual pode ser a visão de mundo de cada ator social. Destaca-se esse posicionamento, pois ele traz uma visão de mundo do indivíduo. Alguns questionamentos podem derivar dessa posição: o quanto esse anseio por um mundo melhor é latente na vida desse indivíduo? É latente ao ponto de influenciar e impactar as práticas cotidianas? E as práticas e atividades no trabalho? Muito além de querer verificar o impacto que esse tipo de visão pode causar na estruturação das práticas dos indivíduos, por ora, destacam-se a existência de uma ligação entre sustentabilidade e certo posicionamento moral do indivíduo, por que não dizer, de um desejo utópico. Outro elemento que surgiu, diz respeito a associar a sustentabilidade com o nível de consciência do indivíduo. Neste caso, a fala 42 (tabela 14) expressa exatamente isso, ao elucidar que é uma questão de consciência saber o que é bom para o planeta. 
A própria definição daquilo que seria sustentabilidade aparece como algo relativo. As falas 43, 46 e 47 (tabela 14) expressam essa pluralidade latente sobre aquilo que seria sustentável. Vislumbra-se que tal constructo tem aparecido em diversas esferas da vida social. Fala-se de sustentabilidade no trabalho, nos meios de comunicação, na tratativa do lixo doméstico, na discussão sobre o clima, na questão ambiental... É de se esperar que o ator social, uma vez constituindo e sendo constituído pelos diversos sistemas sociais com os quais interage, adquira um repertório de elementos que permita reconhecê-los e formar a sua própria ideia sobre o que é sustentabilidade. Tal relatividade surgirá, pois o ator social observa os termos e atividades correlacionadas em diversos aspectos da sua vida social. Ainda, a fala 44 (tabela 14) expressa uma profunda reflexão a respeito da humanidade e sobre os limites da sustentabilidade. Demonstra e reconhece os aspectos sociais que também integram a discussão sobre sustentabilidade.

A fala 48 (tabela 14) dialoga diretamente com os esquemas interpretativos da inovação orientada para a sustentabilidade, e mostra, através da consciência discursiva, os argumentos sobre a causa de sempre se fazer um desenvolvimento destrutivo na era capitalista e como a sustentabilidade é vista com "maus olhos" por muitos setores da economia. Além disso, demonstra a rigidez da estrutura (que dialoga com a categoria agregada da agência), baseada nas experiências anteriores que, de certa maneira, legitimaram o status quo do desenvolvimento até os dias de hoje.

Por fim, destaca-se a fala 46 (tabela 14) como uma crítica direta à maneira de apropriação (presume-se que por parte de empresas) da sustentabilidade como uma temática harmoniosa para se venderem sejam quais forem seus produtos, sem o devido rigor na análise. Tal temática é bastante debatida na academia e é conhecida como o "green washing".

\subsection{Agência}

A última categoria agregada exibida é a agência do indivíduo. Trata-se de reconhecer que as atividades engendradas por cada indivíduo só se instanciam pelo mesmo através de suas agências. Tal categoria é importante, pois a estruturação

\footnotetext{
9 De acordo com o Oxford English Dictionary, "greenwash", ou "greenwashing" é a falsa informação disseminada por uma instituição para apresentar uma imagem pública de responsabilidade ambiental.
} 
das práticas se realiza justamente pela dualidade da estrutura, ou seja, pelo movimento recursivo agente-estrutura. A totalidade das práticas dentro do que é chamado de inovação tradicional acontece por meio dos indivíduos. De certa maneira, essa forma de fazer inovação (que em alguma análise, conduziu o desenvolvimento da sociedade capitalista a uma situação preocupante, em relação aos recursos naturais do planeta e não garantiu um nível de sustentabilidade social digno a uma grande parcela da sociedade) foi e é produzida/reproduzida por todos os atores envolvidos, sejam aqueles que desenvolvem a inovação, sejam os que compram e legitimam os produtos de inovação e, assim, por diante. Com a mesma lógica, a inovação orientada para a sustentabilidade terá sua estruturação e a emergência de suas práticas relacionadas a partir da agência dos atores. Não obstante, ainda que de maneira abstrata, os conceitos de segunda ordem mindset, rigidez da estrutura e hierarquia/posição permitem enxergar a agência como uma categoria emergente na estruturação da inovação orientada para a sustentabilidade.

\section{Mindset (mentalidade)}

O primeiro conceito de segunda ordem dessa categoria foi identificado como mindset. Este vocábulo tem sua tradução sugerida pelo Cambridge Dictionary ${ }^{10}$ como a palavra mentalidade. Neste trabalho, optou-se por utilizar a variante da língua inglesa, pois foi essa a exata palavra repetida e utilizada pelos diversos atores entrevistados.

Primeiramente, é importante pontuar que o mindset que surgiu das entrevistas trata-se de um mindset alheio ao ator social, ou seja, ao mindset do outro. Tal característica é retratada pelas falas 50 e 51 (tabela 15) onde se evidencia que 0 ator social pontua que o mindset "das pessoas" limitam certas atividades. Inicialmente provocados pelo roteiro, tal mindset apareceu como um bloqueio, uma dificuldade ao se fazer inovação com sustentabilidade. O mindset também aparece (mais explicitamente na fala 50 , tabela 15) como certa ignorância ou falta de consciência das pessoas. Poder-se-ia falar ainda da falta de mediação das atividades que fazem com que as pessoas não entendam como as relações sociais estão interligadas e, em última instância, como suas ações influenciam e impactam a

\footnotetext{
${ }^{10}$ https://dictionary.cambridge.org/dictionary/english-portuguese/mindset; Mentalidade é a maneira de uma pessoa pensar e suas opiniões
} 
vida de outras pessoas. A fala 51 (tabela 15) explicita claramente que essa falta de mindset é uma resistência muito grande ao se fazer uma inovação orientada para a sustentabilidade.

Tabela 15: Extratos das falas referentes ao Mindset

\begin{tabular}{|c|c|}
\hline Falas & AGÊNCIA / Mindset \\
\hline $\begin{array}{c}50 \\
E C 1-E\end{array}$ & $\begin{array}{l}\text { Os principais obstáculos são as próprias pessoas, como elas pensam. O problema é } \\
\text { que o futuro não é palpável. As pessoas não tem consciência que pode afetar elas. } \\
\text { Não pensam que pode afetar os meus filhos, netos. Como agora não está afetando, } \\
\text { não preciso fazer nada. É tipo um "dane-se" (sic) mesmo. } \\
\text { [...] O principal obstáculo é a mentalidade das pessoas. As pessoas pensam "se eu } \\
\text { fizer algo sustentável, qual o benefício?" As pessoas pensam no agora. }\end{array}$ \\
\hline $\begin{array}{c}51 \\
\text { EC2-R }\end{array}$ & $\begin{array}{l}\text { Eu estou tentando ser uma agente da inovação que carrega a sustentabilidade como } \\
\text { pilar, mas eu sinto uma resistência muito forte no mindset. Então eu não sou uma } \\
\text { pessoa que carrega a bandeira e sai falando isso e aquilo... mas eu tenho projeto } \\
\text { nessa linha. E é uma dificuldade muito grande, porque o mindset é muito difícil. } \\
\text { Então, eu gostaria de ter mais projetos na área de sustentabilidade, mas as pessoas } \\
\text { não estão abertas a isso }\end{array}$ \\
\hline $\begin{array}{c}52 \\
\text { EC1-E }\end{array}$ & $\begin{array}{l}\text { It's really a question of how everybody is positioning itself regarding this topic. You } \\
\text { can always claiming that political has to do something, companies has to do } \\
\text { something and so on. But in the end I think it's coming from people by themselves. } \\
\text { Ok, and then you can act in different level according to your position and you can act } \\
\text { in your personal life and in your professional life... ok? So my answer was really } \\
\text { dedicated to personal life, but personally I think that all it depends on how people are } \\
\text { paying attention to that. It's so easy to say that politics are not doing what they should } \\
\text { do, because you vote for them, so you know what you could expect for most. So, I } \\
\text { don't say that politician doesn't have enough, or any impact on that. }\end{array}$ \\
\hline
\end{tabular}

Nesta categoria, o que se quer destacar é o fato de a visão do mindset impactar a agência do ator social. Se por um lado, se exterioriza o mindset do outro como um fator limitante para uma prática, não se observa o contrário: o mindset como promotor de agência e impulsionador da recursividade agência-estrutura. Poder-se-ia dizer que tal mindset (o que enxerga o mindset das pessoas como restritivo) é legitimado e diminui a agência. No entanto, é de se ressalvar, que a limitação da agência encontra legitimidade ao longo das experiências do indivíduo. Não iremos explorar a maneira como o indivíduo enxerga essa limitação externa à sua agência, mas deixaremos como reflexão que a não agência (essa que poderia 
produzir / reproduzir novas práticas) pode advir de pura comodidade do agente, ou ainda, de uma consciência prática (tácita), respaldada pelas experiências de limitação da própria agência. Um exemplo que pode elucidar isso seria considerar um ator social que tentou, algumas vezes, fazer algo diferente (uma nova prática mais sustentável), por exemplo, trazer questões sociais referentes ao desenvolvimento de um produto. Se, quando esse tema foi proposto, ele não foi considerado, ou mesmo, não teve importância ou relevância para que se tomasse alguma decisão, o ator poderá entender que sua ação foi em vão, de pouca valia (fala 61, tabela 17). Esse fato, somado a outros eventos, estruturará, ou não, a prática de discussão de aspectos de sustentabilidade social. Nesse caso, a agência ficará limitada devido à experiência prática do indivíduo.

\section{Rigidez da estrutura}

Esse conceito de segunda ordem mantém uma relação bastante dinâmica com os outros dois conceitos que compõem a categoria de agência. De antemão, observa-se, na fala 56 (tabela 16), novamente, a questão de mindset. Como já descrito, tal mindset, posicionado e orientado ao outro com quem o indivíduo se relaciona para instanciar suas práticas, é um elemento que, aparentemente, limita a agência do ator. Neste caso específico, a categoria "rigidez da estrutura" tenta salientar os aspectos que engendram obstáculos à agência do ator. Tais obstáculos podem ser de ordem psíquica e são averiguados pela consciência discursiva dos atores ao se posicionarem. Quando estes afirmam que o mindset das pessoas é um obstáculo para práticas de uma inovação orientada para a sustentabilidade, estão de fato instanciando um discurso baseado em esquemas interpretativos que veem e compreendem a não estruturação das práticas como um efeito da rigidez causada pelo mindset de atores sociais.

Outro aspecto importante e que ressoa fortemente é trazido pela fala 53 (tabela 16) e salientada pela fala 54 (tabela 16). Trata-se da dinâmica empresarial e da forma de trabalho capitalista e da recorrente falta de tempo para se realizar algo diferente. Neste caso, a estrutura rígida é aquela na qual existem práticas bem legitimadas e na qual cada ator "sabe" o que tem de ser feito. Evidencia-se que novas práticas, por exemplo, práticas associadas à incorporação de aspectos de sustentabilidade, não são, à priori, tão importantes ao ponto de ocuparem o tempo 
das principais atividades do ator social. A fala 54 (tabela 16) é uma aula de sociologia oferecida pelo ator onde ele afirma que as práticas bem legitimadas (rotineiras), de certa maneira, são restritivas à emergência de novas práticas. Pela teoria da estruturação, poder-se-ia dizer que tais práticas institucionalizadas estão tão fortemente enraizadas que dificultam a emergência, através da dualidade da estrutura de novas práticas. Para Giddens (1984), as práticas que possuem maior extensão espaço-temporal, dentro da totalidade de um sistema social (neste caso, o sistema social da inovação), podem ser designadas como instituições, demonstrando seus altos níveis de legitimação.

A fala 55 (tabela 16) traz uma visão de rigidez da estrutura que pode ser bem mais entendida por uma análise no nível macro. Entende-se e extrapola-se a condição totalizadora para o engendramento das práticas da inovação. É o fato de se reconhecer que os atores, trabalhando com inovação, engendram práticas estruturadas no nível micro, mas que, ao mesmo tempo, organizam-se também por múltiplas estruturas de variados níveis de mediação (micro, meso e macro). Não se faz necessário refletir muito para entender que estruturas de nível macro influenciam as práticas instanciadas pelos indivíduos nos sistemas sociais micro. Uma política pública de redução de emissão de gases de efeito estufa pode ter efeito nas práticas de inovação por meioatravés da estruturação de práticas como, por exemplo, o cálculo do ciclo de vida de um produto, ou mesmo o cálculo anual da emissão de gases por uma empresa. Além disso, tal fala traz à tona uma problemática da ordem social ligada à vida política e sua dinâmica. Ela realça o caráter político da vida em sociedade e sua influência no nível macro em "organizar" a vida social e, por que não dizer, em estruturar os sistemas sociais. Dessa maneira, reconhece-se a importância da ordem política na estruturação de práticas nos sistemas sociais. É de suma importância reconhecer tal fato, pois a análise e articulação entre os níveis macro e micro, em ciências sociais, é problemática e, como o próprio Giddens (2013) assumiu, há de se ter cuidado para articular esses dois domínios. Enquanto nas práticas em si, engendrada pelo indivíduo, podemos falar de um "domínio micro", não se pode negligenciar a influência do domínio macro (campos). Por uma razão metodológica, este trabalho limitou-se em analisar a estruturação das práticas em inovação dos agentes envolvidos nesse processo e, para tanto, assumiu-se uma análise no nível micro. No entanto, entendeu-se que não há limites claros entre esses dois domínios, a ponto de uma análise específica da atividade do indivíduo 
poder ser analisada por uma lente teórica micro (comopor exemplo, a teoria da estruturação) ou por uma lente teórica macro (por exemplo a teoria de campos).

Tabela 16: Extratos das falas referentes à rigidez da estrutura

\begin{tabular}{|c|c|}
\hline Falas & AGÊNCIA / Rigidez da Estrutura \\
\hline $\begin{array}{c}53 \\
\text { EC1-R }\end{array}$ & $\begin{array}{l}\text { I could have a strong influence on that, push for it. If I would have time to think about } \\
\text { it. And to really take a step back on the different projects. I could have in my position, } \\
\text { and for me that's why I say that managers should be promoters of that to make sure } \\
\text { that the question is always asked and is part of the decision making if you have to } \\
\text { prioritize things and there is different... But today, in the company we don't have time } \\
\text { to take any care about that. }\end{array}$ \\
\hline $\begin{array}{c}54 \\
\text { EC1-U }\end{array}$ & $\begin{array}{l}\text { Um problema é a falta de recursos. Você tem a sua rotina. Ela precisa ser feita. Sem } \\
\text { gente suficiente, você acaba dividindo a rotina com as outras pessoas do laboratório, } \\
\text { mas não sobra tempo para outras coisas que não realizar as atividades rotineiras. } \\
\text { As atividades rotineiras entram na sua cabeça e você não consegue enxergar como } \\
\text { fazer algo diferente, mas isso é para tudo, na vida também. A rotina evita que você } \\
\text { faça as coisas diferentes. }\end{array}$ \\
\hline $\begin{array}{c}55 \\
E C 1-E\end{array}$ & $\begin{array}{l}\text { Para mim é vontade política. Nós não temos um presidente (na França ou em } \\
\text { qualquer país)... Eu não vejo um presidente corajoso, que tome decisões de fato, que } \\
\text { controle a economia. Nós temos a impressão que controla a economia, mas a } \\
\text { posição corajosa... eles dizem que nós já temos... de fato é a sociedade que paga os } \\
\text { impostos na França que seria uma fonte de dinheiro que permitiria fazer ou se } \\
\text { "ocupar" da problemática ambiental, desenvolver a inovação, todas essas coisas, } \\
\text { mas não há coragem política, para taxar as grandes empresas sobre os seus } \\
\text { impactos ambientais, a taxa e carbono é uma piada, é uma piada a taxa de carbono, } \\
\text { é bonita, mas é uma piada. Alguém compra, mas isso não muda nada... por que se } \\
\text { trocam as autorizações de carbono, etc... mas é uma piada isso. É somente para } \\
\text { fazer parecer. Nisso seria necessário obrigar as grandes empresas químicas, a } \\
\text { contribuir com um imposto, uma contribuição de participação, que comece pelo } \\
\text { menos pagando os impostos (devidos) e em seguida, ter que as grandes empresas e } \\
\text { ter o engajamento real / verdadeiro da classe política, do governo, sobre a redução } \\
\text { de uma certa quantidade de consumo de água, de consumo de energia, e depois, } \\
\text { selecionar, para ver se há mesmo esse engajamento. Mas para mim, nesse } \\
\text { momento é a vontade politica, e não há vontade política. Nós estamos lá, a gente faz } \\
\text { o balanço, as coisas, a gente faz a CoP } 21 \text {, nós estamos contentes, e depois nós } \\
\text { vamos fazer o futebol no Qatar em um estádio climatizado. Então, onde está a } \\
\text { coerência? Não há coerência. É isso. Não existe coragem política. }\end{array}$ \\
\hline
\end{tabular}




\begin{tabular}{|c|c|}
\hline EC2-F & $\begin{array}{l}\text { A gente tem uma resistência muito grande no nosso trabalho, e que pra mim é } \\
\text { exatamente isso. É o impacto da sustentabilidade, das pessoas terem dificuldade de } \\
\text { entender e de querer, não de trabalhar com a gente, mas ter o nosso produto, o } \\
\text { nosso processo, independente de nós como pessoas, mas o produto deles, da } \\
\text { mudança dos produtos deles, de trazer algo mais sustentável. Isso é uma } \\
\text { resistência, não é uma vontade. } \\
\text { Da onde vem essa resistência? Mindset total... eu sinto que a resistência na América } \\
\text { do Sul é muito maior do que fora, Estados Unidos, Europa. Por exemplo, como } \\
\text { nossas decisões tem sempre uma ponte aqui perto antes de ir pra alguém mais alto } \\
\text { escalão na Europa é difícil passar aqui, mas as vezes quando isso chega lá, a } \\
\text { pessoa fala "por que isso não chegou aqui antes?/ por que isso ainda não estáa } \\
\text { acontecendo?" entendeu?, então eu vejo que a questão cultural aqui no Brasil tem } \\
\text { um peso ainda maior na minha visão de companhia do que quando, por exemplo, } \\
\text { vem uma decisão da Europa. O impacto cultural é muito forte nesse mindset. }\end{array}$ \\
\hline $\begin{array}{c}57 \\
\text { EC1-H }\end{array}$ & $\begin{array}{l}\text { Isso quer dizer que é seguir, aceitar passar o tempo, e que as equipes sigam umas } \\
\text { as outras, é também os recursos. É uma parte de ter uma ordem de prioridades, é } \\
\text { ser capaz de assumir riscos. Pra mim é isso. Nós temos } 25 \% \text { de termos êxitos. Então } \\
\text { se não testamos, não podemos ter êxito. [...] Na França não há muita gente que } \\
\text { assumi o risco. É bem complicado. Isso quer dizer, a gente coloca na tabela de } \\
\text { recurso com } 25 \% \text { de chances de sucesso... É corajoso... mas ninguém o faz } \\
\text { verdadeiramente. Mesmo que nisso a gente não consiga ter êxito, ainda se pode } \\
\text { capitalizar sobre um novo saber, e outras coisas. E é isso que faz avançar. Para mim } \\
\text { é isso: abertura de mente, saber assumir risco, e não ter o medo de se enganar. }\end{array}$ \\
\hline
\end{tabular}

\section{Posição social / Hierarquia}

Este último conceito de segunda ordem associado à agência, surgiu, principalmente, como respostas às perguntas $R$ e $P$ do roteiro (tabela 5). Basicamente, os atores sociais foram indagados sobre o papel de cada um na promoção de uma inovação orientada para a sustentabilidade; se eles enxergavam que pessoas ocupando posições diferentes teriam responsabilidades diferentes e, também, o que poderia ser feito para incluir / estruturar novas práticas mais sustentáveis no processo de inovação. As respostas foram diversas e plurais, elucidando alguns aspectos. 
Tabela 17: Extratos das falas referentes à posição social / hierarquia

\begin{tabular}{|c|c|}
\hline Falas & AGÊNCIA / Posição Social / Hierarquia \\
\hline $\begin{array}{c}58 \\
\text { EC1-P }\end{array}$ & $\begin{array}{l}\text { The people in contact with the customers. They have to promote sustainability at the } \\
\text { customers. Management has to be a promoter internally, to make sure that we always } \\
\text { keep this a "motor" in our minds and then everyone is an actor, for sustainability. To } \\
\text { make sure that everyone is an actor, you have to have some promoters that bring } \\
\text { that, and then the new comers, will come with the mentality if they are depending the } \\
\text { training they have received. }\end{array}$ \\
\hline $\begin{array}{c}59 \\
\text { EC1-R }\end{array}$ & $\begin{array}{l}\text { Eu acho que não tenho influência. Porque é contextual. Trabalho no laboratório de } \\
\text { aplicação, recebo as demandas, os estudos dos projetos... A gente vai lá e faz... } \\
\text { Pode ser um projeto inovador, mas aqui nas nossas atividades não é muito levantado } \\
\text { a questão de sustentabilidade. Eu acho que nunca levantei essa questão... é uma } \\
\text { questão ampla. }\end{array}$ \\
\hline $\begin{array}{c}60 \\
\text { EC1-P }\end{array}$ & $\begin{array}{l}\text { Cada vez é uma balança. Quanto mais você sobe, mais será a lógica financeira e } \\
\text { econômica que vai predominar. Assim, é por isso que se não houver uma regra bem } \\
\text { posta nesse nível com o engajamento obrigatório da GBU, de fazer os esforços, e os } \\
\text { resultados da GBU... onde os resultados da GBU serão vistos sob esses critérios (de } \\
\text { sustentabilidade), como um plano de ação de } 10-15 \text { anos obrigando a GBU a fazer } \\
\text { os esforços, ninguém o fará. Depois, você pode fazer algo no nível individual, e você } \\
\text { pode fazer isso, mas globalmente, não há uma lógica global, de interesse nisso. Por } \\
\text { que isso não é o dinheiro que virá rapidamente. É alguma coisa que você faz, um } \\
\text { engajamento de médio prazo, de longo prazo... Não é rentável agora. O quê lhes } \\
\text { interessa é a rentabilidade rapidamente, agora. Assim, tem pessoas que pensam } \\
\text { dessa forma e por alcançar essa lógica. Então, eu não vejo no alto nível uma } \\
\text { vontade clara, mesmo coercitiva, que quer dizer "na GBU você não está contente } \\
\text { com o engajamento com a ferramenta, mas verdadeiramente a sustentabilidade, } \\
\text { então, vocês vão receber zero de nota (bônus) por que vocês haviam dito que iriam } \\
\text { melhorar em tanto (\%) vosso consumo e vocês não fizeram, assim, a nota da GBU } \\
\text { será zero". Se tivesse realmente coisas como essas, eu acho que nós } \\
\text { enfrentaríamos melhor o problema, mas no mais alto, não... porque não é isso que } \\
\text { Ihes interessam. É uma cobertura. É falso, é uma hipocrisia. }\end{array}$ \\
\hline $\begin{array}{c}61 \\
\text { EC2-R }\end{array}$ & $\begin{array}{l}\text { Eu acho que é bastante grande, uma vez que a gente está na base assim, na criação } \\
\text { das oportunidades, no "launch" assim dos projetos, tudo aquilo assim que os líderes } \\
\text { vão ver depende da gente, mesmo nessa questão de aprovação, de de puxar um } \\
\text { pouco mais para as métricas de sustentabilidade, a gente precisa medir isso, precisa } \\
\text { identificar esse tipo de atributo, pra que isso de fato seja valor, e que quando você } \\
\text { apresenta isso de uma forma correta pra quem tem o poder de aprovação, fica muito } \\
\text { claro pra ele tomar a decisão. Mas tudo isso, você tem que puxar. Você escolhe os } \\
\text { dados e você escolhe a ênfase para que o projeto se desenvolva. E uma vez que a }\end{array}$ \\
\hline
\end{tabular}




\begin{tabular}{|c|l|}
\hline EC2-P & $\begin{array}{l}\text { gente está na base, e trabalha nessas duas interfaces é... andando com o projeto } \\
\text { que vem a partir de uma demanda da GBU ou muitas vezes começando do começo } \\
\text { assim, vendo a oportunidade e progredindo com isso, é a gente que faz essas } \\
\text { métricas e que tenta puxar um pouco pra sustentabilidade para que as lideranças } \\
\text { consigam pelo menos enxergar isso, consigam enxergar essa diferenciação. }\end{array}$ \\
\hline 62 & $\begin{array}{l}\text { Eu diria que deveria no sentido de que quem está na frente da tomada de decisão } \\
\text { deveria se preocupar mais, se isso de fato fosse uma preocupação. E na realidade é } \\
\text { o inverso. Na base os operadores, pesquisadores, técnicos, se preocupam muito } \\
\text { mais do que a ponta que é quem vai tomar decisão em cima daquilo [...] eu vejo que, } \\
\text { por exemplo, no Brasil hoje a preocupação dos novos produtos e novos projetos não } \\
\text { tem a carga da sustentabilidade. Então isso não vai pra mesa de negociação dos } \\
\text { projetos. E é um tipo de discussão que você não consegue levar de baixo pra cima... } \\
\text { tipo, a pessoa tá preocupada em vender. Nno mercado hoje ela acha que isso não } \\
\text { tem peso, então, internamente ela também não carrega isso como algo importante. } \\
\text { Não vou dizer é 100\%, é claro. O próprio Brasil tem hoje iniciativas que são pesadas } \\
\text { baseadas em sustentabilidade como o produto X. Mas isso é mais a exceção do que } \\
\text { a regra. }\end{array}$ \\
\hline
\end{tabular}

Primeiramente, os diferentes atores reconheceram o que chamou-se de posição social dentro de um dado sistema social. Neste caso, cada ator ocupa uma posição no trabalho (como detalhado no estudo de caso) e tal posição condiciona (ao menos na consciência discursiva) o nível de agência de cada ator em relação às práticas que este instanciará. Exemplificando, a fala 58 (tabela 17) expõe que os principais atores em promover a inovação orientada para a sustentabilidade seriam aqueles que têm contato com clientes e os atores que ocupam posições de gerência (também realçada pelas falas 60 e 62, tabela 17). Os primeiros serão aqueles que irão propor a inovação aos clientes, ou mais importante ainda, entenderão quais são as necessidades de um dado cliente para, a partir disso, "alimentar" a área de inovação para que eles possam desenvolver a inovação. Os segundos serão aqueles que, de fato, tomam decisões e que, em decorrência disso, estruturam práticas através de sanções e regras. Neste último caso, o conceito de poder e alocação de recursos são conceitos importantes da teoria da estruturação que auxiliam a entender melhor tal dinâmica. Vislumbra-se, nesta descrição, a questão de hierarquia condicionando a agência do ator, ou seja, o esquema interpretativo de certas práticas (por exemplo: a prática de tomar uma decisão) deve respeitar uma ordem simbólica e práticas de hierarquia entre os agentes envolvidos nas práticas de 
inovação. A fala 59 (tabela 17) corrobora essas duas observações de posição social e hierarquia. Ela traz o relato de um técnico, posicionando que ele acredita em não ter influência no processo de inovação. Ele realiza atividades sob demanda e sua agência é limitada a práticas já bem estabelecidas e legitimadas.

A fala 60 (tabela 17) também reconhece a posição social dos atores como um fator influenciador na dinâmica de estruturação das práticas em inovação. Ela revela uma visão pessoal de que, quanto mais alta a posição de um ator na hierarquia da empresa (posições de diretoria, gerência etc), mais os aspectos econômicos serão vistos como as principais métricas a serem buscadas e atingidas por esses atores. Há ainda uma crítica e certa proposição de que o comprometimento da alta hierarquia poderia servir como estruturação das práticas ao longo da empresa. Por exemplo, a fala 60 (tabela 17) traz a reflexão hipotética de se colocar na remuneração de cada membro da alta hierarquia uma meta ligada à sustentabilidade. Obviamente, uma decisão como essa levaria à estruturação de práticas, mediante aplicações de sanção e uso de poder (alocação de recursos). que soa interessante são o discurso e clareza de como alguns elementos são estruturantes de novas práticas, neste caso, seria a meta de algo em detrimento a um desejo pessoal (alcance de maximizar o bônus dos empregados que ocupam altos cargos de gerência).

A fala 61 (tabela 17) destoa um pouco das demais, levando o ator a se sentir como agente da inovação e responsável por influenciar e estruturar as práticas da inovação orientada para a sustentabilidade. Neste caso, trata-se do segundo caso associado ao laboratório de biotecnologia onde todos os projetos nascem com 0 conceito de sustentabilidade, ou ao menos essa é uma carga simbólica que emerge dos discursos dos entrevistados. Assim sendo, a posição hierárquica é invertida e entende-se que são os atores da base os responsáveis por mostrar o valor da sustentabilidade. 


\title{
5 DISCUSSÃO
}

"Buenas Noticias:

la tierra se recupera en un millón de años

Somos nosotros los que desaparecemos" (Ecopoemas, Nicanor Parra ${ }^{11}$ )

\begin{abstract}
A seção precedente trouxe os principais resultados do estudo de caso e iniciou uma discussão sobre a estruturação da inovação orientada para a sustentabilidade através da identificação de quatro categorias agregadas. Nesta seção, é realizada uma análise profunda sobre tal estruturação e é discutido um modelo proposto mediante a análise dos resultados. A seção se estrutura a partir de uma breve articulação entre objeto de pesquisa, objetivo da mesma e o modelo proposto. Em seguida, quatro tópicos são discutidos, sendo o tópico 5.2 .2 o principal pilar deste trabalho. Por fim, realiza-se uma síntese.
\end{abstract}

\section{Breve articulação}

O objetivo da pesquisa foi compreender a dinâmica de estruturação das práticas sociais dos processos de inovação orientados para a sustentabilidade. $O$ grande foco deste trabalho foi as práticas sociais, ou seja, as praticadas pelos indivíduos, uma vez que uma prática é alguma atividade / ação instanciada pelo ator social. A lente teórica utilizada é a teoria da estruturação de Giddens (1984). Ela suporta a discussão de como as práticas são estruturadas e se instanciam pelos indivíduos.

$\mathrm{Na}$ seção 2.2, foram apresentados alguns modelos de processo de inovação. Eles são compostos de várias etapas onde várias pessoas interagem e realizam certas atividades. De um ponto de vista micro, uma prática simples (se se pensar no processo de inovação, isso poderia representar a participação em uma reunião, o preenchimento de dados econômicos de um documento que será discutido, a realização de um teste de laboratório, uma apresentação da ideia para os gerentes ou mesmo clientes...) está estruturada como o modelo apresentado na seção 2.3.1, figura 17. Este comentário se faz necessário, pois nesta discussão, sempre que se

\footnotetext{
${ }^{11}$ Acesso em https://www.nicanorparra.uchile.cl/antologia/ecopoemas/ecopoemas.html
} 
fala de práticas, considera-se este modelo, no qual a prática instanciada pelo ator se estrutura mediante regras e recursos, e tal estruturação se dá por meio de certas modalidades da estrutura (facilities, normas e esquemas interpretativos). Ainda, tais estruturas são compostas de aspectos de significação, dominação e legitimação, que envolvem o indivíduo ao longo das interações que o mesmo tem com o sistema, considerando-se o espaço e o tempo em que se insere.

Dessa maneira, a síntese do trabalho que tenta se aproximar do objeto da inovação orientada para a sustentabilidade é um modelo que será apresentado no próximo tópico. Este modelo incorpora principalmente relações no nível micro, mas não ignora que existam relações no nível macro e tenta descrever como está se realizando a estruturação das práticas em inovação orientada para a sustentabilidade, com base no que foi verificado no estudo de caso. Tal modelo pode, previamente, ser entendido da seguinte forma: ele é a matriz em que as práticas se estruturarão. A prática que se instancia como a figura 17 elucida, ocorre dentro dessa matriz de estruturação, representada pela figura 24. Tal modelo reflete o movimento que há no processo de inovação.

\subsection{O modelo}

Antes de discutir e apresentar o modelo, é valido ressalvar algumas limitações do mesmo. O objetivo de pesquisa está relacionado a um fenômeno macro que é o processo de inovação de grandes empresas. Dessa forma, o modelo poderia trazer a conotação de ser algo genérico e de ser aplicável a vários processos reais. No entanto, este modelo foi criado a partir de um estudo de caso concreto de uma empresa do setor químico que posiciona sua área de inovação como uma promotora de sustentabilidade. Assim, qualquer generalização de como ocorre a estruturação das práticas de inovação, precisa ser realizada com bastante cautela. Acredita-se que o movimento de estruturação, descrito no modelo, pode ser entendido como algo mais amplo e aplicado a diversos outros casos reais de inovação, porém, salienta-se a explícita colaboração específica do estudo de caso para a elaboração deste modelo. Resumidamente, tal modelo pode ser instrumento teórico para analisar outros casos de inovação, porém, cada caso é digno de suas próprias especificidades e, certamente, apresentam elementos que não surgiram e não compõem o modelo apresentado na figura 24. 
Figura 24: Modelo de estruturação da inovação orientada para a sustentabilidade

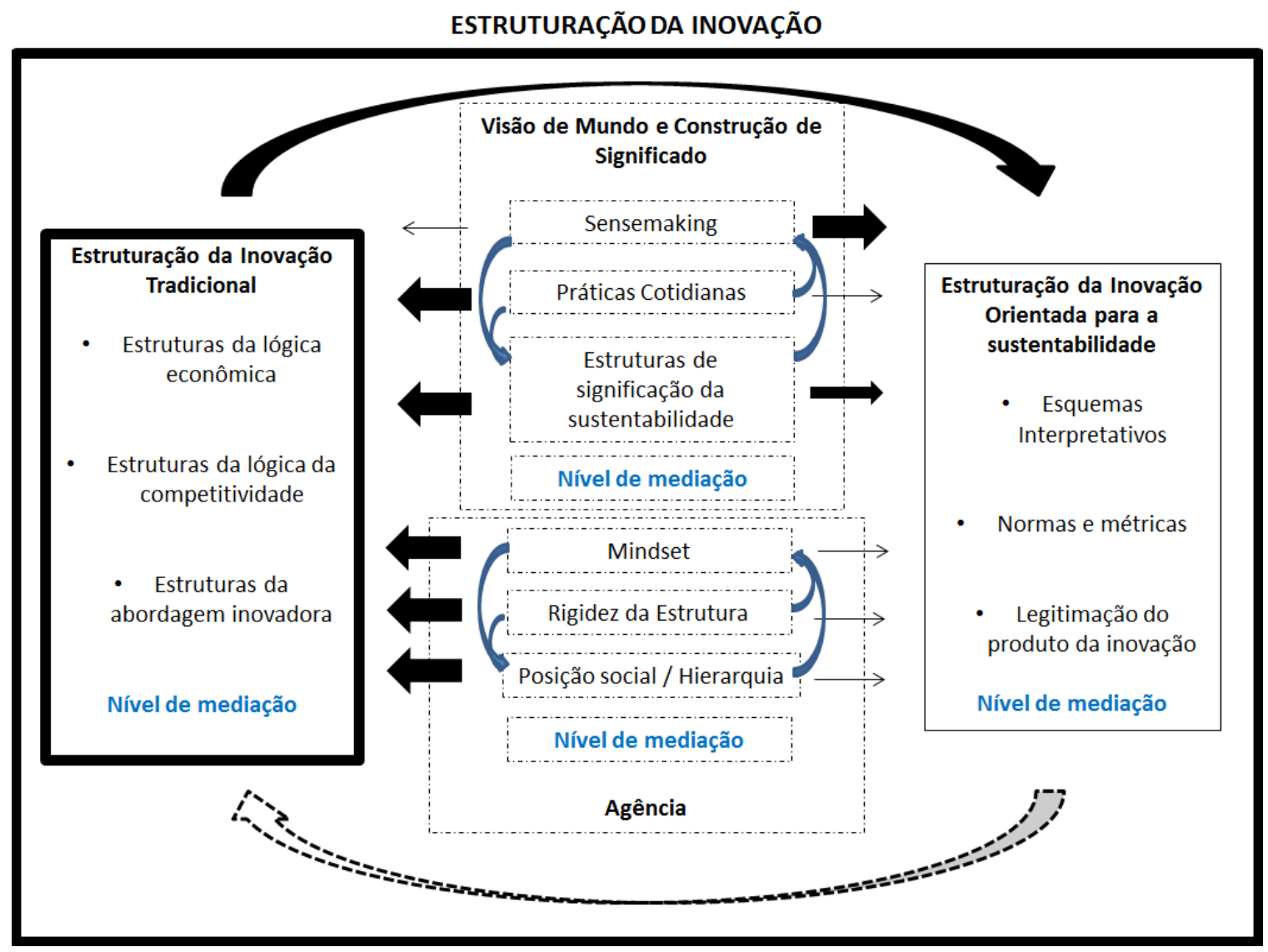

Fonte: Autor

O modelo (figura 24) propõe de que modo se realiza a estruturação das práticas em inovação. Ele é fruto da conjugação das categorias agregadas quando entendidas dentro de um fenômeno dinâmico, no qual os atores sociais estão imersos. O modelo tenta descrever esse movimento de estruturação das práticas. Para tanto, qualquer prática que possa ser identificada no processo de inovação, poderia ser entendida como acontecendo nesse contexto estruturante. Considerando o objetivo deste trabalho, o modelo retrata e traz elementos de sustentabilidade e sua dinâmica na estruturação das práticas.

Primeiramente, uma prática em inovação estará sujeita a uma estruturação bastante legitimada, que foi identificada como a categoria de estruturação da inovação tradicional. Os elementos de estruturação mais evidentes foram identificados como os conceitos de segunda ordem: estruturas da lógica econômica, estruturas da lógica da competitividade, estruturas da abordagem inovadora e um elemento mediador que é identificado como nível de mediação (conceito detalhado e explicitado no item 5.3). Em seguida, identifica-se a categoria estruturação da 
inovação orientada para a sustentabilidade. Em relação a essa categoria, identificaram-se os conceitos de segunda ordem: esquemas interpretativos, normas e métricas e legitimação do produto da inovação. Está presente também um elemento de mediação. Na estruturação de ambas as práticas (inovação tradicional e inovação orientada para a sustentabilidade), surge uma categoria muito importante ligada à agência do ator social. Nesta categoria emergiram os conceitos de mindset, rigidez da estrutura e posição social / hierarquia. Por último e sustentado pelo objetivo deste projeto de pesquisa, há uma categoria identificada como visão de mundo e construção de significado. Tal categoria expressa uma posição bastante individual de cada ator em que os conceitos / subcategorias que surgiram foram sensemaking, práticas cotidianas e estruturas de significação da sustentabilidade. Nestas duas últimas categorias também há elementos de mediação. Embora a seção 5.3 traga a discussão sobre o nível de mediação representado nas quatro categorias identificadas, vale ressaltar, por ora, que o mesmo refere-se a uma dimensão da complexidade das práticas que se estruturam tensionando a intenção da ação e sua instanciação.

Tal modelo traz as estruturações da inovação tradicional e da inovação orientada para a sustentabilidade como caixas em linhas contínuas simplesmente para a visualização do fenômeno. As setas que ligam tais estruturações tentam descrever que não há separação evidente entre elas, mas sim, princípios estruturantes divergentes. A espessura das linhas contínuas traz um elemento de legitimação. Baseado nos estudo de caso, observou-se que as estruturas da inovação tradicional são muito mais legitimadas, ao longo do tempo, pelos atores envolvidos, do que as estruturas da inovação orientada para a sustentabilidade. As categorias presentes no centro do modelo (visão de mundo e construção de significado e agência) são assim dispostas, pois elas suportam e influenciam as estruturações de ambas as inovações. Dessas duas categorias, setas indicando o peso legitimador de seus princípios estruturantes para cada estruturação da inovação são representadas pela espessura das mesmas. Por exemplo, as práticas cotidianas (conceito presente na visão de mundo e construção de significado) legitimam muito mais a estruturação da inovação tradicional do que a estruturação da inovação orientada para a sustentabilidade. Ao contrário, a noção de sensemaking surgida das entrevistas, suporta e legitima muito mais a estruturação da inovação orientada para a sustentabilidade. 
Por fim, dentro dessas duas categorias suportadoras / estruturantes as setas entre os conceitos / subcategorias querem representar que não há uma separação entre elas. Deve-se entender a coexistência de múltiplas estruturas impactando e estruturando as práticas individuais. Isso ficou evidente na análise das falas dos entrevistados, onde certa fala poderia ser entendida a partir de conceitos de segunda ordem distintos.

\subsection{A estruturação da inovação orientada para a sustentabilidade}

A instanciação de uma prática ocorre mediante estruturas (regras e recursos) que são mediadas pelas modalidades da estrutura, a saber, os esquemas interpretativos, as normas e as "facilities". Toda prática traz uma carga de significação, legitimação e dominação. Dessa maneira, a evidência de uma possível estruturação da inovação orientada para a sustentabilidade deve ser suportada pela identificação de princípios estruturantes dessas novas práticas. Como já foi apresentado anteriormente, este estudo não buscou entender se um processo de inovação que se apresenta como orientado para a sustentabilidade é de fato, ou poderia ser considerado, sustentável. O grande objetivo deste estudo é enxergar a dinâmica de estruturação de novas práticas que podem, potencialmente, modificar o processo de inovação tornando-o mais próximo de um processo de inovação orientado para a sustentabilidade. Dessa maneira, o modelo proposto coloca em evidência dois processos de estruturação (inovação tradicional e inovação orientada para a sustentabilidade) que coexistem e se produzem/reproduzem pelas práticas instanciadas pelos atores envolvidos no processo. As modalidades da estrutura que mediam a instanciação das práticas de uma inovação orientada para a sustentabilidade são evidenciadas, principalmente, pelas categorias de visão de mundo e construção de significado e a própria estruturação da inovação orientada para a sustentabilidade, com as suas subcategorias, esquemas interpretativos, normas e métricas e legitimação do produto sustentável.

Para se aproximar da estruturação da inovação orientada para a sustentabilidade é imprescindível situar qual é o ponto de partida. Não é possível definir-se um momento, um marco zero. As falas demonstram que as experiências anteriores dos indivíduos dialogam fortemente com uma maneira (práticas) de fazer inovação tradicional. Tal inovação tradicional apresenta uma estruturação muito 
latente que traz uma rígida visão do fazer inovação. Essa composição coloca e transforma a ação do indivíduo com aspectos fortemente enraizados de significação, de dominação e de legitimação. Isso quer dizer que o indivíduo tem a construção de significados (porque fazer inovação, quais atividades cumprir, como fazer...), o meio pelo qual fazer (dominação) e a legitimação de tais práticas muito influenciados por experiências que acompanham a sua vida no trabalho com processos e práticas de inovação (observação participante e falas 3, 4, 7, 11, 41 e 54, contidas nas tabelas $6,7,14$ e 16). Ou seja, se fosse possível auferir, verificar-se-ia que o indivíduo que trabalha com inovação tem, em seu passado, a realização de inúmeras práticas que se estruturam e dinamizam a inovação tradicional. São práticas como, a participação em reuniões, preparação de apresentações com os dados relevantes para projeto, constatação de aprovações ou reprovações de projetos após avaliações quanto ao cumprimento de requisitos (econômicos, por exemplo) etc. Ao final, todas essas práticas proporcionam elementos que oferecem significação a respeito de como atuar ao fazer inovação. Ao levar em conta sua experiência, o ator social vê e incorpora práticas que são legitimadas ao longo da sua própria existência. Quaisquer ideias, práticas que falhem, provavelmente não se estruturam ao longo do tempo, por ausência de legitimação.

Como resultado das entrevistas e da estruturação do modelo proposto, evidenciou-se que as estruturas da inovação tradicional apresentadas e discutidas por meio dos conceitos de segunda ordem (lógica econômica, lógica da competitividade e lógica da abordagem inovadora) são muito mais presentes e engendram e legitimam a maioria das práticas em inovação. Isso representa uma barreira / rigidez da estrutura para o surgimento de novas práticas que apresentem outras estruturas (esquemas interpretativos e normas) e estejam alinhadas com os princípios de sustentabilidade (fraca ou forte).

É importante destacar o alto grau de polissemia do conceito sustentabilidade. Cada indivíduo traz suas próprias convicções a respeito do constructo e, de certa maneira, este amplo esquema interpretativo dificulta a estruturação de novas práticas. Se sustentabilidade é enxergada como a eficiência de recursos e redução de utilização dos mesmos (falas 17 e 18 da tabela 9 e fala 24 da tabela 10), as práticas em inovação se estruturarão de certa maneira, porém, se sustentabilidade é entendida como redução de consumo (fala 36 da tabela 12 e falas 45 e 49 da tabela 14) e, potencialmente, as empresas precisam diminuir sua produção (possivelmente 
diminuir seus ganhos também), será instaurado um conflito entre a empresa, que quer obter lucros e a ação, voltada para a promoção da inovação orientada para sustentabilidade. Assim, a complexa estruturação das práticas da inovação orientada para a sustentabilidade apresenta um alto grau de divergência e abstração. Se por um lado, são claras as forças motrizes para se fazer a inovação tradicional (gerar lucro, manter competitividade e etc - falas 1, 2, 3 e 4, tabela 6), as correspondentes em uma inovação orientada para a sustentabilidade não o são.

A evidência de que está em curso um processo de estruturação de inovação orientada para a sustentabilidade é revelado pela categoria da visão de mundo e construção de significados e pelos conceitos de segunda ordem da categoria de mesmo nome. Nota-se o posicionamento discursivo dos atores sociais com uma preocupação (no nível discursivo) sobre questões de sustentabilidade e suas indagações e visualizações de conflito (práticas cotidianas, normas e métricas, legitimação do produto da inovação). A reflexão de Bursztyn e Bursztyn evocada na fundamentação teórica auxilia na aproximação com este fenômeno: "se todos estão a favor, então quem está contra?" (BURSZTYN e BURSZTYN, 2013 p. 32).

A categoria visão de mundo e construção de significado é de suma importância, pois ela revela alguns pressupostos básicos da ação do agente social. Embora possa parecer óbvio, é importante salientar que o ator individual tem uma vida fora do ambiente de trabalho, neste caso analisado, fora do ambiente da inovação. Nesta vida (longue durée, neste caso o termo com o significado atribuído por Giddens,1984), cada indivíduo está imerso em diferentes sistemas sociais e reproduz/produz práticas diversas que estão estruturadas na sociedade. Essas estruturas impactam as atividades laborais que cada indivíduo instancia. A visão da teoria da estruturação focaliza-se sob um aspecto importante da ação que é a sua legitimação ao longo do tempo, a saber: uma prática pode ser analisada melhor, não em sua singular instanciação num dado momento, mas na sua reprodução dentro de um espectro de tempo maior, ou seja, na sua legitimação e repetição, ao cabo de transformar-se numa ação rotineira.

Outro ponto importante da teoria da estruturação é a monitoração reflexiva do agente e sua cogniscidade, ou capacidade de se posicionar de maneira discursiva (racionalização da ação) para explicar a motivação das suas ações. O ator individual carrega, ao longo de sua trajetória, uma somatória de experiências que lhe permite, como o próprio Giddens afirma, ser um sociólogo por excelência. Em outras 
palavras, ele é capaz de explicar como a sociedade em que vive funciona, suas razões de ser e suas práticas cotidianas. Esse ator tem por experiência própria, após anos de vivência em certas coletividades, várias estruturas enraizadas, que se expressam por meio de uma consciência prática e discursiva. Poder-se-ia dizer que, quanto mais natural uma prática parecer, ao ponto de se identificá-la como ação pragmática, mais enraizadas estarão as estruturas que lhe dão dinamicidade. Giddens intitula essas práticas de instituições: "Aquelas práticas que possuem a maior extensão espaço-temporal, dentro de tais totalidades, pode sem ser designadas como instituições" (GIDDENS, 2013, p. 20). Se tomado como exemplo a experiência econômica que os indivíduos da sociedade capitalista enfrentam, poderse-ia dizer que a noção de ter dinheiro para sobreviver beira a obviedade. Porém, num sentido bem objetivo, o fato de ter dinheiro não significa propriamente a sobrevivência do ser animal. Esta noção, em última análise, está mais atrelada ao fato de se obter energia (através de alimentos) para manter a dinâmica do corpo funcionando. No entanto, nos sistemas sociais dos coletivos humanos, houve e se legitimou uma estruturação de que obter e ter dinheiro é um meio simbólico de troca pelo recurso material que supre a necessidade da sobrevivência.

Outra observação crucial é o fato de que a estruturação de uma inovação orientada para a sustentabilidade abre um caminho novo para a ação do ator, uma vez que coloca em evidência a visão de mundo que o mesmo tem. Para tal discussão, assumam-se as estruturas da inovação tradicional. Um ator social que trabalha com inovação e tem suas práticas estruturadas pela estruturação da inovação tradicional, encontra na lógica econômica e na lógica da competividade seu posicionamento discursivo do motivo de fazer inovação (exemplos nas falas 3, 4, 8 e 9, tabelas 6 e 7). Trata-se de um posicionamento com referência a algo que, de certa maneira lhe é externo, ou seja, seu posicionamento se realiza sob a ótica da empresa e não na pessoal. Dessa maneira, o posicionamento discursivo descreve as práticas de uma entidade virtual (existente naquele contexto) e inanimada, a saber, a empresa. Atribui-se à empresa as razões das práticas vigentes e não às pessoas que fazem parte da mesma. Nessa perspectiva, os indivíduos vislumbram uma visão de mundo onde a empresa está inserida e estruturada, onde a inovação serve para a sobrevivência da empresa, para ela se manter em posição de liderança, para ela vender e gerar lucro... Em dizeres explícitos "It's to grow and to make sure that the company grows in a business perspective" (extrato da fala 3 , referente à 
pergunta $\mathrm{J}$ sobre o papel da inovação presente na tabela 6). Nessa lógica, a visão de mundo do indivíduo e o que lhe interessa como ser humano e sua relação com outros indivíduos não devem interferir tanto na estruturação de suas práticas no trabalho de inovação, pois a motivação da inovação é clara (falas 1, 2, 3 e 4, tabela 6). Poder-se-ia dizer que há certa harmonia nessa dinâmica, pois a visão mais ampla do indivíduo não é requisitada ou acessada na instanciação de suas práticas no trabalho. De maneira mais direta ainda, é como dizer o seguinte: ainda que um indivíduo entenda e se compadeça da brutal desigualdade social que exista na sociedade contemporânea, tal posicionamento (esquemas interpretativos) não entra na estruturação da inovação tradicional. É neste ponto em que a visão de mundo mais abrangente traz novos ares na estruturação da inovação sustentável, pois ela coloca o indivíduo em posição de reflexão. Se antes (na inovação tradicional) a posição individual que cada um tinha sobre a sociedade era negligenciada, agora o constructo "sustentabilidade" coloca o indivíduo a refletir: "o que é sustentabilidade? Qual a relação disso com o meu trabalho?" Obviamente, essa é uma tensão latente na estruturação da inovação contemporânea. Desse modo, a fala 22 (tabela 9) pondera que uma inovação que não leve em consideração a problemática da sustentabilidade não será legitimada ou não durará muito tempo. A fala 37 (tabela 12) expõe a preocupação do indivíduo em suas práticas pessoais e profissionais. A fala 45 (tabela 14) elucida a problemática do crescimento econômico desenfreado "Growing, Growing is not possible" (extrato da fala 45, tabela 14). Por fim, a fala 55 (tabela 16) traz a dimensão política de tal problemática.

A instanciação de qualquer prática acontece pela agência do ator social. Dessa maneira, poder-se-ia entender, através do modelo proposto, que para cada processo de estruturação (inovação tradicional e inovação orientada para a sustentabilidade) está presente a agência dos atores. Assim o é, porém, no modelo, evidencia-se a agência como uma categoria agregada entre os dois processos de estruturação. Os conceitos de segunda ordem que o acompanham são similares para ambos os processos de estruturação, ou seja, a agência é impactada por um mindset, por uma rigidez da estrutura e pela posição social e hierárquica que o ator possui. As diferenças estão nos esquemas interpretativos que regem tais conceitos de segunda ordem para cada processo de estruturação. Por exemplo, o conceito mindset aparece por meio das falas como uma barreira do fazer inovação (falas 50 e 51, tabela 15). Enquanto na inovação tradicional tal barreira está direcionada a certo 
pragmatismo, na inovação orientada para a sustentabilidade, a mesma encontra seu ponto de conflito justamente por trazer, essencialmente, algo novo (aspectos de sustentabilidade) que desafia as práticas do status quo (fala 48, tabela 14). Intrinsecamente ligado a esta questão do mindset, está o conceito de rigidez da estrutura que encontra, na legitimação de práticas já instauradas, uma dificuldade de se fazer o novo. Principalmente na área de inovação, na qual se imagina que o status quo deva ser superado, pois se pretende criar algo novo, a presença potencial de riscos (um novo produto, processo etc) faz com que as pessoas busquem certas posições de conforto (baseados em experiências anteriores) para mitigarem os riscos de situações indesejadas (a falha de um produto em desenvolvimento, o gasto com um projeto que não foi bem sucedido e outros). A fala 57 (tabela 16) traz esse elemento do risco como algo a ser evitado e, de certa forma, que tem influência legitimadora da rigidez da estrutura.

Um último ponto importante concernente à agência dos atores diz respeito às posições que eles ocupam dentro de um dado sistema social. A agência do ator social traz a noção de poder muito fortemente enraizada, mas nem sempre tão explícita. Realizar uma atividade requer, primeiramente, poder. E, poder, nesse sentido, tem relação com a mobilização da alocação de recursos. Assim, escrever uma ata de reunião, depende do poder em sua forma tácita (o ato de escrever) e alocação de recursos para tal (computador, folha, caneta...). Por outro lado, decidir lançar um produto novo, requer poder e alocação de recursos. Neste caso, o poder é mais complexo e engendra noções de dominação e legitimação. Quando um diretor decide que um novo produto será lançado, ele instancia sua prática de decisão e inaugura uma sequência de práticas que dependem da alocação e mobilização de recursos (humanos e materiais) que se organizarão no tempo para seguir a decisão tomada. É válido destacar que a posição social do ator, de fato, condiciona sua agência. Por outro lado, essa visão de rigidez da posição social é um inibidor da agência, pois, muitas vezes, a falta de agência se justifica (de maneira discursiva e prática) pela posição social que se ocupa. Foi evidente no estudo de caso que algumas pessoas veem que a posição social de cada ator determina a sua influência em fazer uma inovação orientada para a sustentabilidade (falas 58, 59 e 60, tabela 17). Obviamente, cada ator tem, devido a sua posição social, diferentes interlocutores e instancia suas práticas através dos próprios esquemas 
interpretativos. No entanto, é válido refletir que, possivelmente, essa posição social possa ser entendida como um esquema interpretativo de rigidez da agência.

\subsection{Mediação}

No modelo proposto, foi incluído, para todas as categorias agregadas, um elemento identificado como nível de mediação. Esse elemento foi explicitado e, alguns comentários relativos ao mesmo foram realizados ao longo das seções precedentes. Nesta seção, destaca-se mais enfaticamente o que esse elemento traz de significado.

Primeiramente, é importante estabelecer o que fez definir como nível de mediação um aspecto importante das quatro categorias agregadas. Quando Giddens apresenta a estratificação do agente (GIDDENS, 2013), além de discutir e elaborar sobre a motivação, a racionalização e monitoração reflexiva da ação, ele discorre também sobre as consequências impremeditadas da ação. Para exemplificar, Giddens traz o exemplo do gatuno que, resumidamente, descreve uma ação hipotética de um ator social que, ao acender a luz de sua casa, fez que um gatuno, prestes a assaltar a residência, fugisse e, no desdobramento dessa ação, fosse interpelado pela polícia na rua e, consequentemente, preso após julgamento. Giddens provoca a discussão sobre as consequências impremeditadas da ação de acender a luz. Neste caso, a ação de acender a luz desencadeou uma série de eventos que culminou na interpelação do gatuno e sua posterior prisão. No entanto, não se pode afirmar que o fato de acender a luz levou o gatuno à prisão, mas que tal ação inaugurou uma sucessão de eventos que culminaram nessa consequência. De posse desse exemplo, poder-se-ia falar que, quanto mais próximo um dos eventos posteriores está do evento inaugural, maior seria a relação de causalidade entre eles. O fato de o gatuno fugir, ao perceber que a luz foi acesa, expressa uma relação causal de baixa mediação entre os dois eventos. No entanto, o fato de o gatuno ser preso após a interpelação da polícia e posterior julgamento, é um evento de maior mediação entre esse fato e o evento inaugural, pois outros fatores podem ter tido influência na ocorrência dos eventos. O gatuno poderia ter decidido sair correndo da residência $e$ isso ter chamado a atenção dos policiais que o interpelaram. 
Motivado por essa reflexão, o autor desta dissertação definiu o conceito de mediação para compreender a relação entre a intencionalidade e a ação dos atores envolvidos na inovação orientada para a sustentabilidade. Neste caso, ao invés de refletir sobre as consequências impremeditadas de certa ação, pensaremos nos objetivos e proposições premeditados de uma dada ação e a sua prática. Neste caso, pretende-se entender o nível de mediação entre a ação prática e o seu objetivo premeditado.

Nesta elaboração, o nível de mediação carrega dois níveis de análise. 0 primeiro, relacionado à distância entre uma ação realizada e a intenção da mesma. O segundo, também relacionado com uma ideia de distância, mas que engendra uma noção de múltiplos domínios ou sistemas sociais ao qual o sujeito está inserido em sua vida cotidiana. Dessa maneira, uma ação prática pode ter estruturas de poucos ou múltiplos domínios. Neste caso, quanto mais estruturas houver, maior será o nível de mediação.

Quando se analisa a estrutura da inovação tradicional, visualiza-se que 0 nível de mediação, embora seja alto, é menor e mais legitimado do que o nível de mediação da inovação orientada para a sustentabilidade. As práticas de inovação tradicional buscam, em última análise, trazer bons negócios para as empresas (falas 1, 3 e 4, tabela 6). Dessa maneira, as práticas engendradas conseguem gerar e validar o objetivo mediante a produção de produtos, a contabilização do ganho gerado pelas vendas dos mesmos, os gastos do processo de inovação... Por outro lado, as práticas de inovação orientada para a sustentabilidade são débeis em relação ao que medir e a como se confirmar, ao longo da mediação, o êxito da ação planejada (fala 28, tabela 14). Medem-se os mesmos parâmetros econômicos facilmente (muito mais ligados à estruturação da inovação tradicional - falas 26 e 29, tabela 10), mas os aspectos de sustentabilidade ficam à deriva e fazem-se aproximações grotescas ou de baixo nível de mediação (distância entre a ação e intenção da mesma) que não se conectam com a sustentabilidade como um todo. Dessa forma, fala-se de uma melhora relativa, ou seja, um produto é mais sustentável porque, se comparado a outro, ele é mais eficiente, utiliza menos recursos etc. Nesse caso, a mediação é baixa, pois se está analisando somente o fato de o produto ser mais sustentável, no que tange a sua produção, mas não se vislumbra o efeito da ação intencional de, efetivamente, reduzir o consumo absoluto de recursos naturais ou a diminuição, em absoluto, da emissão de gases de efeito 
estufa. A avaliação do impacto global de uma tecnologia permitiria dizer se, de fato, para o mesmo produto/benefício, em valores absolutos, se está poluindo menos. É neste ponto, que outro nível de análise ganha importância e, pode-se dizer que há um maior de nível de mediação entre a ação e a sua intenção. Dessa maneira, fica evidente a importância no nível de mediação para se analisar a ação e sua intenção premeditada. Assim como no exemplo do gatuno de Giddens, que mostra quanto maior a distância entre ação e consequências não premeditadas, mais difícil a relação causal entre os eventos, neste caso, quanto maior o nível da mediação, mais difícil será atribuir uma relação efetiva entre intenção da ação e o alcance desse objetivo.

Uma vez que a inovação tradicional é vista como um sustentáculo da operação da empresa, garantindo sua posição e gerando bons negócios para a mesma, poder-se-ia refletir que a análise sobre a área de inovação poderia ser realizada, tomando-se como referência a própria empresa. Ou seja, sob a ótica da empresa, uma área de inovação é bem vista, se ela consegue garantir a lucratividade da empresa, gerar e desenvolver inovações que mantenham a posição da empresa no mercado... (falas 1, 2, 3 e 4, tabela 6). Ao corroborar os objetivos da empresa, a inovação tradicional e as práticas que ela engendra são legitimadas. No entanto, sob a ótica da inovação orientada para a sustentabilidade, e essa traz a visão de sociedade, é necessária uma avaliação do todo, do coletivo. Isso quer dizer, se a empresa faz uma inovação que é sustentável, qual é o benefício para a sociedade? Imaginemos uma empresa que tenha desenvolvido um veículo que é menos poluente (consome menos energia em seu ciclo de vida). Tal constatação será relativa, pois se trata de ser menos poluente em relação a outro veículo que é mais. No entanto, o que interessa para a sociedade é se o nível de poluição absoluto devido às emissões de gases dos veículos irá diminuir. Conforme discutido com vários membros da Longue Durée, poderia existir um cenário em que 10 carros que poluem muito seriam equivalentes a 15 carros que poluem pouco. $E$ haveria uma contradição se o "business plan" e a visão de crescimento da produção de veículos continuassem a aumentar, pois não haveria diminuição absoluta de emissões de poluentes. Este é um nível de mediação que complexifica a estruturação das novas práticas de inovação orientadas para a sustentabilidade, pois a visão de alto nível de mediação não é clara. Neste ponto, este trabalho julga que políticas públicas e 
regulações de alto nível são necessárias para comporem as regras da estrutura da inovação.

\subsection{Analisando as unidades de análise}

Os dois casos estudados - unidades de análise que compõem o caso estudado - serviram de base para a elaboração do modelo proposto. As principais características de cada um foram apresentadas na seção 3.2. É importante salientar que o modelo reflete a aproximação conjunta sobre os dois casos estudados, ou seja, a identificação dos conceitos de segunda ordem, bem como as categorias agregadas, não fizeram distinção entre eles. Dessa maneira, ambos podem ter suas próprias estruturações de inovação discutidas a partir do modelo. O que deve ser observado é que cada caso terá diferentes estruturas, esquemas interpretativos e especificidades que Ihes garantem singularidade.

Os casos estudados são similares por representarem a atuação de atores que trabalham com inovação dentro de um mesmo grupo corporativo. Neste sentido, os esquemas interpretativos relacionados à visão corporativa da empresa e a sua orientação com relação à finalidade da inovação serão estruturados a partir de cargas simbólicas, normas e métricas ao menos parecidas. Neste sentido, reforçam a perspectiva do Estudo de Caso único estudado.

A estrutura da inovação tradicional está presente em ambos os casos. As falas 3, 4 e 6 (tabela 6) mostram essa similaridade, apontando que a inovação precisa trazer bons negócios para empresa e que ela serve para a manutenção / sobrevivência da mesma nos mercados onde ela atua. A unidade de negócio do caso 1 poderia ser considerada mais legitimada do que a área de inovação do caso 2, uma vez que seus produtos de inovação são, de fato, produzidos e comercializados. Isso representa, de maneira concreta, que os produtos de inovação do caso 1 desencadeiam mais práticas e atividades a partir deles próprios, uma vez que haverá práticas de industrialização, produção, negociação e comercialização envolvendo diversos atores sociais que não se limitam à área de inovação ${ }^{12}$. $\mathrm{O}$ caso 2, por tratar-se de uma área de inovação corporativa que atende outras unidades de negócios, não apresenta a mesma legitimação. Ainda que o desenvolvimento de uma inovação do caso 2 tenha êxito, será uma unidade de negócios diferente (e não

\footnotetext{
${ }^{12}$ Tal entendimento foi suportado pela observação participante
} 
a área de inovação corporativa) que irá produzir e comercializar tal produto. Essa diferença no nível de legitimação não altera o impacto da estrutura da inovação tradicional para ambos os casos. Essa diferença do nível de responsabilidade e aprofundamento na cadeia de valor, é chamada também de mediação. A unidade de negócio do caso 1 apresenta maior nível de mediação, uma vez que desenvolve suas inovações, produzem as mesmas em escala piloto e industrial e comercializam o produto da inovação. Já o caso 2 (unidade de inovação corporativa ligada à biotecnologia) desenvolve a inovação em escala laboratorial, apresentando, dessa maneira, menor nível de mediação.

Para a categoria da estruturação da inovação orientada para a sustentabilidade nota-se uma diferença que pode ser entendida pela essência das duas áreas de inovação. O caso 2 , que está relacionado à biotecnologia, já apresenta aspectos de sustentabilidade na origem de seus desenvolvimentos. Isso está evidenciado pela orientação da consciência discursiva que emergiu das entrevistas, pontuando que a biotecnologia é sustentável por utilizar fontes renováveis e que suas métricas buscam a sustentabilidade (por exemplo, a fala 23). Por outro lado, o caso 1 apresenta alguns esquemas interpretativos relacionados à estruturação da inovação orientada para a sustentabilidade, respaldada pela legitimação do uso da ferramenta "A", pela empresa e por seu principal produto que é direcionado a veículos de alta eficiência energética (fala 18, tabela 9). Em suma, para esta categoria, entende-se que o caso 1 traz uma leitura mais distante dos aspectos de sustentabilidade, muito mais ligados às experiências e visões de mundo dos indivíduos. Isso também é corroborado, pois eles trabalham com uma tecnologia específica (somente um tipo de produto) que já possui sua legitimação ao longo da cadeia de valor. Já no caso 2 , como a biotecnologia é enxergada dentro da área de pesquisa como uma alternativa sustentável de fazer inovação, entende-se que a aproximação com os aspectos de sustentabilidade the seja mais facilmente acessada. Pode-se ainda agregar que o fato de o caso 2 não estar atrelado somente a uma tecnologia (como produto final), isso confere maior liberdade para se pensar e desenvolver estratégias de inovação de produtos e processos que possam abarcar princípios de sustentabilidade.

Com relação à categoria mais abrangente que é a de visão de mundo e construção de significados, não se vislumbram diferenças entre os casos estudados. Uma razão para essa similaridade pode estar relacionada ao fato desta categoria 
estar mais voltada para o indivíduo. A visão de mundo e construção de significados, em relação à sustentabilidade, são plurais e se justificam pelas experiências de cada ator. Desse modo, a fala 42 (tabela 14) traz aspectos regionais de onde os indivíduos vivem (relacionados aos meios de transporte).

No nível de agência, todos os conceitos de segunda ordem estão presentes em maior ou menor nível nos dois casos. Uma posição interessante é o conflito na visão de agência entre eles. Enquanto no caso 1, majoritariamente, acredita-se que pessoas em maiores níveis (posição social hierárquica) são mais responsáveis pela promoção da inovação orientada para a sustentabilidade (falas 57, 58 e 59, tabela 17), no caso 2, observou-se que tal responsabilidade é mais depositada nas pessoas que conduzem os projetos (fala 60, tabela 17). Articulou-se que são essas pessoas que, através de suas práticas e agência, podem "convencer e demonstrar" as vantagens ("ganhos") de uma abordagem de inovação sustentável. Evidentemente, a lógica econômica da inovação tradicional influencia a estruturação dessas práticas. No que tange à rigidez da estrutura, ambos os casos relataram fatores similares, ligados à mindset (mentalidade) das pessoas (falas 50 e 51) e a certa falta de conhecimento / consciência para aprofundarem a abordagem da sustentabilidade em inovação.

A tabela a seguir, traz uma breve compilação e comparação entre os dois casos estudados. 
Tabela 18: Quadro comparativo entre os casos 1 e 2

\begin{tabular}{|c|c|c|}
\hline Categorias & Caso 1 & Caso 2 \\
\hline $\begin{array}{c}\text { Estruturação da Inovação } \\
\text { tradicional }\end{array}$ & $\begin{array}{l}\text { Fortemente presente/ Alto } \\
\text { nível de mediação }\end{array}$ & $\begin{array}{l}\text { Fortemente presente/ } \\
\text { Médio nível de mediação }\end{array}$ \\
\hline $\begin{array}{c}\text { Estruturação da Inovação } \\
\text { Orientada para a } \\
\text { sustentabilidade }\end{array}$ & $\begin{array}{l}\text { Esquemas interpretativos } \\
\rightarrow \text { Presente (muito mais } \\
\text { relacionado ao indivíduo / } \\
\text { visão de mundo) }\end{array}$ & $\begin{array}{l}\text { Esquemas interpretativos } \\
\rightarrow \text { Fortemente presente } \\
\text { para a questão ambiental } \\
\text { (ligado à biotecnologia) }\end{array}$ \\
\hline $\begin{array}{l}\text { Visão de mundo e Construção } \\
\text { de Significados }\end{array}$ & Similar & Similar \\
\hline Agência & $\begin{array}{l}\text { Mindset (mentalidade) / } \\
\text { Rigidez da estrutura } \\
\rightarrow \text { Similares } \\
\text { Posição social / hierarquia } \\
\rightarrow \text { alto nível de barreira }\end{array}$ & $\begin{array}{l}\text { Mindset (mentalidade) / } \\
\text { Rigidez da estrutura } \\
\rightarrow \text { Similares } \\
\text { Posição social / hierarquia } \\
\rightarrow \text { potencialização da } \\
\text { aqência }\end{array}$ \\
\hline
\end{tabular}

\subsection{O tempo}

O tempo é um elemento importantíssimo para a teoria da estruturação. Ao final, toda prática instanciada pelo indivíduo se situa e acontece num dado momento. Em uma reflexão sobre a vida de um dado ator social, ocorrerá o entendimento de que ele nasce animal (espécie do gênero humano). A partir desse momento inicial, tal ator começará a interagir e a fazer parte de sistemas sociais onde aprenderá a realizar atividades que se estruturam no seio das coletividades humanas, apreendendo-as. Assim, acontecerão os aprendizados da língua, da alimentação e do próprio caminhar. Este indivíduo que se torna humano dentro de um processo que poderia ser concebido como o processo de humanização, produzirá / reproduzirá atividades. Ao longo de sua "longue durée" (conceito de Giddens, 1984), acumulará um repertório de experiências que o posicionará dentro dos sistemas sociais. Uma prática será realizada uma vez, uma segunda vez, e, assim, ganhará legitimação no posicionamento do indivíduo no mundo. Algumas práticas serão tão fortemente enraizadas que parecerão praticamente óbvias e inatas. Por outro lado, 
outras práticas poderão sempre ser questionadas, levando o indivíduo a utilizar sua agência como um agente promotor da sua própria história.

Dentro do nosso objeto de pesquisa, a inovação orientada para a sustentabilidade é algo que transita por essa orientação propositiva e de alta agência. Ela é iminente e deriva de um posicionamento capaz de promover mudanças. No entanto, as estruturas da inovação tradicional foram e continuam sendo legitimadas ao longo do tempo por vários atores ao longo dos sistemas sociais dos quais eles participam (pesquisadores, trabalhadores, consumidores...). A questão crucial é a possibilidade de mudança nas práticas de inovação, não devido a um novo potencial, pois a agência sempre esteve presente, mas a novas estruturas de significado que colocam questões centrais de nossa humanidade em destaque. Discutir sobre sustentabilidade em sua totalidade escancara conflitos e contradições de nossa sociedade (degradação social humana e degradação da natureza). A maneira como essa discussão e seus elementos estruturantes irá de fato estruturar uma inovação orientada para a sustentabilidade é um processo lento e empírico. No entanto, está acontecendo.

\subsection{Uma síntese}

Nesta seção de discussão, tratou-se de apresentar o modelo criado baseado no estudo de caso e suportado pela teoria da estruturação. Foi possível verificaremse elementos de estruturação de práticas orientadas para a sustentabilidade que são emergentes nos processos de inovação. Paralelamente, a inovação tradicional é latente e suas estruturas estão fortemente legitimadas pelas práticas que elas engendram, não somente no próprio processo de inovação, mas também ao longo da cadeia de valor à qual uma tecnologia específica se situa. Devido ao fato de a temática de sustentabilidade ser ampla e ser parte constituinte de outros sistemas sociais em que os indivíduos se encontram, foi possível verificar preocupações (subcategorias tais como visão de mundo e construção de significado da sustentabilidade) e certos esquemas interpretativos altamente potencializadores de novas estruturas. Um elemento importante identificado e aportando complexidade na aproximação do objeto investigado foi denominado nível de mediação. Ele traz a ideia de distância entre a intenção da ação da inovação e a prática que se instancia. Além disso, a mediação carrega uma intrínseca relação com a legitimação ao longo 
da cadeia de valor, ou ainda, ao longo de outros sistemas sociais. Dessa maneira, uma lente teórica que consiga articular uma visão mais ampla (nível meso ou macro) pode aportar uma importante contribuição à análise de estruturação das práticas sociais em inovação. A comparação dos casos permitiu a aplicação e uma visão mais concreta do modelo proposto, entendendo nesse contexto, a própria construção do mesmo numa relação de recursividade com a análise dos casos. No entanto, é importante salientar que o modelo proposto é uma primeira aproximação para se entender a estruturação das práticas de inovação orientada para a sustentabilidade que leva em consideração a ação do indivíduo. Por fim, tentou-se articular um elemento importante da teoria da estruturação que é o de compreender a ação de cada indivíduo, situada no tempo, refletindo sobre o significado da legitimação e produção / reprodução das práticas. 


\section{CONSIDERAÇÕES FINAIS}

Donde está la utopia?

Ella está en el horizonte. Yo me acerco dos pasos y ella se aleja dos pasos. Camino diez pasos y el horizonte se corre diez pasos más allá. Por mucho que yo camine, nunca la alcanzaré. ¿Para que sirve la utopía? Para eso sirve, para caminar.

(Eduardo Galeano, Fernando Birri, transcrito e adaptado da entrevista https://www.youtube.com/watch?v=9iqi1 oaKvzs)

Depois de uma longa jornada, é chegada a hora de se deparar com o que se possuía como intenções iniciais: o que foi possível avançar? Apontar novas abordagens e limitações que se descobriu e, muito importante, apontar quais os horizontes que se pode buscar a partir de agora.

Este trabalho teve como objetivo principal compreender a dinâmica de estruturação das práticas sociais dos processos de inovação orientados para a sustentabilidade. Para suportar tal escopo, foram definidos dois objetivos específicos (subseção 1.4). É importante salientar que, embora sejam apresentados como dois objetivos, eles são complementares e dependentes, ou seja, só foi possível alcançar o objetivo 1 (descrever o processo de inovação orientada para a sustentabilidade através da teoria da estruturação), mediante o desenvolvimento do objetivo 2 (desenvolver um modelo relacionando a teoria da estruturação e a inovação orientada para a sustentabilidade). A recíproca é verdadeira.

O primeiro objetivo foi alcançado mediante o aprofundamento e apreensão da teoria da estruturação e as reflexões derivadas da mesma. Já na fundamentação teórica (seção 2.4), este trabalho elaborou uma aproximação entre a teoria da estruturação e o processo de inovação, articulando as condições de estruturação e instanciação das práticas e mostrando a complexidade do processo de inovação. Trazendo à tona a discussão sobre as modalidades da estrutura (facilities, normas e esquemas interpretativos), somada à agência dos atores sociais, pontuou-se a possibilidade de se pensar em múltiplas estruturas que coexistem no tempo e espaço e permitem a produção / reprodução de práticas. Baseado na ideia simplista 
de sustentabilidade que é descrita pelo equilíbrio dos pilares econômico, ambiental e social, foi proposta a reflexão de estruturas diferentes (mas que se relacionam) para cada pilar. A aplicação do estudo de caso permitiu lapidar a descrição do processo de inovação orientada para a sustentabilidade, distinguindo elementos de estruturação que coexistem dentro de dois fenômenos intitulados "estruturação da inovação tradicional" e "estruturação da inovação orientada para a sustentabilidade". É importante reiterar que estes dois fenômenos não ocorrem separadamente e deve ser observados como características do mesmo processo de estruturação. A separação proposta é meramente para elucidar as diferentes estruturas e forças que condicionam a estruturação das práticas.

O segundo objetivo (a elaboração do modelo) foi alcançado mediante a realização do estudo de caso com uma empresa específica (Longue Durée). Dois casos (unidades de análises) foram analisados mediante dois tipos de coleta de dados. O primeiro, constante de entrevistas semi-estruturadas com atores específicos de cada estudo de caso por meio de um roteiro semiestruturado aberto e, o segundo, através de observação participante do próprio autor. A análise dos dois casos e a compreensão do processo de estruturação das práticas foram realizadas utilizando-se elementos da teoria indutiva (CORLEY \& GIOIA,2004), que suportaram a identificação de categorias através dos elementos que emergiram das entrevistas, e da teoria da estruturação que suportou a descrição da estruturação das práticas.

A conjugação dos dois objetivos permitiu alcançar o objetivo geral deste trabalho possibilitando a descrição da estruturação das práticas sociais em processos de inovação orientados para a sustentabilidade, resultando um modelo que descreve a estruturação. A partir da análise dos resultados e da proposição do modelo, este trabalho assinala que a estruturação de uma inovação orientada para a sustentabilidade vem ocorrendo dentro de um cenário complexo, polissêmico, contraditório e de alta mediação. Muito além de se classificar tal fenômeno dentro de uma perspectiva de sustentabilidade fraca ou forte, há de se reconhecer a característica estrutural das práticas humanas nos sistemas sociais. A legitimação de práticas mais sustentáveis se dá num processo lento, de conflitos de interesse e de alto nível de mediação. Este estudo enfoca as práticas, que podem ser entendidas desde uma perspectiva micro. Nesse sentido, não há dúvidas que existem elementos estruturantes sendo construídos e legitimados. Porém, a 
dinâmica da sociedade é um fenômeno macro e a articulação entre micro e macro é bem complexa e altamente mediada.

Este trabalho traz contribuições teóricas e práticas. A primeira contribuição teórica é o emprego de um referencial teórico das ciências sociais para descrever o fenômeno da inovação orientada para a sustentabilidade, o que não é usual. A segunda contribuição teórica é a elaboração de um modelo, relacionando a sustentabilidade e a teoria da estruturação e, a terceira contribuição teórica é a criação do termo mediação para aplicação e discussão de um fenômeno já observado pelos teóricos.

Ao tratar da temática "inovação orientada para a sustentabilidade" ao menos três áreas do conhecimento foram articuladas conjuntamente. $\mathrm{A}$ área de administração e economia ocupa-se dos estudos que envolvem a inovação e suas estratégias no seio das corporações. A sustentabilidade é multidisciplinar com uma grande ênfase nas grandes áreas que abordam a problemática ambiental e social. A teoria da estruturação encontra sua origem e principal disseminação nos estudos de ciências sociais. Ao articular o processo de inovação orientada para a sustentabilidade, através da teoria da estruturação (que advém das ciências sociais), este trabalho contribui, academicamente, com o avanço da multidisciplinaridade para se compreenderem fenômenos complexos da sociedade contemporânea.

A contribuição prática é para gestores de inovação que pretendem ou estejam implementando novas práticas em seus processos, a fim de alinhar suas áreas de inovação com princípios da sustentabilidade. Uma vez que existe a predisposição, por parte das empresas, em alinharem seus processos de inovação à sustentabilidade (conforme apresentado na fundamentação teórica), a reflexão sobre o modelo e o aprofundamento do conhecimento das relações recursivas entre estrutura/agência podem possibilitar novos olhares sobre o processo de inovação e, ainda, desencadear novas estruturas que possibilitem a produção/reprodução de práticas mais alinhadas com a sustentabilidade. Dessa maneira, não se espera uma contribuição prática pela aplicação direta do modelo. No entanto, os elementos contidos no mesmo podem ser de grande valia para gestores e outros atores envolvidos no processo de inovação.

Embora se tenha conseguido alcançar os objetivos deste trabalho, novas perspectivas surgiram e várias limitações ficaram evidentes. Primeiramente, uma limitação metodológica. Embora não se esteja generalizando o modelo proposto 
para todos os casos de inovação orientada para a sustentabilidade, identifica-se que a utilização de somente um estudo de caso, composto por duas unidades de análises, é um limitante para a potencialidade dessa abordagem. Um próximo estudo poderia utilizar mais casos objetivando a configuração de um estudo de casos múltiplos. Além disso, a mesma abordagem poderia ser feita com mais grupos empresariais e de diversos campos de atuação. Outra limitação é o fato de se entrevistar somente pessoas da própria empresa, ficando assim, sem a visão da cadeia de valor durante o desenvolvimento da inovação. Como já destacado anteriormente, o foco nas práticas circunscreve uma análise micro do fenômeno. No entanto, a inovação como um todo pode ser vista e articulada entre diferentes níveis. Dessa maneira, a análise através dos níveis macro e micro dos sistemas sociais onde se dá o processo de inovação orientado para a sustentabilidade pode ser um dos novos horizontes da continuação deste trabalho. Uma possibilidade seria articular a teoria de campos com a teoria da estruturação, expondo-se a relação entre agente (estruturas das práticas) versus estrutura dos sistemas sociais complexos (estruturas dos campos / instituições). Por fim, uma limitação também metodológica em relação à observação participante do autor jaz no fato do mesmo também trabalhar na empresa e poder carregar uma carga bastante subjetiva durante a análise do estudo de caso.

Uma vez expostas as contribuições e limitações deste trabalho, vislumbramse, como possíveis trabalhos vindouros, a validação e aperfeiçoamento do modelo proposto através de novos estudos de caso que englobem outras empresas e áreas de inovação, a potencial articulação entre os níveis micro (das práticas) e macro (dos sistemas) para discutir a legitimação de práticas orientadas para a sustentabilidade nos processos de inovação e, por fim, o estudo da inovação em diferentes empresas, mediante a sua proximidade com o consumidor final.

Em suma, talvez tenhamos chegado ao final deste trabalho com mais dúvidas do que respostas. Foi possível enxergar a estruturação das práticas em inovação a partir da instanciação das práticas dos indivíduos. Sabemos e reconhecemos a dificuldade de articular os fenômenos micro com a continuação dos eventos nos sistemas sociais macro que cada indivíduo está inserido. No entanto, afirmamos que o ator social é, sem dúvida, ator / criador da sua própria história. 


\section{REFERÊNCIAS ${ }^{13}$}

ABRAMOVAY, R. Muito Além da Economia Verde. São Paulo: Ed. Abril, 2012.

ADAMS, R., JEANRENAUD, S., BESSANT, J., DENYER, D., OVERY, P. Sustainability-oriented Innovation: A Systematic Review, International Journal of Management Reviews, 18 (2), pp. 180 205, 2016.

ADAMS, R., JEANRENAUD, S., BESSANT, J., OVERY, P. \& DENYER, D. Innovating for sustainability: a systematic review of body of knowledge, Network for Sustainability; 2012, Disponível em: <https://nbs.net/knowledge>. Acesso em 23 junho 2016.

ADAMS, W.M. The Future of Sustainability: Re-thinking Environment and Development in the Twentyfirst Century, 2006. Disponível em IUCN. In:

http://cmsdata.iucn.org/downloads/iucn_future_of_sustanability.pdf (acesso em 27/12/2011).

ASHFORTH, B. E., SCHINOFF, B. S. Identity under construction: how individuals come to define themselves in organizations, Annual Review of Organizational Psychology and Organizational Behavior, 3:111-37, 2016.

BARBIERI, J. C.; DE VASCONCELOS, I. F. G.; ANDREASSI, T.; DE VASCONCELOS, F. C.; Inovação e sustentabilidade: novos modelos e proposições, RAE, Revista de Administração de empresas. São Paulo, v50, n2, p. 146-154, 2010.

BOFF, L. Sustentabilidade, o que é - O que não é. Petrópolis, RJ, Editora Vozes, 2013.

BOONS F., MONTALVO C., QUIST J., WAGNER, M. Sustainable innovation, business models and economic performance: An overview, Journal of Cleaner Production, 45, p. 1-8, 2013.

BOONS, F., \& LÜDEKE-FREUND, F. Business models for sustainable innovation: State-of-the-art and steps towards a research agenda, Journal of Cleaner Production, 45, p. 9-19, 2013.

BOYATZIS, R. Transforming qualitative information: Thematic analysis and code development. Thousand Oaks, CA: Sage, 1998.

BRUNDTLAND, G.H. Report of the World Commission on Environment and Development: Our Common Future. New York, NY: United Nations, 1987.

BURSZTYN, M., BURSZTYN, M.A.; Fundamentos de política e gestão ambiental: os caminhos do desenvolvimento sustentável.Rio de Janeiro: Garamond, 2013.

CAVALCANTI, C. Sustentabilidade: Mantra ou Escolha Moral? Uma Abordagem Ecológico Econômica, Estudos Avançados, v. 26, n. 74, jan./abr., pp. 35-50, 2012.

COENEN, L., DÍAZ LÓPEZ, F.J. Comparing systems approaches to innovation and technological change for sustainable and competitive economies: An explorative study into conceptual commonalities, differences and complementarities, Journal of Cleaner Production, 18 (12), pp. 1149-1160, 2010.

COOPER, R. G. The seven principles of the latest Stage-Gate ${ }^{\circledR}$ method add up to a streamlined, new-product idea-to-launch process, march/april 2006, Disponível em https://www.stage-gate.net. Acesso em 29 dezembro 2011.

CORLEY, K. G., GIOIA, D. A. Identity ambiguity and change in the wake of a corporate spin-off, Administrative Science Quarterly, 49, 173-208, 2004.

\footnotetext{
${ }^{13}$ De acordo com a Associação Brasileira de Normas Técnicas. NBR 6023 (2002).
} 
DA SILVA, D. O.; BAGNO, R. B.; SALERMO, M. S.; Modelos para a gestão da inovação: revisão e análise da literatura; Production, v. 24, n 2, p. 477-490, 2014.

DIMAGGIO, P., POWELL, W. A gaiola de ferro revisitada. RAE, Revista de Administração de empresas. São Pauo: EAESP-FGV, 2005.

ELKINGTON, J. Cannibals with Forks. Oxford: Capstone, 1997.

FEREDAY, J., MUIR-COCHRANE, E. Demonstrating Rigor Using Thematic Analysis: A Hybrid Approach of Inductive and Deductive Coding and Theme Development, International Journal of Qualitative Methods, 5 (1), 2006.

FLIGSTEIN, N., McADAM D. A Theory of fields. Oxford University Press, New York, 2012.

FREIRE, P. Educação como prática da Liberdade. Paz e Terra, Rio de Janeiro, 1979.

GALEANO, E. El libro de los abrazos, Siglo Veintiuno Editores Argentina S.A. Buenos, 2012

GIDDENS, A. Central problems in social theory. Action, structure and contradiction in social analysis. Berkeley; Los Angeles; University of California Press, 1979.

GIDDENS, A. The Constitution of Society: Outline of the Theory of Structuration. Berkeley: University of California Press, 1984

GIDDENS, A. A reply to my critics. D. Held, J. B. Thompson, eds. Social Theory of Modern Societies: Anthony Giddens and his Critics. Cambridge University Press, Cambridge, U.K. 249301,1989

GIDDENS, A. A Constituição da Sociedade, Tradução Álvaro Cabral, $2^{2}{ }^{2}$ ed. - São Paulo: Martins Fontes, 2013.

GONÇALVES-DIAS, S. L. F.; TEODÓSIO, A. S. S.; Perspectivas de análise do ambientalismo empresarial para além de demonizações e santificações. RGSA: Revista de Gestão Social e Ambiental, v. 5, p. 3-17, 2011.

GRANOVETTER, M. Economic Action and Social Structure: The Problem of embeddedness, American Journal of Sociology, 91:481-510, 1985.

HALLSTEDT S.I., THOMPSON, A. W., LINDAHL P. Key elements for implementing a strategic sustainability perspective in the product innovation process, Journal of Cleaner Production 51, pp. 277-288, 2013.

HUNG, S.C. Explaining the process of innovation: The dynamics reconciliation of action and structure, Human Relations, volume 57 (11): 1479-1497, 2016.

JACKSON, T. Prosperidade sem Crescimento: Vida Boa em um Planeta Finito. São Paulo: Abril, 2013.

JARZABKOWSKI, P. Strategy as practice: Recursiveness, Adaptation, and Practices-in-Use, Organization Studies 25(4): 529-560, London: Sage Publications, 2004

JONASH, R. S.; SOMMERLATTE, T.; O valor da inovação: como as empresas mais avançadas atingem alto desempenho e lucratividade. Rio de Janeiro: Campus, 2001

JONES, O., EDWARDS, T., BECKINSALE, M. Technology Management in a Mature Firm: Structuration Theory and Innovation Process, Technology Analysis \& Strategic Management, Vol 12, No. 2, 2000.

LOCK, M. J. Applying Anthony Giddens' Structuration Theory to Committee Governance Translating theoretical propositions into methodological principles, Ostrom Workshop, 2015. 
Disponível em: <https://ostromworkshop.indiana.edu/pdf/seriespapers/2015s c/Lock paper.pdf> Acesso em 23 fevereiro 2018.

LOUNSBURY, M.; CRUMLEY E. T. New Practice Creation: An Institutional Perspective on Innovation; Organization studies, 28 (07): 993-1012; 2007

MARX, Karl. O 18 brumário e Cartas a Kugelman. Rio de janeiro, Paz e Terra, 1974

MCALOONE, T. C., TAN, A R, Sustainable product development through a life-cycle approach to Product and service creation: An exploration of the extended responsibilities and possibilities for Product developers. In: Proceedings of Eco-XConference: Ecology and Economy in Electronix.Vienna, Austria, pp. 1-12, 2005.

MASKELL, P.; MALMBERG, A. Localized Learning and Industrial Competitiveness, Cambridge Journal of Economics, vol. 23, issue 2, pages 167-85, 1999.

MEDEIROS, J.F., RIBEIRO, J.L.D., CORTIMIGLIA, M.N. Success factors for environmentally sustainable product innovation: A systematic literature review, Journal of Cleaner Production, 65, pp. 76-86, 2014.

ORLIKOWSKI, W. J. Using Technology and Constituting Structures: A Practice Lens for Studying Technology in Organizations; Organization Science, Vol. 11, N4, pp. 404-428, July-August, 2000.

OKOLI, C., SCHABRAM, K. A Guide to Conducting a Systematic Literature Review of Information Systems Research. Sprouts: Working Papers on Information Systems, 10(26), 2010. Disponível em : <http://sprouts.aisnet.org/10-26> Acesso em 25 maio 2016

PAGOTTO, E. L. Greenwashing: Os conflitos éticos da propaganda ambiental, Dissertação de Mestrado na Escola de Artes, Ciências e Humanidades da Universidade de São Paulo, 2013.

PARODI O.; AYESTARAN, I.; BANSE G. Sustainable Development - Relationships to culture, Knowledge and Ethics; Karlsruher Institut für Technologle (KIT), Karlsruhe, Scientific Publishing, 2011.

PECI, A. A nova teoria institucional em estudos organizacionais: uma abordagem crítica, Cadernos EBAPE. BR, v. 4, No 1, Mar. 2006.

PORTER, M., LINDER, C. Green and competitive: ending the stale mate. Harvard Business Review, pp. 119-134, September October, 1995.

ROCKSTRÕM, J. et al. A safe operating space for humanity, Nature, Vol 461, pag. 472-475, 2009.

ROOZENBURG, N. F. M, EEKELS, J. Product Design: Fundamentals and Methods. John Wiley \& Sons Ltd, Chichester, England, 1995.

SACHS, J. D. The age of sustainable development, New York. Columbia University Press, 2015.

SARKIS, J. A strategic decision framework for green supply chain management, Journal of Cleaner Production 11 (4), 397-409, 2003.

SILVERMAN, D. Interpreting Qualitative Data. Methods for analyzing talk, text and interaction, London: Sage Publications Ltd, 1993.

SCHUMPETER, J. Business Cycles: a Theoretical, Historical and Statistical Analysis of the Capitalist Process. McGraw-Hill, New York, 1939.

SERVA, M., JÚNIOR, P. J. Observação participante e pesquisa em administração, uma postura antropológica. RAE, Revista de Administração de Empresas, São Paulo, v.35, n.1, p. 64-79, 1995.

STAKE, R. E. Multiple Case Study Analysis, Guilford Publication, 2005. 
STOCK, T., OBENAUS, M., SLAYMAKER, A., \& SELIGER, G. A model for the development of sustainable innovations for the early phase of the innovation process. Procedia Manufacturing, 8 , 215-222, 2017.

TIDD, J; BESSANT, J; PAVITT, K. Gestão da Inovação. Porto Alegre: Bookman, 2008.

VARADARAJAN, R. Innovating for sustainability: A framework for sustainable innovations and a model of sustainable innovations orientation, Journal of the Academy of Marketing Science, 45(1), 14-36, 2017. 


\section{ANEXO - Roteiro das entrevistas traduzido para o inglês}

\begin{tabular}{|c|c|}
\hline A & What does it come to your mind about the sustainability theme? What is sustainability for you? \\
\hline B & What's the importance of sustainability? \\
\hline C & Is sustainability a harmonious topic? Are there some contradictions in this topic? \\
\hline D & What are the main topics that the discussion about sustainability bring to you? \\
\hline E & What are the constraints / challenges to achieve the sustainability? \\
\hline $\mathbf{F}$ & $\begin{array}{l}\text { Does your company care about sustainbility? How do you see the level of committement of your } \\
\text { company to sustainability? Any examples? }\end{array}$ \\
\hline G & What is innovation? \\
\hline H & What is necessary to make innovation? \\
\hline I & What is the role of innovation for sustainability? \\
\hline $\mathbf{J}$ & In your opinion, what is the role of innovation to your company? \\
\hline K & $\begin{array}{l}\text { Taking into account the innovation process of your company, what are the main objectives? What } \\
\text { are the main metrics for that? }\end{array}$ \\
\hline $\mathbf{L}$ & Does your company seek to promote sustainability through innovation? How? \\
\hline M & Which moment of the innovation process is sustainability discussed? \\
\hline $\mathbf{N}$ & How does it do to include sustainability in the innovation processes? \\
\hline $\mathbf{O}$ & $\begin{array}{l}\text { Are there practices in the daily activities of doing innovation that help to include / discuss the } \\
\text { sustainability during the management of the project? What are these practices? }\end{array}$ \\
\hline $\mathbf{P}$ & In terms of sustainability, what is the role of each person in the innovation process? \\
\hline Q & Are there any metrics, norms, guidelines in the management of projects related to sustainabilty? \\
\hline $\mathbf{R}$ & What is your influence for promoting an innovation oriented to sustainability? \\
\hline $\mathbf{S}$ & In your work, your GBU, how are you helping the sustainability? Which problem are you facing? \\
\hline $\mathbf{T}$ & $\begin{array}{l}\text { Your workday is full of activities... Full of practices. In which of them do you address } \\
\text { sustainability aspects? }\end{array}$ \\
\hline $\mathbf{U}$ & $\begin{array}{l}\text { In the more important practices in your work of innovation, what are the main deliverables? What } \\
\text { do you need to accomplish? }\end{array}$ \\
\hline
\end{tabular}

